Portland State University

PDXScholar

1973

\title{
Group experience with parents of preschool children with seizure disorders
}

\author{
George R. Jacobsen \\ Portland State University \\ Grant R. Kane \\ Portland State University \\ Joan Sacia \\ Portland State University
}

Follow this and additional works at: https://pdxscholar.library.pdx.edu/open_access_etds

Part of the Disability and Equity in Education Commons, Mental and Social Health Commons, and the Social Work Commons

Let us know how access to this document benefits you.

\section{Recommended Citation}

Jacobsen, George R.; Kane, Grant R.; and Sacia, Joan, "Group experience with parents of preschool children with seizure disorders" (1973). Dissertations and Theses. Paper 2932.

https://doi.org/10.15760/etd.2892

This Thesis is brought to you for free and open access. It has been accepted for inclusion in Dissertations and Theses by an authorized administrator of PDXScholar. Please contact us if we can make this document more accessible: pdxscholar@pdx.edu. 
GROUP EXPERIENCE WITH PARENTS OF

PRESCHOOL CHILDREN WITH SEIZURE DISORDERS

\author{
by \\ George R. Jacobsen \\ Grant R. Kane \\ Joan Sacia
}

\begin{abstract}
A Practicum
Submitted in Partial Fulfillment of the

Requirements for the Degree of

MASTER OF SOCIAL WORK
\end{abstract}

Portland State UnIversity

June 1973 
APPROVED,

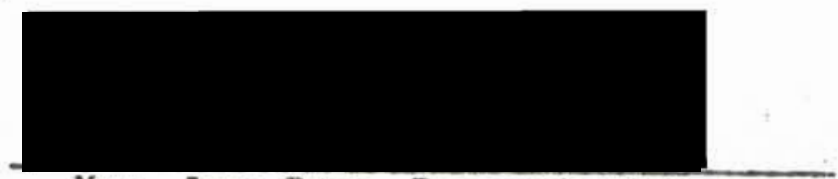

Mrs. June Dunn, Research Advisor 
ACKNOWLEDGEMENTS

We wish to express appreciation to Dr. James R. Schimschock, Director of Good Samaritan Hospital and Medical Center Children's Clinic, for his encouragement, guidance and direction.

Gratitude is also expressed to Mrs. June Dunn, M.S.W., research advisor, and Quentin D. Clarkson, statistical consultant, at Portland State University, for their counsel; to Mrs. Betty Stokes, executive director of the Epilepsy League of Oregon, Inc., for her assistance in making this research possible; to Dr. Russell Tackson and Dr. Leif Terdal, for their efforts in managing the video-taping; and to the other members of the Children's Clinic for their time and patience.

Special appreciation goes to Jarvis M. Finley, Ph.D., Associate Professor of Sociology, Pacific University, for his suggestions on assembling the material and for his timely guidance during the final stages. 
Chapter

I. INTRODUCTION

Problem

Purpose

II. METHODOLOGY

Funding

Data Collection

Socio-Economic Inventory

Epilepsy Questionnaire

Handicap Problems Inventory

Brochure For Parents . .

Evaluation Questionnaire

Video-Taping

III. PARENT SEMINARS

Design

Group Membership

Unit of Study

Sequence of Events .

Group Discussion Sesseion

Page

IV. RESULTS

Hand1cap Problems Inventory . . . . . 22

Evaluation Questionnaire . . . . . 22

Epilepsy Questionnaire . . . . . . . 25

Video-Taping . . . . . . . : 30

V. SUMMARY AND CONCLUSTONS . . . . . . . 35

SELECTED BIBLIOGRAPHY . . . . . . . . . . 40

APPENDIX • • • • • • • • • • • • • 55 


\section{CHAPTER I}

INTRODUCTION

A project using parent seminars in alding parents of children w1th seizure disorders was designed at the request of $\mathrm{Dr}$. James $\mathrm{R}$. Schimschock, pediatric neurologist and director of the Clinic for Neurologically Impaired Children, Good Samaritan Hospital and Medical Center. The clinic provides a diagnostic and educational therapy for neurologically impaired children. In addition to providing multidiscipline diagnostic evaluation, clinic services include operating classrooms for preschool and school-age children. The classrooms function for children with any type of neurologic impairment who are e1ther excluded from school due to their delayed academic performance, their physical or developmental delay, emotional or behavior problems, or the severity of their condition. Having the classroom located in the Good Samaritan Hospital complex provides immediate access to medical assistance if $1 \mathrm{t}$ is required. Information derived from classroom observation is available to the child's physician. This information is valuable in the medical management of these children and is part1cularly useful with children having intractable seizure disorders.

The school age-program is directed by Mr. Pat Highhouse, M.S. In Special Education and Elementary Education, and currently has an enrollment of six. The preschool program is directed by Mrs. J1ll West, M.S. In Special Education, which serves children between the 
ages of one and one-half and five, and currently has an enrollment of 10 (includes one set of identical female twins). Miss Sandy Withrow, B.S. In Elementary Education, functions as administrative secretary and clinic coordinator of services. Several volunteers contribute their time and talents to the program. Referral sources include teachers, physicians, public health nurses, social workers, and parents. The clinic is currently funded by Good Samaritan Hospital, the federal Developmental Disabilities Services Act, Multnomah County, and Portland Public Schools.

\section{Problem}

Observations by local neurologists and the staff of the Epilepsy League of Oregon, Inc., Indicated a need for expanded contact with parents of children with seizure disorders. These observations led to discusston of problems in identifying the major concerns and sensetive areas of these parents. Mrs. Betty Stokes, executive director of the Epilepsy League of Oregon, noted that there were no known programs designed to deal with this problem and suggested that the League might fund a study designed to investigate certain areas of concern, provide a supplementary learning experience, and set up a program to correlate these efforts.

As a preliminary project, parent group education was presented as one form of supplementary learning experience. The use of parent groups for varlous educational as well as therapeutic purposes has 
been well documented. A number of authors have reported studies of groups of parents having children with epilepsy. ${ }^{1}$

\section{Purpose}

A pilot study was designed by establishing a six-week series of parent group discussions. The purpose of this descriptive study was two-fold: (1) to observe and record parental knowledge of and attitudes toward seizure disorders by documenting their most nrevalent questions and concerns about epilepsy, and (2) provide an opportunity for parents to deal with these specific areas in a constructive manner in order to alter parents' influence on their children.

${ }^{1}$ See Appendix G for a review of the literature of these studies as well as related topics such as roup approaches with parents of preschool children, relationships between social and emotional child behavior and seizures, primary parental reaction to a diagnosis of epilepsy. 


\section{METHODOLOGY}

Under the guidance of James R. Schimschock, M.D., pediatric neurologist, Mrs. June Dunn, M.S.W., faculty advisor from Portland State University, and Quentin D. Clarkson, PhD., statistical consultant also on the P.S.U. faculty, various questionnaires were desioned. All questionnaires were coded to establish an information retrieval system for future use in the clinic. Every mother involved in the project was individually video-taped in a 20-minute interaction with her child. In the case of the mother of twins the activity was taped with each child independently as well as with both children. The video-taping was done by Leif Terdal, Ph.D., and Pussell Jackson, Ph.D., consulting clinical psycholorists, in onder to provide objective ovservation and recording of behavior.

\section{Funding}

A proposal in the form of request for a prant of $\$ 1,700,00$ was written and presented to the Enilepsy League of Oreron on May 22, 1972 (see Appendix A for the oripinal proposal). The entire project was funded as submitted.

\section{Data Collection}

The multi-discipline approach of the Children's Clinic for 
services to neurologically impaired children and their families presented problems in record keeping. Data collected on each child included neurological workup, psychological, social work, and educational evaluation. These data were collected on each patient and discussed at a staff conference. The confidentiality of each patient's record was carefully guarded.

Good Samaritan Hospital provided the impetus, structure, and consultation to assist the clinic staff in meeting the need for adequate records. Record keeping for diagnostic evaluation, however, remained strictly within the domain of the clinic staff.

\section{Socio-Economic Inventory}

The clinic's use of a multi-discipline team of consultants (neurology, psychology, social work, and special education) for dianostic evaluation presented complexities in developing a uniform procedure in clinical recording. Representatives of each discipline assumed responsibility for establishing relevant criteria.

Social work members developed and used a formal procedure for collecting and recording data obtained during the clinical process of diagnostic evaluation. This procedure took the form of the SocioEconomic Inventory (Appendix I). Although the optimum condition of entirely objective and quantative data could not be fully achieved, a great deal of quantifiable information about each client was collected. Accessibility of this information for future use became the next obstacle. The clinic staff proposed that this 
recorded information had potential to describe certain characteristics of the clinic population in addition to diagnostic evaluation of individual cases. For purposes of this project, the information was used to describe various socio-economic aspects of the participants. Responses on the Socio-Economic Inventory were coded appropriately to facilitate storage of data on key-punch cards. When the diagnostic process and the record of each individual client was completed, coded responses on the Inventory were transferred to coding sheets and the key-punch cards processed.

Information stored on these cards represents a readily available source of diagnostic and demographic data on each clinic patient as well as the entire clinic population since July 1, 1972.

\section{Epilepsy Questionnaire}

A questionnaire that attempted to assess parental feelings toward, and knowledge of, epilepsy was constructed. Information from medical specialists on seizure disorders, the Epilepsy League of Oregon, and personal correspondence with Lydia Colon ${ }^{2}$ was used in developing the Epilepsy Questionnaire (EQ). The final questionnaire presented to the parents consisted of 61 questions on epilepsy and attitudes, four questions on the position of the individual respondting

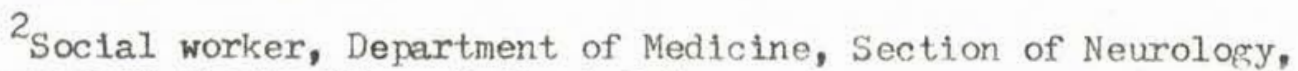
University of Puerto Rico, Medical Sciences Campus, San Juan, Puerto Rico. 
a list of available films, and a request for additional areas of interest (Appendix D). All responses were tallied and are reported In order that the information be available for use in planning future seminars. However, consulting professionals felt that 15 of the original 61 questions were nebulous or ambiguous. The Epilepsy Questionnaire was distributed to the parents included in the study prior to the seminars and again two months after the sixth session.

\section{Handicap Problems Inventory}

The Handicap Problems Inventory (HPI) consists of a check list of 280 problems attributable to physical disability. The Inventory was designed by C. N. Wright, Ph.D., program director for the National Epilepsy League, Inc., and H. H. Remmers, Ph.D., Professor of Psychology and Education at Purdue University (for a copy, detailed description. history and interpretation of the HPI, see Appendix E). In an attempt to discover the impact of their child's handicap on parental attitudes, this Inventory was administered prior to the series of parent seminars. The original HPI was designed for use with physically handicapped teenagers and adults. Instructions were adapted for use of parents of preschool children with selzure disorders.

\section{Brochure For Parents}

A Brochure For Parents was compiled, using materials from several sources. A bibliography was provided at the end of the Brochure. The Brochure attempted to provide information in commonly questioned areas 
concerning seizure disorders (Appendix B). Information was included on causes of seizures, first aid, treatment of seizure disorders, kinds of seizures, etc. Each parent was provided with a copy of the Brochure as soon as he or she returned the completed EQ. All parents had received a copy prior to the third seminar.

\section{Evaluation Questionnaire}

A brief questionnaire was designed to evaluate the effectiveness of the parent seminars. The Evaluation Questionnaire consisted of 12 questions concerming the entire series of seminars (Appendix D). This final Evaluation Questionnaire was distributed two months after the series ended. This questionnaire was designed to provide assistance in establishing future parent seminars by noting areas of deficiency or confusion, pertinent material, and interest in the current series.

\section{Video-Taping}

During the six weeks the parents participated in the seminars, each mother was individually video-taped in a play interaction with her child. This tape was then viewed by both parents separately. Dr. Russell Jackson and Dr. Leif Terdal, University of Orepon Medical School, discussed with them the behaviors observed. This portion of the video-taping was part of a lareer project currently in progress by Dr. Jackson and Dr. Terdal. The objectives of video-taning behavior were to record the kinds of behavior operating between mother and child and note tendencies toward disturbing or pathologic behavior 
and to compare the behavior of this study population with others. The objectives were essentially an attempt to establish a point of reference for future study.

The children were taken to the Child Development and Rehahilitation Center by their mothers and a 20-ninute mother-child interaction was video-taped. From the video-tape, two kinds of assessment were undertaken: (1) a coding of the mother-child interaction, along certain dimensions, and (2) a transcript and analysis of their report made while watching a video-tape playhack of the interaction. 


\section{PARENT SEMINARS}

As a result of the recognition that parents of children with seizure disorders frequently seemed anxious and had numerous childrearing problems, often not directly associated with the child's seizure disorder, a series of parent seminars were initiated. The purpose was to help parents share concerns in regard to their children, to help them understand their child's seizures, to develop an awareness of work in the clinic and school, and attempt to prepare fanilies for future events. Efforts were made to provide parents with pertinent information and afford them some relief from anxiety. Scherz discusses the role of parent-group sessions when dealing with families where the problem is a chronic or congenital handicap of one member. ${ }^{3}$ He feels the aim is to further understanding of the disablement, reduce guilt, and to improve role functioning and patterns of communication.

Alerting the clinic to any emergency problem which may require attention also was considered a possible result of parent-group interaction. Konopka points out how the social stigma of epilepsy

3rances Scherz, "Multiple-Client Interviewing: Treatment Implications" Soclal Casework. 42 (March 1962), 120-125. 
alone may drive people into isolation. ${ }^{4}$ The seminars were designed to provide parents with an interpretation of epilepsy which would be transmitted to the community. By increasing parental skills in meeting their child's handicap, it was hoped their talents might be used to help change attitudes in the community.

\section{Design}

The assumptions were that parents could explore some of their expectations, fears and fantasies, and check them against reality; look at their own emotional reactions and come to know and accept themselves better; and begin to think differently about things they can and want to do regarding their children. Anticipations in supplying guidance and information were that parents would learn at their own pace and focus on what was most significant for them.

The parent seminars were based primarily on the conception of the family as a "school for Iffe" and on the development of interpersonal relationships using learning techniques. The group was assisted by three co-facilitators who were graduate student social workers and additional professional personnel as the need arose. The focus of attention was on the parent and parent-child relationships and on assisting them in using their own resources. A number of the principles and practices, discussed by Auerbach in Parents

${ }^{4}$ Gisela Konopka, Soclal Group Work: A Helping Process (Englewood Cliffs, New Jersey: Prentice Hall, Inc.. 1972), 201. 
Learn Through Discussion, were incorporated into the program. 5

These included: helping parents become familiar with basic concepts of child growth and development and parent-child interaction from a dynamic view, recognizing crisis points in different stages of the family cycle, and clarifying parental and other roles.

For greater clarity, contracts were drawn between parent and clinic. Such contracts enabled the facilitators to express their roles and expectations (see Appendix G for forms and initial correspondence between clinic and parents). Berne notes that such contractual arrangements often bring out actual realities in a situation which might have gone unnoticed. 6

The decision was arbitrarily made to restrict the seminars to six weekly sessions. An evaluation and discussion meeting followed two months after the sixth session of the series. Each session was audio-taped for future review and evaluation. Free baby sitting was provided for each session. The seminars were scheduled for the early evening hours to make it easier for fathers to attend. In planning and organizing the parent discussion group, the original intention was that the primary topic of discussion would be the child's seizure disorder. This included exploring predominant family attitudes and

5Aline B. Auerbach, Parents Learn Through Discussion: Principles And Practices of Parent Group Education, (New York: John Wiley and Sons, Inc.., 1968).

6 Eric Berne, Principles of Group Treatment, (New Yorkı Grove Press, 1966), p. 34 . 
behavior. Voeller and Rothenberg found that parental attitudes are of such importance in the therapeutic management of seizure disorders that much time and effort can be saved by expending more energy in this area.

In the course of interviewing and treating many children in seizure clinic, we have been Impressed by the fact that the parents' and the child's attitudes about the illness may significantly influence the therapeutic course. We have seen that these attitudes arise again and again in predictable patterns and form a recurrent theme during the diagnostic and therapeutic phases of management.

Thousands of man-hours are expended in the treatment of seizure disorders, and it would appear that in the long run the initial investment of time devoted to exploring the family's attitudes and feelings regarding seizures results in a saving of time and better seizure control.

\section{Group Membership}

This study originally was planned around the school-age population of the clinic. Because of staff changes and a delayed schoolage program, a decision was made to work with parents of preschool children. Inclusion of the parents of school-age children with seizure disorders is left for consideration in future programs and studies. Considerable pressure and numerous questions from parents of preschool-age children also were influencing factors in establish-

7Kytja K. S. Voeller, and Michael B. Rothenberg, "Psychosocial Aspects of the Management of Selzures in Chlldren," a 26-page paper written for the Albert Einstein College of Medicine, Bronx Municipal Hospital Center (no date), p. 1, 20-21. 
ing the program with this particular age group.

Membership was limited to parents whose children were enrolled in the preschool program. One set of parents had identical female twins in the classroom. The severity and type of seizure disorders represented was variable. This group of children and parents had demonstrated need of the program and met the entrance requirements. These requirements were that the child have a neurological impairment and be between the age of one and six.

The eroup consisted of eight pairs of parents pluse one single parent. Mean attendance was 83.5 percent includin one father who never attended. A variety of ethnic and cultural hackerounds were represented.

\section{Unit of Study}

The unit is this study was the child with a seizure disorder. Ten children were selected, five boys and five firls. Two of the girls were identical twins ( $N=10$ for children, $N=9$ for families).

\section{Childrens' Ages $(n=10)$}

\begin{tabular}{|c|c|c|c|c|}
\hline \multirow[b]{3}{*}{ Mean are males $n=5$} & \multicolumn{2}{|c|}{ Male } & \multicolumn{2}{|c|}{ Female } \\
\hline & yrs & mos & yrs & mos \\
\hline & 2 & 10 & 6 & $8 *$ \\
\hline 2 yrs 11.4 mos & 2 & 0 & 2 & 9 \\
\hline Mean age females $n=4$ & 4 & 1 & 2 & 9 \\
\hline 3 yrs 11.8 mos & 2 & 6 & 2 & 4 \\
\hline $\begin{array}{c}\text { Mean age sample } n=9 \\
3 \text { yrs } 3.1 \text { mos }\end{array}$ & 3 & 4 & 2 & 10 \\
\hline
\end{tabular}

*This child was considered a preschool child because of her status in a preschool setting rather than in normal classes. 
Birth Order of Children $(n=10)$

$$
\text { Male }(n=5) \quad \text { Female }(n=5)
$$

$\begin{array}{lll}\text { Only child } & 1 & 0 \\ \text { 1st child } & 1 & 3 * * \\ \text { 2nd child } & 0 & 2^{* *} \\ \text { 3rd child } & 0 & 0 \\ \text { Adopted child } & 3 * & 0\end{array}$

* Of the three adopted children, one was adopted as the first child in the family, and the other two were adopted after the birth of natural children.

**Identical twins included

Composition Of Household $(n=10)$

\begin{tabular}{lcc} 
& Male & Children \\
& 0 & Female \\
Single-Parent Family & 5 & 1 \\
Two-Parent Family & & $4 * *$ \\
& 1 & 0 \\
\hline No siblings & 1 & $2^{* *}$ \\
One biological sibling & 1 & 1 \\
One adoptive sibling & & 2 \\
One biological and one & 2 & 1 \\
adoptive sibling & 0 &
\end{tabular}

**Identical twins included

Seven children were living with their biological parents, six in two-parent households and one child in a one-parent household. Three adopted children were living in two-parent households which included four additional adopted children. 
Parents' Ages ( $\mathrm{n}=17$ )

Range of Fathers' ages

Mean age of Fathers

Range of Mothers ${ }^{\circ}$ ages

Mean age of Mothers

Parents' Educational Attainment $(n=17)$

High School Diploma

Some College, No Degree

College Degree

Advanced or Professional Degree
26 to 42 years of age

32.6 years of age

25 to 41 years of age

30.9 years of age

Employment of Parents $(n=17)$

Clerical

Clerking

Architect

Fathers $(n=8)$ Mothers $(n=9)$

Physician

Supervisory

Sales

Attorney

Other (self-employed)

$\begin{array}{ll}1 & 2 \\ 2 & 3 \\ 1 & 2 \\ 4 & 2\end{array}$

Annual Income of Families $(n=9)$

$$
\begin{gathered}
\$ 3-\$ 4,999 \\
\$ 7-\$ 8,999 \\
\$ 9-\$ 14,999 \\
\$ 15-\$ 19,999
\end{gathered}
$$

$\begin{array}{ll}0 & 1 \\ 1 & 0 \\ 1 & 0 \\ 1 & 0 \\ 1 & 0 \\ 1 & 0 \\ 2 & 0 \\ 1 & 8\end{array}$

Marital Status of Parents $(\mathrm{n}=9)$

Family intact, no separations or previous marriages by either parent

Family divided, father not at home, mother has custody of child 
Sequence Of Events

Following the study design and funding, parents were given the Socio-Economic Inventory and a summary social evaluation was made at that time. A letter, detailed information, and authorization forms were mailed approximately one month prior to the first seminar. Upon receipt of the agreement to participate in the parent groups, the $E Q$ and HPI were malled to the parents. Those parents who returned the EQ and HPI prior to the first parent seminar were then given Parent Brochures. The rest of the parents received their Brochures following the first session after returning the $E Q$ and $H P I$.

\section{Group Discussion Sessions}

The group began as rather apprehensive, anxious, and somewhat antagonistic. Parent involvement was low and facilitator input high. At the end of six weeks, facilitator input was reduced while parent involvement was very high, centering around additional sessions without facilitators. Because one of the goals of this study was to record parental concern, the majority of the questions asked in each session are presented in AppendixH. Major areas of concern expressed included etiology of seizures, future uncertainties, diagnostic confusion, medications, sibling involvement, labeling, percentage of adoptive children with selzure disorder, physiology of seizures, what to tell others, problems with the schools, and funding. Each item of concern was discussed by group members. 
1. The first group session was an introductory and orientation meeting with 16 parents in attendance. Leif Terdal, Ph.D., clinical psychologist with the University of Oregon Crippled Children's Division, was present as a consultant. He explained the purpose of videotaping interaction of parent and child in a play setting. Re-scheduling of the preschool program, changes, and policles to adhere to state guidelines was briefly discussed. Two books were presented as reading materiali Living With Children, and Parents Are Teachers. The $E Q$ was discussed. Questions asked were primarily concerned with methods to be used in measuring their child's progress in the classroom, how additional information could be helpful to them as parents, EFG telemetry, the etiology of seizures, education advantages, and the social stigma attached to the word "epilepsy." A five minute film entitled "Benjamin" was shown. The meeting lasted for one and one-half hours.

2. The second session was a familiarity meeting with emphasis focused upon parent-group interaction. Specific questions were centered around agreements and disagreements with the Brochure For Parents. Each set of parents gave information regarding their child and his problems. Questions arose concerning heredity, obtaining precise scientific information, the relationship between seizure activity and developmental delay, and more understanding of various medications. A 23-minute film entitled "Not W1 thout Hope" was shown and discussed. 
There were 16 parents in attendance. The meeting lasted for two hours.

3. The thind meeting was a continuation of the second where parents continued to exchange information about their children. Questions asked ranged from inquiry into EEG reliability, etiology of epilepsy, anticipated problems of the future in education, health and society, and treatment available. The question of the percentage of adopted children having a selzure was raised as a result of parent-group interaction. A 30-minute film entitled "Grand Mal Epilepsys Diagnosis And Management" was shown and discussed. Fifteen parents attended. The meeting lasted for one and one-half hours.

4. The focus of the fourth meeting was in response to the desires of parents who wanted to receive some information from one of two reliable medical resources in the community. Dr. James R. Schimschock spoke to the group. A specific question and answer period centered around etiology, heredity, and anticipated problems. Descriptions, labeling, and classifications of definitions were discussed with suggestions for a more practical approach. Community education was a concern. Discussion ensued of involving other organizations for help in acquiring insurance, social acceptance and medical reference. During this session, some parents expressed hostility at not being told definitely that their child had epilepsy. Dr. Schimschock felt that they had falled to hear when they were being told. Wolfenberger refers to several authors who report parental hostility which is 
directed toward professionals when the parents are experiencing difficulty in accepting their child's handicap. ${ }^{8}$ The meeting, lasting two hours, was attended by 17 parents.

5. Mrs. Pat Sawyer, a preschool special education teacher from the University of Oregon Crippled Children's Division, and Russell Jackson, Ph.D., clinical psychologist, attended the fifth meeting. Mrs. Pat Sawyer provided each parent with a list of Day Care, Kindergarten, and Nursery Schools in the metropolitan area. The speaker was James Watson, M.D., neurologist.

Community education was the major topic of the question and answer period with more specific questions centering around medication, seizures, and their effects upon the brain. The meeting lasted two hours and 17 parents attended.

6. The sixth session was a meeting to summarize and assess the group in terms of education. Mrs. June Dunn, M.S.W., research advisor from Portland State University, attended. The group discussed the topics covered during the previous five meetings, along with comparison of the speakers. Considerations of contacts with other parents and the possibilities of having more than one group were summarized in terms of future parent groups. Interest was shown in encouraging parents

8.lf Wolfensberger, "Counseling The Parents Of The Retarded," in Alfred A. Baumeister (ed.) Mental Retardation (New Yorks Alpine Publishing Co., 1967), 366. 
of other neurologically impaired children to become involved in future events. Legislative action was considered by the group to further their cause. A tentative date was extablished to meet the original membership in two months for the seventh and last time. The objectives of the seventh meeting were outlined. There were 16 parents in attendance and the meeting lasted for one and one-half hours. 
RESULTS

Fifteen of the original 17 parents responded to both the Evaluation Questionnaire and the Epilepsy Questionnaire on the first and second trials. One father did not participate and another was not available at the end of the project.

\section{Handicap Problems Inventory (HPT)}

Most of the parents expressed confusion and resentment toward the HPI. They felt that they could not answer the questions meaningfully because their children were too young. Although the Inventory was originally designed for the respondent to be the Individual with the handicap, it has been used at the University of Oregon Medical School with parents of children with a handicap. Several parents refused to return the Inventory. On the basis of strong parental resentment, the HPI was eliminated as part of the project. This group of parents apparently were not ready to deal with many of the items included in the Inventory. For some of the parents whose children were only mildly handicapped such a confrontation might not be necessary and it appeared inappropriate at this time.

Evaluation Questionnaire

The final Evaluation Questionnaire provided pertinent and 
helpful suggestions for future parent sessions (see Appendix D for detailed replies). Individuals were rather evenly divided on most "Yes" and "No" answers. All parents checked "Yes" on question 11, recommending this type of seminar to other parents of children with seizure disorders. This is consistent with conclusions drawn from a study in the state of Oregon by Dr. James J. Cereghino. He remarks on the need to avoid emotional and behavioral problems which may create difficulties in future interpersonal relations if they are based on prejudices and fallacies.?

Material which the parents felt was most interesting and informative involved speakers (especially physicians and educators), group discussion, and exchange of individual case histories. The out-dated movies presented (which were the only ones available on epilepsy) were unanimously felt to be of least interest and in some cases emotionally disturbing. One parent suggested that the next project be devoted to making a more adequate movie on seizure disorders!

9 James J. Cereghino, Survey of Existing Services and Facilities for the Epileptic in the State of Oregon. Neurological and Sensory Disease Control Program, Division of Chronic Disease Programs, 4040 North Fairfax Drive, Arlington, Virginia 22203, f. 33. 
A need to summarize information and specific responses to each question in the Epilepsy Questionnaire was pointed out. Problems of the adult with a seizure disorder, a study of the brain and its functions, testimonials from "successful" and "unsuccessful" epileptics were among a number of suggestions made by the parents. There was a strong response in favor of more speakers, participation, group discussion, information on convulsions, and that the seminar for parents should continue to be a requirement for school placement. This latter statement was a reversal of the resentment expressed at the beginning of the series.

Parents demonstrated considerable enthusiasm by their verbal and written comments. They also expressed a desire to continue to meet twice a month, without the assistance of facilitators, after the initial series of six seminars ended. A Sunday "potluck" social gathering was held which included the children as well as the parents.

One parent attended a meeting of an ad hoc committee of the Oregon State Legislature to assist in obtaining funds for the clinic, while two other parents involved themselves in the public school system in an effort to influence the public image of eptlepsy. All such continuing efforts were initiated and performed without professional involvement. 
Epilepsy Questionnaire

Specific questions in the Epilepsy Questionnaire attempted to elicit parental opinions and feelings in regard to their expectations, fears, overprotectiveness, and knowledge of epilepsy. Wolfensberger comments on these areas and others in a review of studies on the dynamic aspects of parent functioning. ${ }^{10}$ Overprotectiveness, for example, though not beneficial in all aspects, is considered adaptive and desirable rather than pathogenic. Instead of treating overprotectiveness as rejection, as many authors do, Wolfensberger protrays overprotectiveness as a result of parents' attempts to convince themselves that they enjoy responding to long-term infantile dependency needs. This, in turn, can result in a more infantile and dependent child, either aggressive or quite passive.

First trial replies on the Epilepsy Questionnaire to question 13 ("A child with epilepsy should not be punished for misbehaving if such punishment aggravates his seizures?") and question 19 ("I would trust an older epileptic child to handle his own medications.") showed a relatively large number of "Don't Know" replies. On the second trial, after the parents had been exposed to the six-week parent seminar series, the shift to more definitive answers of e1ther "Agree" or "Disagree" appears to represent increasing

10 Wolfensberger, 329-400. 
confidence by parents in their own handling of the child and confidence in the child's abilities. There were only two "Don't Know" answers on each of these questions.

Responses of both professionals and parents to question 45 ("A child who has a seizure may die in one of his seizures.") are interesting. Although professionals could not reach a consensus between "Agree" and "Disagree", parent responses showed a definite shift to "Disagree". This shift may indicate an increasing conf1dence in both child rearing and child ability. A similar situation was noted in the dramatic shift in question 43 ("Epileptic children generally lead a long and healthy life.") from "Don't Know" to "Agree". There were six fewer "Don't Know" and five more "Agree" answers on the second trial. Concerns over the future of children with selzures were expressed a number of times in the parent seminars (see Appendix $\mathrm{H}$ for areas discussed).

Those parents whose chlldren were more severely handicapped felt more confident in a more protective role, and those whose children did not need such concern were more aware of the child's greater abilities and their own overprotectiveness. Some of this confidence and awareness developed during the seminars, and some occurred during social gatherings when all the parents and children met one another. A number of parents commented that meeting the other children put their own child's condition in better perspective. 
Question 59 ("A child with epilepsy should be trusted the same as any other child.") on the first trial elicited eight "Disagree" and three "Don't Know" answers. There was a change to 13 "Agree" answers on the second trial. Where possible, treating the child with a seizure disorder like other children is recommended by experts such as Henry Baird. ${ }^{11}$ Much of the material presented to the parents contained this message, so that the shift in responses to question 59 is possibly a result of this effort. Discussions on the need to change the public image of epilepsy also were involved.

Questions 7, 14, 24, 40, and 60 attempted to approach the problem, common for children with a seizure disorder, of being "different," "welrd," "possessed," etc. A slight shift from agreeing that the child should be treated as someone different was noted.

Questions dealing with medications (such as 17 and 18) show interesting responses. There was a shift from "Don't Know" answers to "Agree", a "wrong" answer in this case. Epilepsy is not cured through the use of medications, but controlled (question 17). Such medications are not generally habit forming (question 18) according

${ }^{11}$ Henry Baird, The Child with Convulsions: A Guide for Parents, Teachers, Counselors, and Medical Personnel. New Yorkı Greene and Stratton, 1972 . 
to authorities consulted. This information was presented to the parents and therefore there is some difficulty in interpreting their replies.

The majority of parent responses to question 34 on both trials (first trial, "Agree" 11; second trial, "Agree" 14) were in agreement that many people are afraid of an epileptic child. However, the professionals were divided between "Agree" and "Disagree". This discrepancy may have been related to the nature of the question, with parents responding more on a "feeling" level than the more "impersonal" professionals. Parent responses to question 44 ("It is difficult to plan for the future of an epileptic child.") changed from "Don't Know" with an increase in "Agree", whereas professionals, aware of the statistics and programs available, answered "Disagree". This material was presented to the parents during the seminars. Because the children were very young, parents might not have been ready for such areas as career planning at the time. This was observed in the number of "Don't Know" responses on both first and second trials to question 35 ("People with epilepsy generally have good work records."). Again, the excellent work records of many people with seizure disonders were discussed during the seminars. Questions involving specific knowledge, such as driving cars, programs offered by the Epilepsy League of Oregon, medications, types of situations affecting seizure frequency, how to manage a 
seizure, showed a definite change from "Don't Know". Question 56 ("Never put anything between a person's teeth during a seizure.") decreased from eight to two "Don't Know" responses. A change from seven "Agree" to 13 "Disagree" answers occurred for question 55 ("A child may swallow his tongue during a seizure.") Question 31 ("Epilepsy can cause heart trouble.") changed from nine "Don't know" and one "Agree" answer to almost unanimous "Disagree". Other questions involving specific knowledge such as question 50 ("Screen doors have been known to trigger seizures."), question 52 ("Males have more violent seizures than females."), and question 46 ("The child with epilepsy suffers no pain during his selzures.") decreased in "Don't Know" responses between first and second trials. Some of the lack of change in response might be attributed to the parent's absence during the discussion session in which the particular material was presented.

In general, there was a decrease in the number of "Don't Know" responses by parents. The number of these responses was still substantially larger, however, than replles by professional consultants who gave a total of only three "Don't Know" answers. This large discrepancy can be attributed to difference in approach and to the way in which discussions were conducted. Parents were assumed to answer questions initially in terms of experiences with their children rather than from a more objective perspective. Each 
question was not discussed separately but information designed to assist parents in finding their own answers was presented throughout the six weeks.

Several parents made critical comments about parts of the questionnaire and have agreed to assist in re-writing before 1 is used again. Pre-testing the questionnaire with non-handicapped persons or parents of non-handicapped persons or parents of nonhandicapped children apparently did not indicate adequately the needs and information desired by parents of children with seizure disorders.

Video-Taping And Evaluation of Parent-Child Interaction

1. Mother-child interaction. Fach child was observed interacting with his mother. This was a standard situation divided into two parts: (1) a 15-minute period of free play, and (2) a command situation where requests were made of the child. The observations were recorded using an interaction matrix system. ${ }^{12}$

During the free play, the child's hehavior was recorded in regard to whether he was responsive to the mother and whether the mother's behavior was facilitative of play. Whether the parent was aware of the child's level of develonment was noted. Special

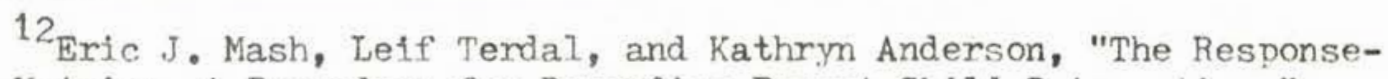
Class Matrix: A Procedure for Recording Parent-Child Interaction," University of Oregon Medical School, Crippled Children's Division (In press). 
interest was to see if this particular group of children followed a pattern which had been observed with other handicapped children and their parents. In addition, observations were recorded as to ability of these children at providing feedback to the parent, and whether the way the parents structured the task and their personal perception of the child affected the type of interaction in which they engaged. The latter point represented a major part of the study.

Following the free play session, each mother was asked to give the child three tasks. Since the tasks were geared to each child's developmental level, there was some variation of the specific tasks. For the child, attempts were made to observe and record the child's response to directives from his mother. The mother's pattern of structuring a task and her response to either compliance or noncompliance from her child were observed.

2. Video play back and unstructured interview. After the group sessions at Good Samaritan Hospital, the parents were invited to look at the video-tape. With one exception, all of the parents (husband and wife) chose to participate. The standard procedure was to inform the parents that they would have a chance to review the video-tape and to make any descriptive comments or give impressions and feelings which the tapes generated. In each case, the video was shown without interruption in its entirety. To ensure a standard situation, the tape was viewed in separate rooms concurrently by 
husband and wife. Their comments, as well as questions, were recorded by audio-tape and transcriptions of the sessions are currently being made for further analysis. The role of Dr. Jackson and Dr. Terdal during the video playback was to support any comments and encourage them to continue to express themselves.

3. Joint discussion with husband and wife. Dr. Jackson and Dr. Terdal, after viewing the video-tape, answered questions from the parents. Perceptions of the interactions were discussed, sometimes in detail, involving the total family situation.

4. The data. Only the data relating to an initial analysis of the mother-child interaction of the ten children are given. Data. are presented that was selected as sensitive to variations in parentchild interactions when a handicap is involved. A report will be made at a later date in which the data from the groun will be compared with a normal control group and another handicapped oroup along the same dimensions.

The ten children were classified on the basis of ability to communicate. Four of the children had limited verbal skills and the data show that they differed from the six children who were more fluent in verbal skills and had normal or near normal intelligence. Under the heading "Play Session" is a column for "child reciprocates interaction" which shows the proportion of time that the children reciprocated or responded to the mother, following some action by her. The four children with limited verbal skills responded less often (.29 versus .73). The mothers of the children with limited 


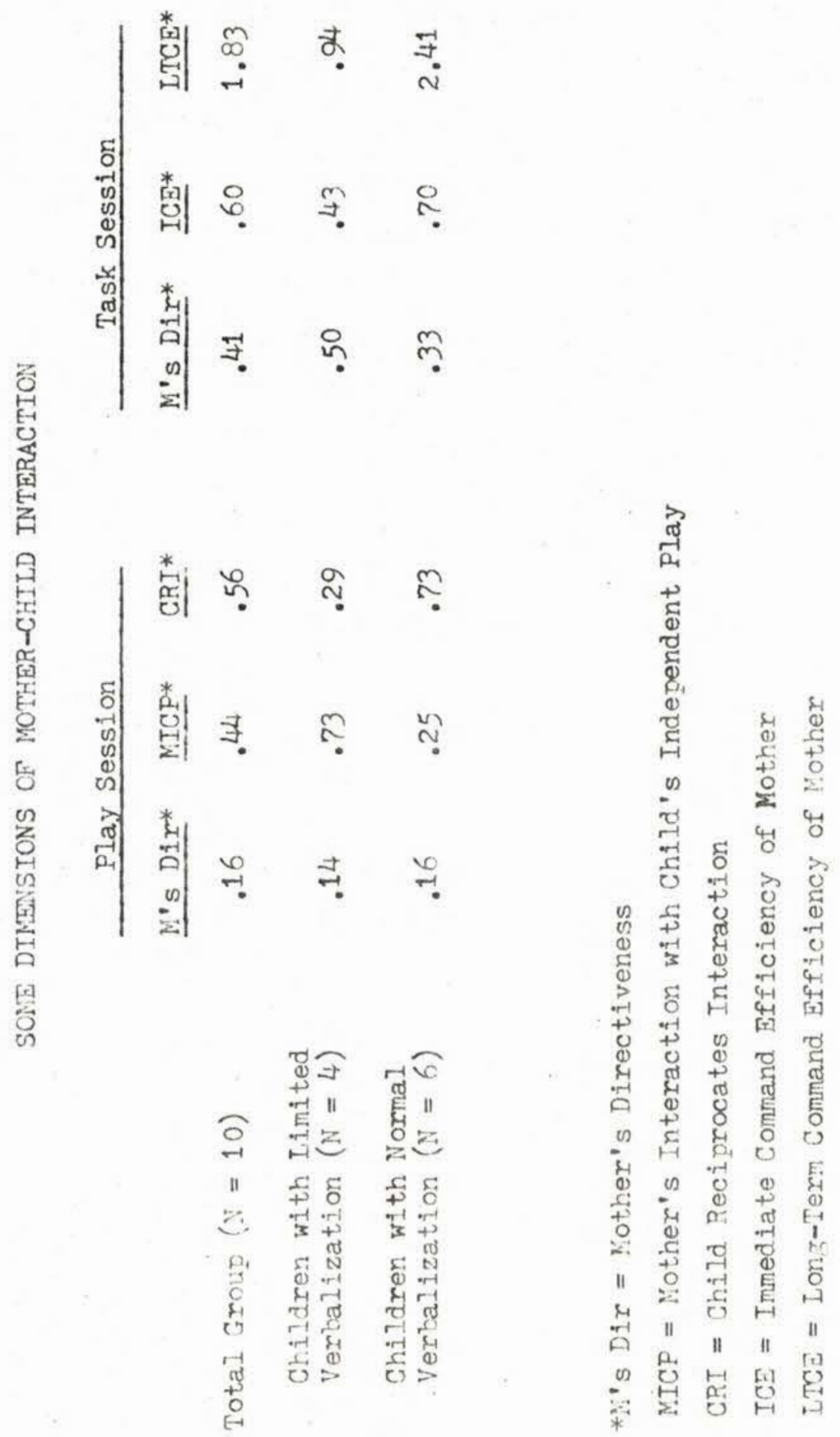


verbal skills wero not passive, however, as indicated by the high rate of respondine to the children (.73 versus .25) while their children were engaged in independent activity. The column "mother's directiveness" gives the ratio of the mother's commands to the number of the total responses she gave during the play sessions. The ratio was similar for the two groupings.

In the "Task Session," the two groupings also differed from each other. When tasks were requested by the mothers, the mothers of the more verbally fluent group gave fewer commands (directive ratio of .33 versus .50 ), their children were more likely to show immediate compliance, immediate command efficiency of mother (.70 versus .43), and they stayed with tasks for longer time units per command (2.41 versus .70 , a time unit of $1=10$ seconds).

The data indicate that as far as interactions were concerned, the effect of limited verbal fluency was marked. The six children were more fluent verbally showed similar interaction patterns to a group of forty normal young children (data to be given the later report). This may indicate that proprams for parents of children with seizure disorders should be based in part on the presence or absence of other significant handicapping conditions. The data for individual mother-child interactions was noted to reflect the overall competency of each individual mother. 


\section{CHAPTER V}

\section{SUMMARY AND CONCLUSTONS}

Parents raising children with seizure disorders have an urgent need for more information about their child's disorder as well as emotional support. Comments in the literature, observations by professionals, and requests from parents attest to this need. This project was an effort to respond to this need by designing and facilitating a series of parent group seminars. It was our plan to describe parent need more clearly and evaluate the usefulness of the group process in meeting these needs. The type of proups developed attempted to reflect parent demands. No effort was made to separate group effect from educational and other experiences, Facilitator knowledge of available materials and speakers was used to deal with specific issues pertinent to a groud whose members all were parents of preschool children with seizure disorders. The group focused on parent-child and parent-parent interaction, child-rearing techniques, and specific information on the disorder called "epilepsy." Included in the project was an attempt to objectively recond happenings and a final assessment.

A major roal was the designing of a group program and methods of recording the activities of that group which the clinic could continue to use in the future. An effort also was made to develop enthusiasm in this initial proup of parents to extend their knowledpe 
and experience to other parents, institutions, and community involvement.

Objective attendance records, examining replies to questionnaires, reviewing verbal comments, and noting the independent continuation of the sessions by the parents after the formal program had terminated. Parental expression of greater confidence in themselve, their child, and in their child's future was evidenced by changes in their response to the EQ developed for this study. A reduction in overprotectiveness and increased knowledge in specific areas were noted in the question naire replies. This was further demonstrated in increased social contacts between parents outside of the group setting and included reciprocal transportation, assistance, and sharing of other resources. In addition, several of the parents began providing volunteer assistance and materials to the clinic and participated more actively in the school program.

Revisions in several areas of this initial program became apparent. There appeared to be a reater demand for more speakers and more time for discussion in the groups. In some cases, certain parents had emotional problems which were detected in the videotaping of mother-child interaction and subsequent discussions with the psychologists. Some parents may have discovered new fears from additional knowledge and contact with parents of nore severely handicapped children. Parents who expressed such concerns were referred to the appropriate counseling resources. 
A certain inconsistency was evident between responses that requested more time for discussion and yet a more directive approach involving more speakers and greater structure in the program. Facilitator requests for more parental involvement and guidance in the group was met with resistance. Requests for more time for informal discussions were almost unanimous and not adequately met.

A critical issue that was not satisfactorily resolved was that of the definition of "epilepsy". Lack of national, regional, and local consensus in laws and definitions left the parents somewhat condused as to whether epilepsy is a "disease, a symptom or a disorder".

The parents have already taken on the project of assisting with the revision of the Epilensy Questionnaire. Questions designated as "nebulous" by the professionals generally produced divided responses by the parents. Parents of children with a seizure disorder appear to have a different perspective and attitude than do professionals. As an attempt to discover parent "attitudes," the EQ was only partly successful. However, several of the questions dealing with "feelings" received different responses from the first to second trial.

No attempt has been made to generalize these findinfs for all parents of children with seizure disorders. This has been a pilot study with a specific roup of parents, all of whom had children in a problem oriented setting designed to serve specific problems. 
Inique features in the experience were the volume and variety of records (audio-tane, video-tape, questionnaires, slides, etc.) and the qualifications of the group leaders.

This rroup of parents benefited from the social work skills used in the project. Knowledge of group dymamics, interviewing techniques, research methods, family orientation, inter-personal communication, human development, and available services in the community contributed to the success of the proup seminars.

A considerable amount of information on parent attitudes was obtained diring this study and recorded for future use. Dr. Schimschock is proposing a follow-up study on this grour of parents and children in five years, after the children enter school. Dr. Terdal and Dr. Jackson are interested in using some of the data in a study of parental attitudes at the Crippled Children's Division of the University of Oregon Medical School.

Several unexplored aspects of this group need further study. The proportion of adopted children with seizure disorders (30\%) apnears high. The number of first or only children also appears relatively hich. This latter case may be related to the are of the parents but is an interestin problem when one considers the hopes and expectations that parents often place on an oldest or only child. What happens to parent-child relationships when a child is found to be "imperfect" and unable to respond adequately to parental expectations? What is the parents' reaction to, and in, a oroun experience in relation to the severity of the child's seizure disorder? 
Revision of the Epilepsy Questionnaire, using a parent's perspective, may have important implications for follow-up studies. Objective assessment of the parental perspective might influence both physiological and psycholorical treatment methods.

Comparison between males and females is another possibility for future study in attitude and attitude changes. Because the group was designed to involve fathers as well as mothers, including the evaluation of video-taping, an analysis of responses by sex might be of interest. All material is recorded and coded to make this feasible.

The Parent Brochure might be printed as a pamphlet for Eeneral distribution if there appears to he a demand for such material. It was assembled with parents of preschool and school-ase children in mind.

This study has demonstrated the value, and feasibility of group experience for molifying parental attitudes toward their children and their children's seizure disorders. Adoption of parent seminars as a regular function of the Children's Clinic will enable refinement of methods of presentine information. Study of additional groups should provide data for continual evaluation of the effects of the program on relationships between parents and children and effects of these relationships on child learninf and behavior. 


\section{SELECTED BIBLIOGRAPHY}

Amster, Fanny. "Collective Psychotherapy of Mothers of Emotionally Disturbed Children." American Journal of Orthopsychiatry. 14 $(1944), 44-52$.

Andrews, Jean, "We Learned to Live with Epilepsy." In William G. Kvaraceus, and E. Nelson Hayes, If Your Child is Handicapped. Boston: F. Porter Sargeant, 1969.

Appell, Melville V., Clarence Williams, and Kenneth N. Fishell. "Changes in Attitudes of Parents of Retarded Children Effected Through Group Counseling." American Journal of Mental Def1ciency. 68:6 (May 1964), 807-812.

Auerbach, Aline B. Parents Learn Through Discussion: Principles and Practices of Parent Group Education. New Yorks John Wiley and Sons, Inc., 1968.

- "What Can Parents of Handicapped Children Gain from Group Experience." Helping Parents of Handlcapped Children. Boston: Children's Hospital Medical Center and Child Study Association of America (October 1959).

Bagley, Christopher. The Social Psychology of the Child with Epilepsy. Londons Rutledge S. Kegan Paul, Ltd., 1971.

Baird, Henry. The Child with Convulsions: A Guide for Parents, Teachers, Counselors, and Medical Personnel. New York Greene and Stratton, 1972.

Bakwin, Harry, and Ruth Morris Bakwin. Clinical Management of Behavior Disorders in Children. Philadelphia: W. B. Saunders Co., 1967 .

Bakwin, R. M., and Harry Bakwin. "Epilepsy." The Journal of Pediatrics. 39:4 (December 1951), 775-784.

Barker, W. "Studies in Epilepsy: The Petit Mal Attack as a Response within the Central Nervous System to Distress in OrganismEnvironment Integration." Psychosomatic Medicine. 10 (1948), 73-94.

Barnwell, John E. "Group Treatment of Older Adolescent Boys in a Family Agency." Social Casework. 41 (May 1960), 247-253. 
Barsch, Ray H. The Parent of the Handicapped Child. Springfield: Charles C. Thomas, 1968.

Baus, Gaston J., L. LaVerne Letson, and Edith Russell. "Group Dynamics in the Treatment of Epilepsy." The Jourmal of Pediatrics. 52:3 (March 1958), 270-273.

Beasley, J. "Social Aspects of Epilepsy in Childhood." PostGraduate Medical Journal. 40:464 (June 1964), 344-345.

Becker, Wesley C. Parents Are Teachers. Champaign, Illinois: Research Press Co., 1971.

Bergen, Helen M., and Anton O. Kris. "Services to Parents of Adolescent Mental Patients." Social Casework. 53:2 (February 1972), 85-90.

Bice, Harry V., and Margaret C. Davitt Holden. "Group Counseling with Mothers of Children with Cerebral Palsy." Social Casework. 30:3 (March 1949), 104-109.

Bice, Harry V. "Parent Counseling and Parent Education." Cerebral Palsy: Its Individual and Community Concerns. William M. Cruickshank and George M. Raus, eds. Syracuses Syracuse University Press, 1955.

Blatt, A. "Group Therapy with Parents of Severely Retarded Childrenı A Preliminary Report." Group Psychotherapy. 10 (1957), 133-140.

Bradley, Charles. "Characteristics and Management of Children with Behavior Problems Associated with Organic Brain Damage," Pediatric Clinics of North America. 14:4 (November 1957), 1049-1060.

"Behavior Disturbances in Epileptic Children." Joumal of the American Medical Association. 146:5 (June 1951), 436- $\sqrt{41}$.

Bradley, Charles M. "A Normal Life for Children with Convulsions." Epilepsy Speaks. Portland The Epilepsy League of Oregon (September 1958). Two pages mimeograph.

Bridge, E. M. Epilepsy and Convulsive Disorders in Children. New Yorks McGraw-Hill Book Co., 1949.

Broida, Daniel C. "Psychological Aspects of Epilepsy in Children and Youth." Psychology of Exceptional Ghildren and Youth. 
New Yorks Prentice-Hall, 1955, 345-390.

Brullerman, L. H. "Group Therapy with Epileptic Patients at the 'Instituut Voor Epilepsiebestrijding." Epilepsia. 13 (1972), 225-231.

Burden, G. "Social Aspects of Epilepsy." Epilepsia. 3 (1962), 201 204.

Caveness, William. "A Survey of Public Attitudes Toward Epilepsy." Epilepsia. 3:3:99 (1954), 102.

Cereghino, James J. Survey of Existing Services and Facilities for the Epileptic in the State of Oregon. Neurological and Sensory Disease ControI Program, Division of Chronic Disease Programs, Arlington, Virginia, p. 33.

Chao, Dora Hsi-Chih. "The Over-All Management of the Epileptic Child." Medical Clinic of North America, 42 (1958), $461-478$.

Children's Hospital Medical Center. Helping Parents of Handicapped Children. Child Study Association of America, 1959.

Child Study Association. When Parents Get Together: How to Organize a Parent Education Program. New York: Child Study Association of America, Inc. (Rev. February 1964).

Cohen, Lord of Birkenhead. "Epilepsy as a Social Problem." British Medical Journal, 1,5072 (March 22, 1958), 672-675.

Coleman, James C. "Group Therapy with Parents of Mentally Deficient Children." American Journal of Mental Deficiency, 57 (1953), $700-704$.

Crow, Maxine S. "Preventive Intervention Through Parent Group Education." Soclal Casework, 48:3 (March 1967), 161-165.

Crowther, D. L. "Psychosocial Aspects of Epllepsy." Pediatric Clinics of North America, 4:14 (1967), 921-932.

Cummins, Jean. "The Family as a Factor in the Epileptics Soclal Adjustment." Social Casework, 3:9 (November 1949), 384-387.

Cummins, S. Thomas. "Brief Group Therapy of Mothers of Retarded Children Outside of the Specialty Setting." American Journal of Mental Deficiency, 66 (1962), 739-748. 
Davidoff, Eugene, George M. Doolittle, and Vincent I. Bonafede. "Psychiatric Aspects of Epilepsy." Journal of Nervous and Mental Disease, $100(1944), 170-184$.

Davidson, Elabe McL., and Joan C. Thomas. "A Social Study of Epileptic Patients." Social Casework, 30.9 (November 1949), 380-384.

Davis, Jack A. "The Use of Discussion Groups in a Military Setting in Japan." Soctal Gasework, 44:2 (February 1963), 74-80.

Day, Max, Elvira Day, and Rosalind Herrmann. "Group Therapy of Patients with Multiple Sclerosis." A.M.A. Archives of Neurology and Psychiatry, 69 (February 1953), 193-196.

Day, Max, and Irving Rosen. "The Group Behavior of Mothers of Schizophrenics." Journal of Nexvous and Mental Disease, 119 (1954), 365-369.

DeColon, Lydia Santiago, Richard D. Trent, and Louis Sanchez Longo. "A Group Work Experience for Mothers of Adolescents with Epilepsy." Counseling Parents of the IIl and the Handicapped. Springfield, I1l.: Charles C. Thomas. 1971, 219-226.

deFrles, Zira, and Sue Browder. "Group Therapy with Epileptic Children and Their Mothers." Bulletin of the New York Academy of Medicine, 28:4 (April 1952), 235-240.

Deutsch, Leopold, and Louise L. Wiener. "Children with Epilepsy، Emotional Problems and Treatment." American Journal of Orthopsychiatry. 18 (1948), 65.

Dreikers, Rudolf. "Basic Principles in Deallng with Children." Adlerian Family Counseling: A Manual for Counseling Centers. (ed.) Rudolf Dreikurs, et. al. Eugene, Oregon: University Press, 1959.

87 (1959); $2148 .^{\text {"Do Teachers Understand Children?" School and Society. }}$

- "Counseling for Family Adjustment." Individual Psychology Bulletin, 8 (1949), 3.

The Challenge of Parenthood. Rev, ed. New York: Duell, Sloan, and Pearce. 1958.

Dreikurs, Sadie Garland. "Psychological Techniques Applied in a Group Situation." Individual Psychology Bulletin, 4 (1954), 4. 
Driscoll, Chancellor B., and A. Harold Lubin. "Conferences with Parents of Children with Cystic Fibrosis." Social Casework, 53.3 (March 1972), 140-146.

Durkin, Helen E. Group Therapy for Mothers of Disturbed Children. Springfield, III.: Charles C. Thomas, 1954.

Durkin, Helen $E_{.}$, Henriette T. Glatzer, and Jeanette S. Hirsch. "Therapy of Mothers in Groups." American Joumal of Oxthopsychiatry. 14 (1944), 68-75.

Epilepsy Center of Michigan. First Aid for Epileptic Convulsions. Detroit: Epilepsy Center of Michigan (March 1971).

Force, D. "A Descriptive Study of the Incidence of Seizures and Teacher's Attitudes Toward Children with Epilepsy in the Minneapolis, Minnesota, Public Schools." Minnesota Epilepsy League, (December 1965), 75 pages mimeographed.

Fremont-Smith, Frank. "The Influence of Emotion in Precipitating Convulsions." American Journal of Psychiatry, 13,90 (1934), 717-723.

French, A. C., Levbarg, M., and H. Michal-Smith. "Parent Counseling as a Means of Improving the Performance of a Mentally Retarded Boy, A Case Presentation." In C. L. Stacey and M. F. DeMartino, eds. Counseling and Psychotherapy with the Mentally Retarded. Glencoe, IIl.1 The Free Press. (1957), $438-445$.

Funt, Irene G. "The Application of Casework Principles in Family Life Education." Social Casework, 43:3 (March 1962), 130-137.

Ganoung, Laura D. "Educational Problems of Epileptic Children." Epileptic Seizures. Baltimores The Williams and Wilkins Co. $(1956), 63$.

Gardner, Harry H. "Personality and Behavioral Aspects." In George N. Wright, Frederic A. Gibbs, and Shirley Motter Linde eds. Total Rehabilitation of Epileptics - Gateway to Employment. Washington, D.C.: U. S. Department of Health, Education, and Welfare. Office of Vocational Rehabilitation (January 1962).

Garrard, Sterling D., and Julius B. Richmond. "Psychological Aspects of the Management of Children with Defects or Damage of the Central Nervous System." Pediatric Clinics of North America. (November 1957), 1033-1048. 
Gerofski, Ruth. "The Patient Faces Epilepsy." Social Casework, $29: 5$ (May 1948), 182-187.

Glidewell, John C. Parental Attitudes and Child Behavior. Springfield: Charles C. Thomas (1961).

Goldin, George J. The Rehabilitation of the Young Epileptic. Boston: D. C. Heath and Co., 1971.

Goller, Gertrude. "Use of the Small Discussion Group in Parent Education." Social Work, 2:2 (April 1957), 47-53.

Goodman, L., and R. Rothman. "The Development of a Group Counseling Program in a Clinic for Retarded Children." American Journal of Mental Deficiency, 65 (1961), 789-795.

Gordon, Ira J. Early Stimulation Through Parent Education. Gainsville, Floridas Institute for the Development of Human Resources, University of Florida. (1969).

Gowers, W. R. Epilepsy and Other Chronic Convulsive Diseases: Their Causes, Symptoms and Treatment. New York: Dover Publications, Inc. (1964).

Graves, Valerie. "The Discussion Group." The Postgraduate Medical Joumal, 40:459 (January 1964), 1-3.

Grunwald, Hanna, and Bernard Casella. "Group Counseling with Parents." Child Welfare, (January 1958), 11-17.

Hallowitz, Emmanuel, and Bernice Stephens, "Group Therapy with Fathers." Social Casework, 40:4 (April 1959), 183-182.

Hartlage, L. C., and J. B. Green. "The Relation of Parental Attitudes to Academic and Social Achievement in Epileptic Children." Epilepsia, 13 (1972), 21-26.

Hereford, Carl F. Changing Parental Attitudes Through Group Discussion. Austin: University of Texas Press (1963).

Horowitz, Mardi J. Psychosocial Function in Epilepsy. Springfield, Ill.1 Charles C. Thomas (1970).

Hughes, J. G., and J. T. Jabbour. "The Treatment of the Epileptic Child." The Journal of Pediatrics, $53: 1$ (July 1958), 66-68. 
Ireton, Harold R. "Psychologic Problems of Children with Seizures." Postgraduate Medicine, 64:2 (August 1969), $41-45$.

Jensen, R. A. "Importance of the Emotional Factor in the Convulsive Disorders of Children." American Journal of Psychiatry, 104 (1947), 126-131.

Kahn, Carl L. "Pills that Control Epileysy." Your Life. Portland, The Epilepsy League of Oregon (August 1959), two pages mimeograph.

Kamin, Sheldon H., Charley Jackson Llewelleyn, and Winnie L. Sledge. "Group Dymamics in the Treatment of Epilepsy." The Journal of Pediatrics, 53:1. (October 1958), 410-412.

Kanter, Stanley S. "Dynamic Insights Gained from Group Therapy with Obesity Patients." Journal of Nervous and Mental Disease, 119 (1954), 367.

Karnes, Merle B., and Earladeen D. Badger. Mother's Training Program: The Group Process. Urbana, IIl, ERIC Clearinghouse for Early Childhood Education (1970).

Karnes, Merle B., William M. Studley, Willis R. Wright, and Audrey S. Hodgins. "An Approach for Working with Mothers of Disadvantaged Preschool Children." Merrill-Palmer Quarterly, 14:2 (April 1968), $174-183$.

Kemp, Robert. Understanding Epilepsy. London: Tavistock Publications (1963).

Kemph, J. P., I. A. Zegans, K. A. Kooi, and R. W. Waggoner. "The Emotionally Disturbed Child with a Convulsive Disorder." Psychosomatic Medicine, 25 (1963), 441-449.

Kimball, O. P. "On the Inheritance of Epilepsy." The Wisconsin Medical Journal, 53 (May 1954), 271-276.

Laibman, Erwin M. "Group Counseling with Parents in an Agency Serving Adolescents. Social Work, 6:2 (April 1961), 67-73.

Lampe, J. "Education and Epilepsy." Journal of School Health, 29:6 (June 1959), 220-223.

Lennox, William G. and C. H. Markham. "The Sociopsychological Treatment of Epilepsy." Journal of the American Medical Association, 152 (August 1953), $1690-1694$. 
Lennox, William G. and Margaret A. Lennox. Epilepsy and Related Disorders. London: Churchill Press (1960).

Lennox, William G. "Mental Defect in Epilepsy and the Influence of Heredity." American Journal of Psychiatry, 98 (1942), 733-739.

"Psychiatry, Psychology and Selzures." American Journal of Orthopsychiatry, 19 (1949), 432-446.

Brothers (1 941$)$.

Sclence and Seizures. New York: Harper and

"The Social and Emotional Problems of the Epileptic Child and His Family." The Journal of Pediatrics, 44:5 (May 1954), 591-601.

Leonhard, Jacqueline T. Diagnosis Epilepsy--A Guide for Parents. Cleveland, Ohios Parents Committee on Epilepsy, Family Health Association, Inc. (1962).

Levenstein, P. "Cognitive Growth in Preschoolers Through Verbal Interactions with Mothers." American Journal of Orthopsychiatry, 14:3 (Apri1 1970), 426-432.

Liebman, Samuel. Emotional Problems of Childhood. Philadelphia: J. B. Lippencott Co. (1958).

Lippman, Hyman S. Treatment of the Child in Emotional Conflict. New York: McGraw-Hill Book Co., Inc. (1962).

Livingston, Samuel. Living with Epileptic Selzures. Springfield: Charles C. Thomas (1963).

"The Social Management of the Epileptic Child and His Parents." The Journal of Pediatrics, 51:2 (August 1957), $137-145$.

Long, Robert T. "Insights Gained Through Group Therapy with Multiple Sclerosis Patients." Journal of Nervous and Mental Disease, 119 (1954), 366.

Love, Harold D. Parental Attitudes Toward Exceptional Children. Springfield: Charles C. Thomas (1970).

Lowrey, Lawson G. "Group Therapy." American Journal of Orthopsychiatry, 13 (1943), 648-690.

Lunt, Carroll. How to Live with Epilepsy. New York: Twayne Publishers $(1 \overline{961})$. 
Mallison, Ruth. Education as Therapy: Suggestions for Work with Neurologically Impaired Children. Seattlei Special Child Publications (1968).

Mann, David, Luther E. Woodward, and Nathan Joseph, Educating Expectant Mothers. New Yorkı $\mathrm{H}$. Wolff Book Manufacturing Co. (1961).

Mann, James. "The Theoretical Concepts of the Group Process." Journal of Nervous and Mental Process, 119 (1954), 365.

Mannino, Fortune V., and Margaret M. Conant. "Dropouts from Parent Education Groups." The Family Coordinator, 18:1 (January 1969), 54-59.

Mash, Eric J., Leif Terdal, and Kathryn Anderson. "The ResponseClass Matrix, A Procedure for Recording Parent-Child Interaction." University of Oregon Medical School, Crippled Children's Division (In press).

McGriff, Dorothy. "Working with a Group of Authoritative Mothers." Social Work, 5:1 (January 1960), 63-68.

McMichael, Joan K. Handicap. London: Staple Press (1971).

McPherson, Sandra B., and Cyrille R. Samuels. "Teaching Behavioral Methods to Parents." Social Casework, 52:3 (March 1971), 148-153.

Milman, Doris H. "Group Therapy with Parentsi An Approach to the Rehabilitation of Physically Disabled Children." The Journal of Pediatrics, 41:1 (July 1952), 113-116.

Morgan, Margaret, Harold GoodGlass, Angela Folsom, and Fred A. Quadfasel. "Epilepsy and Social Adjustment." Social Work, 12:2 (April 1967), $70-76$.

Nadal, Robert M. "A Counseling Program for Parents of Severely Retarded Preschool Children." Social Casework, 42:2 (February 1961), 78-83.

Nardini, John, and Genevieve O'Leary. "How Much Protection?" Portland, The Epilepsy League of Oregon (no date), one page mimeograph. 
"Teaching Him to Manage His Epilepsy." Portland, The Epilepsy League of Oregon (no date), one page mimeograph.

National Epilepsy League. "Our Schools and Our Children with Epilepsy." National Epilepsy League (1958), 80 pages mimeograph.

Summaries of Articles on Juvenile Epilepsy.

National Epilepsy League: Park, Davis and Co., 1967.

"The Care and Education of Children with Epilepsys

A Nationwide Survey by John W. Tenny." Chicagos The League

(1958), 16 pages mimeograph.

National Society for the Study of Education. The Twenty-Eighth

Yearbook: Preschool and Parental Education. Bloomington, IIl.:

Public School Publishing Company (1929).

Neubauer, Peter B. "The Technique of Parent Group Education: Some Basic Concepts." In Parent Group Education and Leadership Training. New York: Child Study Association of America (1953), 11.

Otto, John L. "Psychologic Problems in Epilepsy." Epileptic Seizures. Baltimore: The Williams and Wilkins Co. (1956), 63.

Ounsted, C. "The Hyperactive Syndrome in Epileptic Children." Lancet, 2(August 1955), 303-311.

Papademetrious, Marguerite. "Use of a Group Technique with Unwed Mothers and Their Families." Social Work, 16:4 (October 1971), $85-90$.

Patterson, Gerald R. Living With Children. Rev, ed. Champaign, Ill.: Research Press Co. (1971).

Penfield, Wilder, and Kristian Kristiansen. Epileptic Seizure patterns. Springfield, Charles C. Thomas (1951).

Penfield, Wilder, and Theordore C. Erickson. Epilepsy and Cerebral Localization. Springfield, Ill.: Charles C. Thomas (1941).

Penfield, Wilder, and Herbert Jasper. Epilepsy and the Functional Anatomy of the Human Brain. Boston: Little, Brown and Co. (1954).

Peterman, M. G. "Behavior in Epileptic Children." The Journal of Pediatrics, 42:6 (June 1958), 758-769. 
Price, Jerry C. "The Epileptic Child in School" Ohio State Medical Journal, 46:3 (1950), 794-805.

Price, Jerry Seizure Clinic. Brochure for Parents. Los Angeles: Children's Hospital (November 1963), 10 pages mimeograph.

Price, Jerry C., and Tracy J. Putnam, "The Effect of Intrafamily Discord on the Prognosis of Epilepsy." American Journal of Psychiatry, $100(1944), 593-598$.

Pond, D. "Psychiatric Aspects of Epileptic and Brain-Damaged Children." British Medical Journal, 2 (1961), 1377-1382; 14541459.

Pond, D. A., and B. Bidwell. "Management of Behavior in Epileptic Children." British Medical Journal, 2 (December 1954), 15201523.

Putnam, Tracy J. Convulsive Seizures: A Manual for Patients, Their Families and Friends. Philadelphia: J. B. Lippincott Co. $(1945)$.

Puvrez, Marguerite. "Experiences in Working with a Group of Seizure Patients." Differential Diagnosis and Treatment in Social Work. Ed. Francis J. Turner, New Yorki Free Press (1968), 379-386.

Redl, Fritz. "Dlagnostic Group Work." American Journal of Orthopsychiatry, 14 (1944), 53-60.

Redwin, Eleanore. "Mothers Therapy Groups." Adlerian Family Counseling, A Manual for Counseling Centers. Ed. Rudolf Dreikurs, et. al. Eugene, Oregoni University Press (1959).

Rodin, Ernest A. "Medical and Social Prognosis in Epilepsy." Epilepsia, 13 (1972), 121-131. Charles C: Thomas (1968), of Patients with Epilepsy. Springfield:

Rodin, Ernest A., P. Rennic, R. Dennerll, and Y. Lin. "Vocational and Educational Problems of Epileptic Patients." Epilepsia, 13 (1972), 149-160.

Ross, Alan 0. The Exceptional Child in the Familys Helping Parents of Exceptional Children. New York; Grune S. Stratton (1964). 
Rupp, Charles. "Management of Epilepsy." Jourmal of the American Medical Association, 166 (April 1958), 1967-1970.

Sands, Harry. "Epilepsy." In M. E. Fraupton and Elena D. Gall, eds. Special Education for the Excpetional. Boston: Porter Sargeant. $3(1956), 204-214$.

Sands, Harry, and Jacqueline Seaver. Epjlepsy--Today's Encouraging Outlook. Public Affairs Pamphlet No. 317, Produced in cooperation with Epilepsy Association of America, 1969.

Scheldlinger, Saul, and Marjorie Pyrke. "Group Therapy of Women with Severe Dependency Problems." American Journal of Orthopsychiatry, 31 (October 1961), 776-785.

Schilder, P. "Analysis of Ideologies Psycho-Therapeutic Method, Especially in Group Treatment." American Journal of Psychiatry, $93(1936), 601$.

Scholl, Mary Louise. "Let Them Ask." Epi-Log. Portland, The Epilepsy League of Oregon. From the Greater Kansas City Epilepsy League, Inc. (no date), one page mimeograph.

Schwentker, Francis F. "Social Management of Epilepsy" In Samuel Livingston, The Diagnosis and Treatment of Convulsive Disorders in Children. Springfield: Charles C. Thomas (1954), 236-249.

Scott, Donald. About Epilepsy. New Yorkı International Universities Press, Inc. (1969).

Siegel, Ernest, Helping the Brain Injured Child. New York: Association for Brain Injured Children (1961).

Sonstegard, Manford A. "A Center for the Guidance of Parents and Children in a Small Community." The American Journal of Individual Psychology. 11 (1954), 1.

Slavson, S. R. Child Centered Group Guidance of Parents. New York: International Universities Press, Inc. (1958).

Speers, Rex W., and Comelius Lansing. Group Therapy in Childhood Psychosis, Chapel Hill: University of North Carolina (1965).

Spock, Benjamin, and Marion 0. Lerrigo. Caring for Your Disabled Child. New York: Mackillan Co. (1965). 
Staprans, Theodore. "Epilepsy and Personality." Epilepsy Speaks. Portland: The Epilepsy League of Oregon. 5:3 (March 1958), two pages mimeograph.

Stern, Edith M., and Elsa Castendyck, The Handicapped Child, A Guide for Parents. New Yorkı A. A. Wyn, Inc. (1950).

Sterm, H. H. Parent Education: An International Survey. Hamburg: The University of Hull and the Unesco Institute for Education (October 1960).

Stone, F. B., and V. M. Rawley. "Children's Behavior Problems and Parental Attitudes." Journal of Genetic Psychology, 107 (1965), $281-287$.

Sullivan, Ellen B., and Lawrence Gahagan. "On Intelligence of Epileptic Children." Genetic Psychology Monographs, 17 (October 1935), 309.

Suter, C. G. "Psychological Factors in Epilepsy." Neuropsychiatry, 3 (Fall, 1955), 153-171.

Tavriger, R. "Some Parental Theories About the Cause of Epilepsy." Epilepsia, ? (1966), 339-343.

Tempkin, Owsei. The Falling Sickness. Baltimore: The Johns Hopkins Press $(1971)$.

The Epilepsy League. "Alcoholism and Epileptic Seizures." Epi-Gram. Portland: The Epilepsy League of Oregon. From the Leavenworth Epilepsy League (no date), one page mimeograph.

- A Patient's Guide to EEG. Washington, D. C.:

Epilepsy Foundation of America (March 1972).

"Epilepsy and the Teen-ager." Portland: The Epilepsy League of Oregon (no date), one page mimeograph.

- "Oregon Laws Relating to Epilepsy." Portland: The Epilepsy League of Oregon (no date), one page mimeograph.

- "Suggestions for the Care of Children with Epilepsy." Epilepsy Speaks. Portland: The Epilepsy League of Oregon. 6:8 (November 1959), two pages mimeograph.

Thomas, Evan W. Brain Injured Children. Springfields Charles C. Thomas (1969). 
Tretakoff, Maurice. "Counselling Parents of Handicapped Children, A Review." Mental Retardation, (August 1969).

Tymchuk, Alexander, and Robert M. Knights. A Two-Thousand Item Bibliography: The Description, Etiology, and Treatment of Children with Learning Disabilities or Brain Damage. Carlton University, Department of Psychology, Ottowa, Ontario, Canada, (1969).

U. S. Department of Health, Education, and Welfare. Epilepsy: A Review of Basic and Clinical Research. Washington, D. C.: Public Health Service, National Institutes of Health, National Institute of Neurological Diseases and Blindness, 1965.

The Clinical Neurophysiology of Epilepsy: A Survey of Current Research. Washington, D. C.8 Public Health Service, National Institutes of Health, National Institute of Neurologic Diseases and Blindness (1968).

(1963). Infant Care. Washington, D. C.8 Children's Bureau

- Your Child From 1 to 6 . Washington, D. C.:

Children's Bureau, (1962).

- Your Child From 6 to 12 . Washington, D. C.: Children's Bureau, (1966).

Voeller, Kytja K. S., and Michael B. Rothenberg. "Psycho-Social Aspects of the Management of Seizures in Children." A 26-page paper written for the Albert Einstein College of Medicine. Bronx Municipal Hospital Center (no date).

Walker, Earl A. Postraumatic Epilepsy. Springfield, Charles C. Thomas $(1949)$.

Wallin, J. E. Wallace. Children with Mental and Physical Handicaps. New Yorks Prentice-Hall (1949).

Ward, M. M. "Group Therapy for Eleven Preschool Cerebral Palsied Children." Exceptional Child, 21 (1955), 207.

Weingodl, J. T., and R. P. Hormouth. "Group Guidance of Parents of Mentally Retarded Children." Journal of Clinical Psychology,

9 (1953), 118-124. 
Whildin, 0. "The Epileptic Child in the Public School." Nervous Child, 6 (1947), 99-104.

White, B. L. "Clinical Team Treatment of Mentally Retarded Child and His Parents: Group Counseling and Play Observation." American Journal of Mental Deficiency. 63 (1959), 713-723.

Wiener, Louise I. "group Work with Parents." In Hubert S. Coffey and Louise I. Wiener, eds., Group Treatment of Autistic Children. Englewood Cliff: Prentice-Hall, Inc. (1967), 89-92.

Williams, Dennis. "Structure of Emotions Reflected in Epileptic Experiences." Brain, 79 (1956), 29-67.

Wittenburg, Rudolf. "Psychiatric Concepts in Group Work." American Journal of Orthopsychiatry, 14 (1944), 76-83.

Wittes, Glorianne, and Norma Redin. "Two Approaches to Group Work with Parents in a Compensatory Preschool Program." Social Work, 16:1 (January 1971), 42-50.

Wolfensberger, Wolf. "Counseling the Parents of the Retarded." In Alfred A. Baumelster, ed., Mental Retardation. New York, Alpine Publishing Co. (1967), 329-400.

Yahr, Melvin D., and Houston H. Merritt. "Current Status of the Drug Therapy of Epileptic Seizures." Jourmal of the American Medical Association, 161 (May 1956), 333-338.

Yahraes, Herbert. Epilepsy-The Ghost is out of the Closet. Public Affairs Pamphlet, No. 98. New York Rev. (1954).

Yaworsky, W., and J. Kemp. "A Study of Affects in an Emotionally Disturbed Child with a Convulsive Disorder." Psychosomatics, ? (1966), 315-319.

Zweibel, A. D. "Re-educating Parents and Teachers." Individual Psychology Bulletin, 6 (1946), 1-2. 
APPENDIX

A. Application for Funds

B. Brochure for Parents

C. Epilepsy Questionnaire

D. Evaluation Questionnaire

E. Handicap Prohlems Inventory

F. Letters of Introduction and Contract

i. Review of the Iiterature on the Value of Parent Groups

H. Session Questions

I. Socio-Economic Inventory and Instructions

T. Interviews 
APPENDIX A

Application For Funds 


\section{APPLICATION FOR}

RESEARCH DEVELOPMFNT FUNDS

1. DATE, May 22, 1972

2. APPLICANT, Research Committee, Good Samaritan Hospital and Medical Center Clinic for Children with epilepsy, learning and behavior problems. A non-profit organization.

3. ADDRESS: 1015 Northwest 22nd Avenue Portland, Oregon 97210

4. AUTHORIZING PERSON: Robert S. Dow, M.D., Project Director, 2525 Northwest Lovejoy Portland, Oregon 97210 Telephone $224-5424$

5. PROGRAM CONTACT PIRSON: James R. Sch1mschock, M.D. Research and Program Coordinator 2800 North Vancouver Avenue Portland, Oregon 97227 Telephone 288-5151

6. ADDRESS OF PROGRAM SITE: Good Samaritan Hospital and Medical Center 1015 Northwest 22nd Avenue Portland, Oregon 97210

PART I - FISCAL INFORMATION AND BUDGET

7. Research funds are requested for the period from June 1, 1972 through December 31, 1972.

8. Funds requested from the Epilepsy League of Oregon $\$ 1700.00$

9. PROJECTED EXPENDITURES:

a. Parent education program development including expendable training supplies. . . . . . . \$200.00

b. Parent education program service equipment (film rentals, video taping blanks, etc.). . . . \$150.00 
c. General operating expenses:

(1) Clerical assistance . . . . . . \$250.00

2) Office supplies (paper, postage). : $\$ 100.00$

(3) Telephone . . . . \$ $\$ 50.00$

(4) Reproduction (photocopying, printing and

(5) Transportation.

d. Copyrighted materials . . . . . . . $\$ 100.00$

๑. Computer programing . . . . . . . $\$ 150.00$

f. Data processing . . . . . . . . $\$ 300,00$

g. TOTAL RESEARCH PROGRAM COST . . . . . . $\$ 1700.00$

PART II - RESTRARCH STAFF

Research Committee Coondinator

James R. Schimschock, M.D.
Clinic Coordinator, Children's Clinic
Good Samaritan Hospital

Statistical Consultant

Quentin D. Clarkson, Ph.D.

Faculty Consultant

Graduate School of Social Work

Portland State University

Research Advisor Mrs. June Dunn, M.S.W. Faculty Instructor Graduate School of Soclal Work Portland State University

Information Retrieval Srstem Quentin D. Clarkson, Ph.D. Consultant

George Jacobsen, B.S. Graduate Student

Parental Attitude Assessment Llef Terdal, Ph.D. Consultant Clinic Psychologist Joen Sac1a, B.S. Graduate Student
Parent Education Program Russell Jackson, Ph.D. Consultant Clinic Psychologist Grant Kane, B.A. Graduate Student 
PART III - NARRATIVE DESCRIPTION OF RESEARCH PROPOSAL

OBJECTIVBS? The proposed research by this committee has two major objectives:

1. To obtain information concerning parent expectations and interpretations of behavior management, in terms of their child's diagnosed epileptic symptoms.

2. To fulfill the research requirements for three members of the committee for their Masters of Social Work Degree, Graduate School of Social Work, Portland State University.

CONCERNS, The basis of this proposed research is founded upon the assumption that parents having children with diagnosed epileptic symptoms hold certain attitudes about opilepsy which may significantly influence their childs' performance in academic and social pursuits. A further assumption is that these parental attitudes occur in a majority of cases, and taken as a group perspective, present problematic areas in the therapeutic management of childhood epilepsy.

SCOPE, The areas with which this research will deal are as follows:

1. Parental attitudes about epilepsy will be measured in a sample population of parents having chlldren with diagnosed epileptic symptoms. These parents are associated with the Good Samaritan Hospital and Medical Center Children's Clinic.

a. Identify parental interpretations of epilepsy held by all parents having children with suspected ep1leptic symptoms, at the time of the initial screening interviow.

b. Identify problematic areas in parental interpretation of epilepsy with regards to the treatment of the childhood opileptic condition.

c. Measure the frequency of occurrence of problematic interpretations in the designated target population and comparison population. 
2. A parent education program, in conjunction with concurrent child participation in the Clinic's special education classroom, will be designed and implemented.

a. The program will be structured on a group basis at a time when eight to ten couples can meet conjointly.

b. Professional participants in group instruction will include a pediatric neurologist, social worker, child psycholog1st, special educator and other allied professions as indicated by parent needs.

c. The purpose of the group is to help the parent participants gain a clearer understanding of their children, their role as parents, and the expectations they should have for their children.

d. Subject to modification, the tentative schedule of events shall be:

(1) Prior to the first session, individual fanilies will meet with the group coordinator at which time the families can express their individual concerns.

(2) The primary focus of the group during the first three sessions will be professional presentation of relevant material with limited discussion periods. The remaining three to five sessions will emphasize group discussion of problens based upon individual family concerns as they relate to group concerns.

(3) A followup group discussion will be held at a three month interval after formal termination of the group program.

(4) Attempts will be made to have familles with similar concerns in the same group.

3. An information retrieval system w1ll be established to make clinic data avallable for current and future research use. Neurological, psychological, school performance and social assessment data will be coded and indexed.

SUMMARY, This research is oriented toward the goal of coordinating clinic efforts to reintegrate children with diagnosed elleptic disorders into the public school system. Further research will be needed to assess the current discrepancies between the Clinic and public school systems, but it is hoped that our proposed research will lay a foundation for future program development in the area of childhood epilepsy management. 


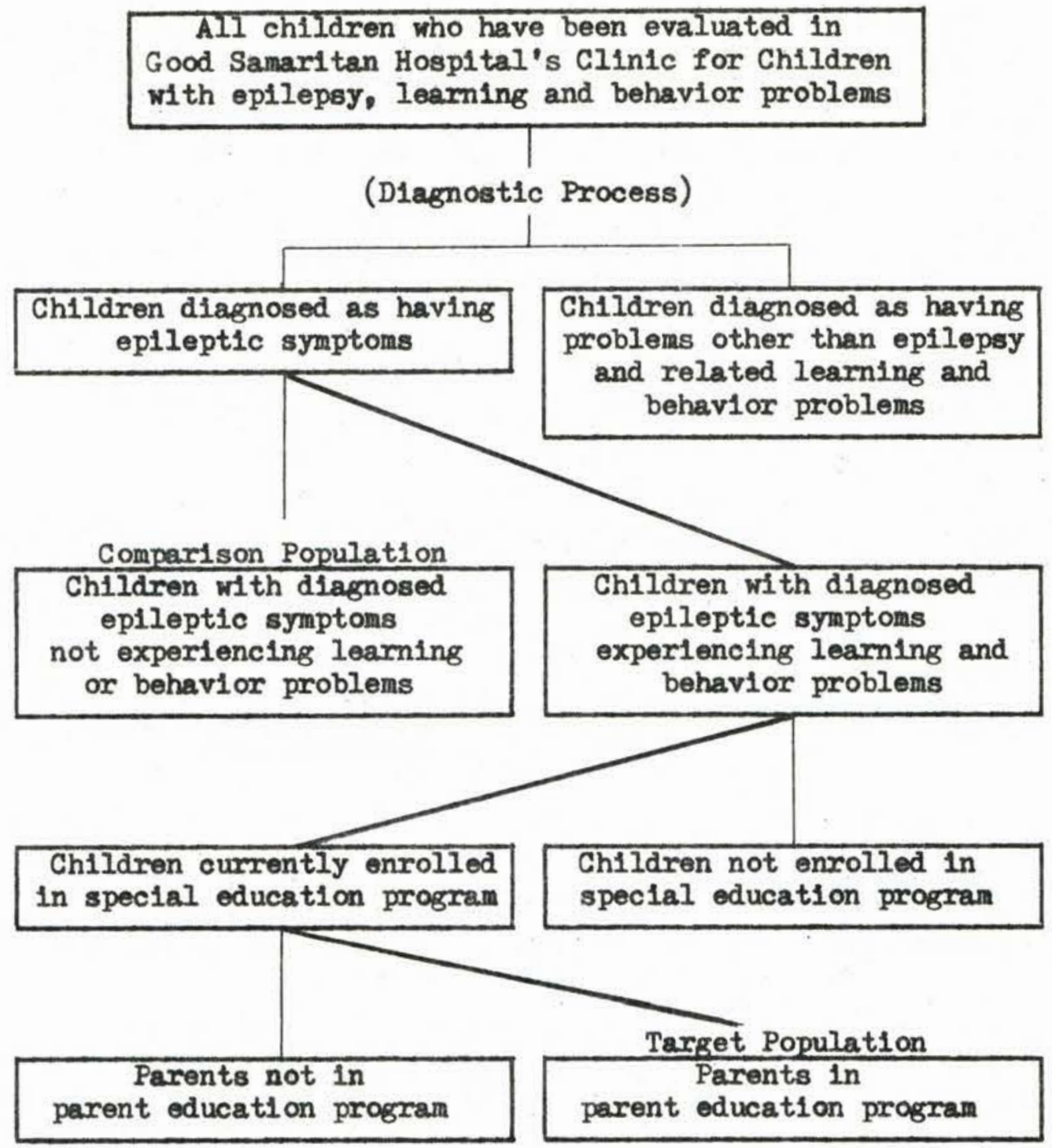


APPENDIX B

Brochure For Parents 
BROCHURE FOR PARENTS

GOOD SAMARITAN HOSPITAL \& MEDICAL CENTER CHILDREN 'S CLINIC 
EVERYTHING YOU ALWAYS WANTED TO KNOW ABOUT EPILEPSY*

*BUT WERE AFRAID TO ASK 


\section{INFORMATION ABOUT SEIZURES}

The aims of the staff in the Good Samaritan Hospital and Medical Center Children's Clinic are not limited to the medical treatment of your child's selzure disorder. Resources are extended to include ovaluation of other environmental factors affecting your child (1.e., parent-child interaction, child-teacher-school interaction, childpeer relationships). We are all trying to work together, both parents and hospital personnel, to help your child maximize his potential for social adjustment. A child can be happy even though he has selzures, but he cannot be happy if he cannot get along with people. Our goal 1s to assist your child's growth into a reasonable and responsible adult.

We recognize the difficulties of finding a balance in raising children. A child must loarn gradually to assume responsibility and to make decisions for himself as he grows up. He needs to experience self-expression and yet must leam to live within certain Iimits. He needs to learn to know what he may and what he may not do.

Consistency in child management is an important key to the successful maturation of your child. A child who has seizures should be treated the same as the other children in the family. He should not be allowed to use his selzures as a means of getting his way with parents or other adults who are guiding his growth processess (1.e., teachers, neighbors, grandparents, etc.).

The following are common questions raised by parents seeking a better understanding of their chlldren and new methods of handling them. 
WHAT IS EPILEPSY?

Epilepsy is a term which means convulsions or seizures. Epilepsy involves a group of symptoms which occur periodically and not constantly. The symptoms that we see (that is the type of seizure which occurs) depends upon which area of the brain is involved. The one thing which is common to all forms of epilepsy is that the symptoms arise from the brain. Usually they are associated with a partial or complete loss of consciousness.

WHAT IS THE CAUSE OF EPILEPSY?

In some youncsters no definable cause is apparent. In other children, infections, injuries, congenital defects or growths on the brain may cause seizures. Like many conditions, the actual causes for epilepsy are many and varied. We do know that a seizure results from abnormal electrical activity in the brain. What causes this abnormal activity is not known.

IS EPILEPSY CONTAGIOUS?

No.

WHAT SETS OFF A SETZURE?

No clear precipitatins cause can be found. However, a variety of factors may influence the frequency of seizure activity. In some people a seizure apparently can be traced to such thines as a time of rreat tension, nervousness, a sudden noise, or bright flickering lichts. of course this depends upon each individua.l.

TS A CHILD LIKFLY TO DIE BECAUSE OF HIS SEIZURES?

Epilepsy is a symptom, not a disease, and the symptom will not cause death, unless it is allowed to continue untreated for an extended period of time.

WHAT SHOULD BE DONE DURTNG A SEIZURE?

Wait until it is over. In the meantime protect the patient from falling off from what he may be lying on, or 
otherwise injuring himself. Remove any objects from the immediate area to prevent injury to him, but do not try to interfere with his movements. It is not necessary to restrain him. Turn him, if possible, onto the stomach or the side. Do not attempt to put something between the teeth or the jaws. It would only result in injury to the teeth or the gums and would not help the child. Keep him company so someone is quietly at his side for reassurance when the seizure is over. Let him rest or sleep afterwards if he so desires.

\section{DOES A CHILD SWALIOW HIS TONGUE DURING A SEIZURE?}

No. It looks that way because of breathing interference which is part of the seizure. However, precaution can be taken by placing the patient on his side or stomach to prevent the tongue from falling against the back of the throat. Air passages are then kept open more easily.

DO SEIZURES LEAD TO NERVOUS OR MENTAL ILLNESS?

There are certain conditions which may cause both nervous and/or mental 11lness and selzures. It is possible that Improper management of the selzures may eventually lead to one or both, but by obtaining medical attention the chances are very slight.

DOES EPILEPSY CAUSE MENTAL RETARDATION?

No. Remember, epllepsy is merely a symptom. It cannot cause anything. Many people with epilepsy are of normal intelligence. Again, without proper management of the selzures it may be possible over a period of time for the selzure activity to hinder a child's normal progress.

DO SETZURES CAUSE HEART DAMAGE?

No. The heart beats faster from activity of the selzures just like running makes the heart beat faster. This does not damage the heart.

IF SEIZURES BECOME LESS SEVERE, IS THIS A SIGN OF IMPROVEMENT?

Yes.

SHOULD A DOCTOR BE CAIIED FOR EACH SEIZURE?

Usually this is not necessary, unless the seizure is 
followed almost immediately by another major seizure, or if the seizure lasts more than about ten minutes.

\section{HOW IS EPILEPSY TREATED?}

By the use of medicines called anticonvulsants. Doses are given daily. It is very important that an ample supply be on hand and that no doses be missed. Only in very rare cases are specific surgical procedures attempted.

\section{HOW DOES ANTICONVULSANT MEDICATION HELP SEIZURES?}

Anticonvulsant medication helps control epilepsy in two ways! (1) by lessening frequency, (2) by lessening severity. Either one, or both, indicates improvement. In some cases the medication has been known to completely eliminate seizures. Not only medication but age and time can also lessen frequency and severity.

\section{CAN ANTICONVULSANT MEDICATION CAUSE REACTIONS IN MY CHILD?}

Yes, almost any medication that has ever been used may cause a reaction or side effect--dizziness, drowsiness, unstable gait, and others--which the physician may eliminate by reducing the dosage. However, only a very few of the medicines that we use in treating epllepsy have any serious reaction. Any child who is recelving one of these is followed closely in the Clinic and by laboratory tests in order to determine when a reaction is occurring.

\section{ARE ANY OF THESE MEDICATIONS HABIT FORMING?}

Some of the medicines used in the treatment of epilepsy fall within the habit-forming category, but virtually never lead to undue dependence when administered in connection with treatment of epilepsy. Some medicines, in certain doses and combinations, lead to a certain amount of temporary slowing of mental processes but this does not mean they are habit forming or lead to addiction.

IF ANOTHER CHILD IS BORN, COULD HE HAVE EPILEPSY?

Yes, but the chances are against it. It is very unusual to have more than one child with epilepsy in the same family. In some families the risk will be slight, almost non-existent; in others, it may be higher. Much depends on what causes the epilepsy and whether or not other members of the family, relatives, etc., have had seizures. 
WHAT ARE THE KINDS OF SEIZURES?

There are many types. A few are listed here:

Petit mal - (absences) A person stares and blinks and sometimes the head and arms may jerk slightly. He may or may not fall. The seizure lasts a few seconds and sometimes as long as a minute or two.

Grand mal - There may be a preliminary cry or "how " " and can be associated with choking sounds. Consclousness is lost and the body muscles become rigid. This is usually followed by jerking of the arms and legs. When the breathing muscles are involved, there is some loss of normal color. The seizure lasts a few minutes or longer, and is usually followed by a sleeping period. This is part of the seizure.

Minor motor - A person suddenly jerks forward from the neck or the hips which usually results in a fall. Recovery is prompt and seldom followed by sleop.

Psychomotor epilepsy - A person has a seizure which, Instead of being a convulsion, appears to be unusual behavior from which he cannot be stopped. He does not remember after the attack what was done during the seizure. It seldom lasts more than a few minutes.

WILI A CHILD WHO HAS GRAND MAL SEIZURES ALWAYS HAVE THE SAME TYPE OF SEIZURE, OR WILL THEY CHANGE?

Some people with epilepsy always have the same type of selzure while others will go through changes. There is no way of telling which child will continue with the same type of seizure and which child may develop other types of seizures.

DO CHILDREN WITH EPILEPSY HAVE LOWER RESISTANCE TO INFECTIOUS DISEASE THAN THE AVERAGE NORMAL CHILD?

No.

IS THEIR DIET EVER AT FAULT?

Generally, no. Like everyone else, persons with seizures need a well-rounded diet. In some patients, use of alcohol tends to lead to a seizure. Excessive fluids, depressants, and stimulants should also be avolded. 
CAN A CHILD WHO HAS EPILEPSY BE PERMITTED TO ENGAGE IN SPORTS?

Yes, when the proper precautions are taken. Actually, physical activity is good for these children and seems to reduce the number of attacks. Each case must be decided on an individual basis. When swimming, the child who has epilepsy should be observed closely and continuously by a responsible person. We usually advise against any type of climbing where loss of consciousness might result in a fall and consequent injury. Specific limitations for your child should be discussed with the Clinic physician.

IF IT IS KNOWN AHEAD OF TIME THAT A SEIZURE IS COMING, WHAT CAN BE DONE TO PREPARE FOR IT?

This is a good point to discuss with the doctor who is following your child. He can advise you what measures to take as all individual cases may be different.

ARE STARING SPELIS A SYMPTOM OR FORM OF EPILEPSY?

A true staring spell is true epilepsy.

CAN EPILEPSY BE INHERITED?

Epilepsy, 1tself, is not passed on to the next generation. In some cases a patient may have inherited tendencies that make it easier to develop seizures, but this is only a tendency, and there are persons who do not have epllepsy who have inherited such traits.

CAN A CHILD HAVE SEIZURES ONLY DURING SLEEP?

Yes. As a person goes to sleep, he goes through various depths of sleep. Certain brain centers which may have been preventing selzures then relax and the child may have a selzure. The most common times for sleep seizures are elther shortly after falling asleep or shortly before awakening. These selzures which only occur during sleep are called nocturnal seizures.

ARE SOME CHILDREN WITH EPILEPSY MORE IRRITABLE THAN OTKER CHILDREN IN THE SAME FAMILY?

Yes. Varlous authorities belleve some of the irritability may be caused by the same condition which caused the seizure. Also this irritability may be related to the fact that the child has been treated differently than the other children in the family because of his problem. Some of the 


\section{irritability may improve noticeably after the child's selzures are controlled.}

CAN ANTICONVULSANT MEDICATION CONTRIBUTE TO A CHID"S IRRITABILITY?

Yes.

DOES A CHILD WHO HAS SEIZURES HAVE TO TAKE MEDICATION ALL HIS LIFE?

Again this depends upon each individual. Some take it for many years while others only a few.

WHEN THE DOCTOR ADVISES ME TO "PAY AS LITTLE ATTENTION TO SEIZURES AS POSSIBLE," I WONDER IF HE REALIZES WHAT WE PARENTS HAVE TO GO THROUGH.

The child having selzures is a very disturbing thing for parents. But parents can learn not to be overprotective, and can in time understand that seizures are not so terrible. This in turn sets the proper example for the child. Naturaliy, one wants to protect the child from injury to himself and from getting into situations involving his life just as one would protect any youngster.

EVERYONE TENDS "TO SPOIL" OUR CHIDD WHO HAS SEIZURES AND THE OTHER CHILDREN IN THE FAMILY RESENT IT.

Efforts should be made by all persons handling the child to avold making him a special case by allowing him to have the usual kinds of frustrations and letting him learn how to handle his anger just like everyone else. Then, the child w1ll grow up a better adjusted youngster; otherwise, he will go on expecting everything his special way. Parents will have to assume the responsibility of establishing procedures in those situations which interfere with the child's management program.

OUR FRIENDS SAY OUR CHILD IS NOT NORMAL BBCAUSE HE SEFMS TO GET VERY ANGRY EVERY TIME THINGS DO NOT GO HIS WAY.

Just because a child becomes angry does not necessarlly mean that he is abnormal; the parents would have more cause for worry if the child never expressed anger. Anger is merely a way the child uses for getting his frustrations out of his system. Moreover, it is not a case of the child working himself up to a seizures it may be that the child is more imitable preceeding a seizure, which may be part of a selzure. 
It should be obvious to everyone that children who do not have epilepsy get angry and have temper tantrums too. Temper tantrums may be an example of the child's attempt to express something. When a child is very young he does not know about the things which will hurt him or give him pain; all he knows is that he won't give up things which give him pleasure. If he gets no attention whatsoever with a temper tantrum he will eventually stop using this method of objection. Thus, discipline is many things, which administered in the proper way, is something to keep the child from becoming maladjusted. As time goes on the seizures may become controlled, but the child will become a behavior problem unless he has discipline.

A child should be treated with consistency. One should not love him one day and hate him the next; the consistency of the relationship is the important thing. When a child becomes three, four or five years of age his world only begins to look something like it does to his parents. The type of punishment depends upon the age of the child and depends upon the factors involved. In general terms, we do not think a "pat on the bottom" is going to hurt any child.

\section{WILL A CHILD EVER OUTGROW EPILEPSY?}

Yes. Often it is correlated with the type of seizure the child has. Medical research has found that some children whose selzures are well controlled with medicine, later on need less medicine. Eventually they may need none at all. However, there is no way of determining who will and who will not be able to discontinue treatment until several years have passed. In many children the tendency to have selzures appears to become lessened as they grow older.

\section{WILL MY CHILD BE ABLE TO MARRY?}

Yes, if the seizures are controlled so that he can undertake the responsibilities of marriage, and the prospective mate is informed of the situation.

\section{CAN MY CHIID HAVE NORMAL INTELLIGENCE?}

The intelligence of persons with epllepsy varies markedly, but many have normal or above-normal intelligence. Some children might be encouraged to know that a large number of famous people have been epileptics, including Julius Caesar, Socrates, Buddha, Alexander the Great, Mohammed, 
the Duke of Wellington, Lord Byron, Vincent Van Gogh, and Joseph Handel.

\section{WHAT IS THE BRAIN WAVE TEST?}

This is what is called an electroencephalogram. The BEG for short, is a graphic recording of the electrical activity of the brain. It does not make a diagnosis of epllepsy, give the patient electric shocks, nor does it hurt. It is an additional means of examining a patient. It is information which must be evaluated along with all the other factors in any case.

HAS ANYTHING BEAN DONE TO EDUCATE THE GENERAL PUBLIC ABOUT EPILEPSY?

Epilepsy is one of the last of the "hush-hush" diseases. Once cancer, tuberculosis and many other diseases were in this category, but public opinion is changing. Research is going on all over the country, results of which are constantly being distributed to educators, doctors, professionals, and the lay public.

HOW CAN A PARENT OF A CHILD WITH EPILEPSY HELP EDUCATE PEOPLE?

1) By accepting the fact that epilepsy is a condition of which you need not be ashamed.

2) Mentioning without embarrassment the word epilepsy when it is appropriate.

3) Recognizing that people who make you feel ashamed are ignorant, and explain to them calmly about epllepsy. This may mean becoming more informed about epilepsy, as you can help by answering any questions in general and provide information to correct any misconceptions.

4) Considering the "emergency" measures involved in epilepsy and preparing for them.

Also, there are statewide and national organizations for epilepsy which are working on educational programs, as well as many regional organizations.

AM I WRONG IF I KEEP MY CHILD'S DISORDER A SECRET?

Each member of the family should be encouraged to develop the attitude that $1 t$ is true that one member of the family has epllepsy, and that they are perfectly willing to talk it 
over at an appropriate time. Thus, if adequate control is lacking, it is probably a good idea for the youngster's older brothers and sisters to explain the facts to their friends. This does not mean, of course, that members of the family should begin each and every conversation by proclaiming to one and all that someone in the family has epilepsy.

It is probably a good idea to tell neighbors and other adults who will come in contact with the youngster about his disorder. The explanation should be as simple and direct as possible.

Some people will, of course, react badly to this information and may attempt to keep their children from playing with the child who has epilepsy. This is unfortunate, but it does happen from time to time. Nevertheless, it should be recognized that there are more important considerations in the development of a child than whether he is going to have a particular playmate.

If disclosure to others of the child's disorder does produce an unpleasant reaction, there is no need to burden the child with the resentment this will undoubtedly cause his family. Instead, he should be encouraged to make the best of the friendships he is able to establish with children of more understanding families.

By leaming how his family handles this problem, the child will develop patterns of communication that will make his own efforts to get along with others seem much less threatening. Unfortunately many epileptics and their families go through life in constant fear that the "secret" may be disclosed. The constant anxiety this produces naturally tends to prevent normal relationships of any kind from developing. 
HANDLING OF CHIIDREN WHO HAVE EPILEPSY

DISCUSS THE ATTITUDES OF THE PARENTS AND HOW THEY MAKE THE CHILD A SPECIAL INDIVIDUAL.

Many questions have been asked about the behavior and emotional problems of the child with epilepsy. People are quite aware of the physical developments going on in a child, as such developments can be seen. But the emotional and psychological development going on can sometimes be a little puzzling since it is not as obvious a factor as is the physical development. While the bones and muscles develop independently, the child's emotional growth is largely related to his place in the family and his relationship with the family. Therefore, much more responsibility is placed on the parents in regard to a child's emotional growth than on his physical growth.

When we speak of emotional growth, we mean that aspects of the individual that deals with what he thinks and feels, his attitudes, and his likes and dislikes, which make him an individual. It is not just by chance that we are the individuals we are. Rather, it is because of our relationships with our families and other associations. We take a little bit from each contact, which makes us what we are.

Parents want to know about epilepsy as it relates to emotional growth. They want to know if their child is going to have temper tantrums and if their child behaves as he does just because he has epilepsy, and how to handle a child who has epilepsy. Other factors being equal, the child with epilepsy should be treated as a child without epilepsy! If he is not regarded as a special individual, then the child will not regard himself as a special individual. When problems of behavior come up, the parent should flrst ask himself, "How would I treat any other child of this age?"

The parent finds himself in the position of looking for something different in the child. The only difference is at the time of a seizure. The attitude parents have toward a child will determine to a large extent the attitude the child will have towards himself. If parents have the attitude of fearfulness and that the child should be watched carefully because he might have a seizure, then the child himself will think of himself as being sick, queer or persecuted. Even though the chtld has selzures, he will also have other problems in life to which he must adjust. In 
most cases he can have a satisfactory life if he has a healthy attitude toward it, in spite of having seizures.

DISCUSS THE DISCIPLINE OF A CHID WITH EPILEPSY. THIS IS OUR BIGGEST PROBLEMM.

This first hurdle to get over is to realize that the child is not going to die because of seizures. The child who is normal in all other respects than selzures can be expected to live a normal happy life if handled in a wholesome way. The child with epilepsy should be treated the same as any other child in the family who does not have seizures. Many people expect children with epilepsy to behave differently than other children, but they do not behave differently if handled properly. Behavior is related to how a child is handled and to parental tensions and moods. Problems can arise from parent attitudes. The child should be handled in such a manner that he can learn to have self-confidence. The only difference between the child with epilepsy and the average child is when the child is having a selzure.

DOES THE EMOTIONAL ATMOSPHERE IN THE HOME, SUCH AS FRICTION BETWEEN PARENTS, OR TROUBLES WITH RELATIVES, HAVE A DEFINITE BHFFET ON SEIZURES?

Family conflicts, crisis, changes, etc., can definitely have an effect upon a child's emotional state which in turn may be reflected in the frequency of seizures. It is important that general procedure patterns and medications be maintained as well as providing a stable emotional attitude.

DISCUSS THE EMOTIONAL DEVELOPMENT OF A CHILD WITH EPILEPSY.

The emotional development of a child with epilepsy will not be materially different from that of the child who doesn't have epilepsy, everything else being equal. True, this child will need to take medicine daily for an indefinite period, but then children are given vitamin preparations daily without any concern of what it might do to their emotional development. And, a child might be limited in certain activities which could be dangerous in the event of a seizure, such as swimming or tree climbing. Yet a child without epilepsy, falling out of a tree or falling from a fence is certainly not a rare thing. There is much tendency to exaggerate the injury potential of a child with epilepsy out of all proportion to the facts. 
The years from one to five are the formative years of our lives. The child senses the feelings of the members of his group, parents, brothers, sisters, grandparents and others who handle $\mathrm{him}$, and the child reacts to these feelings. The child with seizures should be handled and treated the same as other children in the family.

Because he has a selzure now and then doesn't make him different during the time between seizures. He needs self-confldence, ability to get along with people and the ability to gain satisfaction out of life. Most of this is gained by imitation of his parents and other associates and by his trials and errors. A good start by the parents can be attained by setting a good example.

CAN OTHER MEMBERS OF THE FAMIIY BECOME INVOLVED TO SEE THAT THE MEDICATION IS NOT FORGOTTEN?

The medical aspects of epilepsy should become so routine that taking a pill at certain set periods or following any of the other guidelines laid down by the doctor for the benefit of the individual patient do not dominate the life of the youngster--or, for that matter, that of the whole family.

Brothers and sisters are often more effective than parents in helping to establish this type of routine. In any event, the whole family must take responsibility for medication programs and protective measures suggested by the doctor-but always with the goal of gradually shifting this responsibility to the child. Of course, this is not really different from the training of a child in any other areas of his life. Also, there may be certain specific techniques which may need to be developed in this area. Parents should be cautioned against harrassment or nagging, for this can become a hindrance.

WE HAVE BHEN AFRAID TO SPANK OUR CHILD FOR FTAR OF BRINGING ON A SEIZURE.

The child should be disciplined the same as any other child even if he does have a selzure. He can and will have a seizure even though he isn't disciplined. Discipline which is administered in the proper way is a means of keeping a child from becoming maladjusted, which could become a major problem in addition to the epilepsy. 
Parents should cooperate with each other even though they may not be in agreement on methods of discipline so that the child will not play one parent against the other. To be consistent is to let the child know what is expected of him. Actually, a child wants the parents to control him because he feels his weaknesses and realizes he needs the control of parents. Therefore, control and discipline must be put on a child for his own protection.

However, eating is such a personal thing that it doesn't lend Itself to discipline. "Cleaning-up-the-plate" policy is not recommended. Our appetites vary according to taste, age, and need for food. Health is not a matter of eating vegetables or drinking milk. A helping of one food is only half enough for one child while it is three times too much for another child. The child balances the diet during a three or four-month period, not by the meal. He will eat enough and eat properly without the need for cleaning up the plate. If one parent wants him to clean up the plate, while the other doesn't see why he should, then give the child smaller helpings of food.

If the child is old enough he can be punished by withdrawing certain things or restricting them. Sometimes a parent is angry when he punishes a child; quite often this is exactly why the child is being punished. It doesn't set a good example. We believe punishment should be carried out with firmness and calmness. The most important thing is for a parent to be consistent in his discipline. Punishment serves to let a child know where he stands. Do not confuse him by letting him get by one time and not get by the next. If the situation is one in which you cannot be consistent, then don't bring it up as a matter of discipline in the first place. If the child's behavior is out of proportion to the situation, consultation may be necessary with your doctor.

CAN YOU RECOMMEND A GOOD BOOK ON HOW TO HANDLE A CHILD WITH EPILEPSY?

Perhaps one of the most important things to learn is that the handling of a child with epilepsy is usually no different than the handling of a child without epilepsy. For this reason when a book is recommended it is done from the standpoint of considering every child to be average. Children with epilepsy are no exception. Hence it is recommended that you read material which deals with the "handling of 
the average child."

Studies and books are available regarding general development in terms of walking, talking, eating, use of crayons, etc., which may be helpful. However, the danger in reading only this kind is that parents might expect their child to "conform to the pattern." This would be a great mistake because every child is different.

The United States Children's Bureau publishes several good pamphlets which are available at any local Health Department center. The local one for this area is Multnomah County Health Department, $12240 \mathrm{NE}$ Glisan, Portland, Oregon, Phone 284-3681. Several of these pamphlets have been included in your packet, namelys

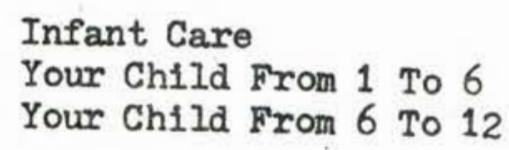

Some of the information in these has been helpful to many
parents. 
ARE CHILDREN WHO HAVE EPILEPSY ALIOWED TO GO TO SCHOOL?

Yes, and with some children we may recommend a conference with the principal or other school personnel to inform them of the child's problem so that a selzure can be handled in an intelligent way should one occur at school. It may also be recommended that a conference be held with the school physiclan or nurse. When possible, children with seizures attend regular public school. At times placement in special classes or in one of the special schools is arranged when a child cannot be managed in regular classes. Usually a behavior problem such as hyperactivity or righting, rather than actual selzures, makes it necessary to have a special program for a child. A member of our Staff can send any reports and could frequently hold conferences with a member of the Board of Education Staff, local teachers or principels, or school physicians and nurses, to try to work out the best possible plan for school work.

\section{WHERE CAN A PARENT FIND OUTSIDE HELP WITH FAMILY PROBLEMS?}

Children with seizures are faced with many difficulties such as their own feelings about their condition, their family's attitudes and feelings about the seizures, the effect of seizures on school attendance, the way playmates react to seizures, any restriction of activities which may give the child a feeling of belng treated differently from other children. These problems oblige a child to make continuous readjustments which in turn create emotional problems which affect the entire family. Many parents have found 1t helpful to talk over family situations with a social worker, who can help with problems related to your child's having epllepsy. If the social worker cannot be of assistance, he may be able to locate an agency in the community which can provide the help needed.

IS THERE AN EPILEPSY ORGANIZATION IN PORTLAND?

Yes, and the address is:

Ep1lepsy League of Oregon, Inc. 718 w. Burnside, Rm. 208

Portland, Oregon 97209

Phone 228-7651 
WHAT SERVICES ARE OFFERED BY THE EPILEPSY LEAGUE OF OREGON?

The League serves as a source of correct information about epilepsy and related problems. Although it does not function primarily as a casework agency, it does serve as a center of information for anyone seeking services. This is accomplished by providing interviews and acting in a referral capacity to guide persons with specific needs to reliable resources for medical treatment, counseling, employment, rehabilitation, job motivation and other related problems.

The League distributes Iiterature, identification cards (League produced), and publishes a bulletin, Epilepsy Speaks. The League supplies films, speakers, educational exhibits, and tape recordings. A lending library at the League office offers a variety of rellable books and current Iiterature on epilepsy. Students are assisted by the League staff in preparation of papers and talks on epilepsy.

A Medical Advisory Committee assists in presenting educational programs which are regularly provided for schools and colleges in Oregon. Programs are also available for public groups.

WHAT IS THE COST FOR THESE SERVICES?

Nothing. All of the League's services are free, however, both the CIInic and the League encourage all interested parents to participate in and join the Epilepsy League of Oregon. The League's services can be further enhanced with strength from more parents.

ARE THERE ANY SUMMERTIME OUTINGS OR CAMPS WHICH ACCEPT CHIIDREN WITH EPILEPSY?

There are several summertime camps in the Portland area which children with epilepsy attend, both day camps and resident camps. More information can be obtained from the Epilepsy League of Oregon. They will be glad to talk with parents individually about the camp programs. 


\section{BIBLIOGRAPHY}

Bakwin, Ruth Morris, and Harry Bakwin. "Epilepsy." The Journal of Pediatrics. 39 (December 1951) 776-784.

Jerry Price Seizure Clinic. Brochure For Parents. Los Angeles: Children's Hospital (November 1963). 10 pages momeograph.

Livingston, Samuel. "The Social Management of The Eplleptic Child And His Parents." The Journal of Pediatrics. 51:2 (August 1957) $137-145$.

National Institutes of Health. Epilepsy: Hope Through Research. Public Health Service Publication, No. 938. Washington, D. C.I U. S. Department of Health, Education, And Welfare, 1957.

Sands, Harry, and Jacqueline Seaver. Epilepsy--Today's Encouraging Outlook. Public Affairs Pamphlet, No. 387. New York: Public Affairs Committee, Inc., 1966.

The Epilepsy Foundation. Current Information. Washington, D. C.. Epilepsy Foundation of America (October 1971).

- Don't Be Afraid Of The Child With Epilepsy. WashIngton, D. C.1 Eptlepsy Foundation Of America (October 1971).

- Epilepsyi Answers To Some Of The Most Frequently Asked Questions About Epilepsy. Washington, D.C.I Epilepsy Foundation of America, 1967.

- Epilepsyi Recognition, Onset, Diagnosis, Therapy. Washington, D.C.1 Epilepsy Foundation Of America (October 1971).

- Epilepsyi The Employer's Role. Washington, D.C.: Epllepsy Foundation of America (July 1968).

- Epilepsyi The Teacher's Role. Washington, D.C.I Epilepsy Foundation of America (February 1969).

- Occupational Guides For Epilepsy. Washington, D.C.I Epilepsy Foundation of America (March 1971).

- You, Your Child And Epilepsy. Washington, D.C.: Epilepsy Foundation of America (October 1971).

Series At Children With Epilepsy: "A Child's View", "The Family's Vlew", "The Teenager's View". Washington, D.C.I Epilepsy Foundation of America, 1965. 

The Epilepsy League. A Teacher's Guide
Epilepsy League on Epilepsy. Portland: The Epilepsy League Of Oregon (no date). 
APPENDIX C

Epilepsy Questionnaire 


\section{EPILEPSY QUESTIONNAIRE}

The questionnaire you are about to fill out is important in helping to set up future educational programs in epilepsy. Your answers will guide us in the areas of greatest need. Do not worry about questions you cannot answer or are unsure of, just circle "Don't know." Take the time you need to finish the questionnaire. Please circle the answer that is the most meaningful to you. Your answers will be confidential. Thank you for your cooperation.

Gender: M F Marital Status: M S

$$
\text { Age: }
$$

1) Do you have epilepsy or have you ever had epilepsy? - . - . - . . - Yes No kon't

2) Do you have a child who has epllepsy? - . Yes No Ron't

3) Has anyone in your family ever had epilepsy? - . . - . - . - Yes No kon't

4) Do you know anyone outside of your family who has epilepsy? . . . . Yes No Ron't 
Code \#

1. Epilepsy is an emotional disease - Agree Disagree Ron't

2. Epilepsy is inherited - . - $\begin{aligned} & \text { Agree } \\ & 2(2)\end{aligned} \frac{\text { Disagree }}{5(9)}$ know't

3. Epilepsy may be likened to an

electrical storm in the brain

$\begin{array}{lll}\text { Agree } & \text { Disagree } & \begin{array}{l}\text { Pon't } \\ \text { know }\end{array} \\ 12(15) & 0(0) & 3(0)\end{array}$

4. I would rather my child had diabetes than epilepsy .

$\begin{array}{ll}\text { Agree } & \text { Disagree } \\ 2(1) & 7(7)\end{array}$

Ron't $6(6)$

5. A person with epilepsy may not drive a car in the State of Oregon . . . . .

$\begin{array}{lll}\text { Agree } & \text { Disagree } & \begin{array}{l}\text { Pon't } \\ \text { know }\end{array} \\ 3(5) & 5(9) & ?(1)\end{array}$

6. A person with epilepsy may participate in the following activities:

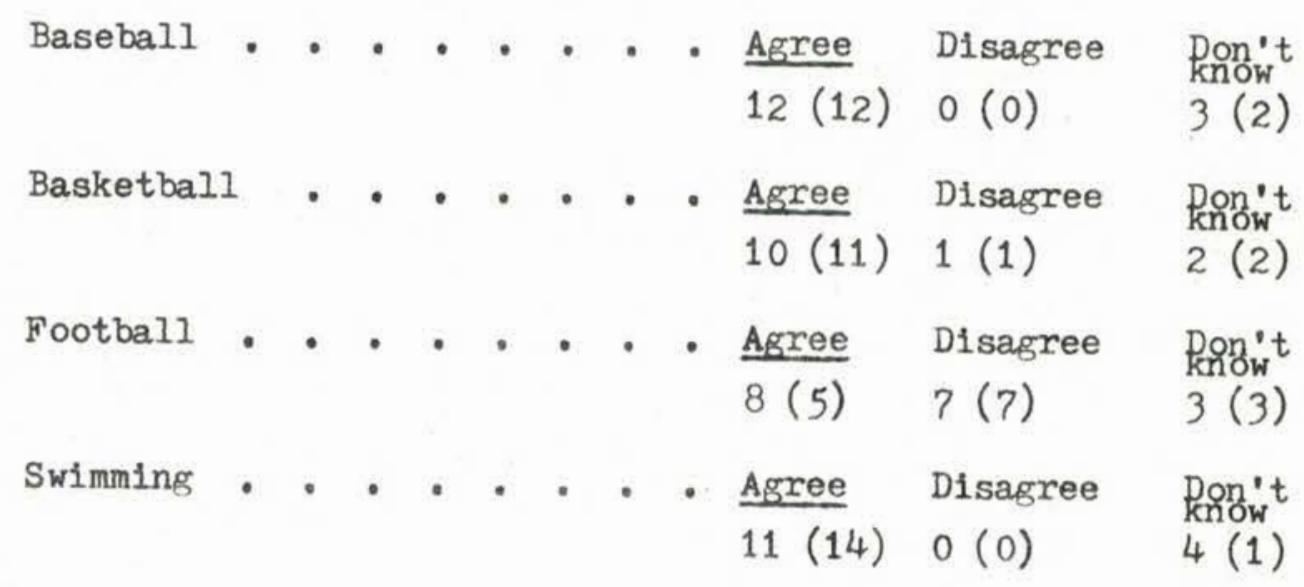

*Considered "nebulous" or disagreed by professionals \#Answer: Trial one

(\#)Answers Trial two

Underlined is professional response 


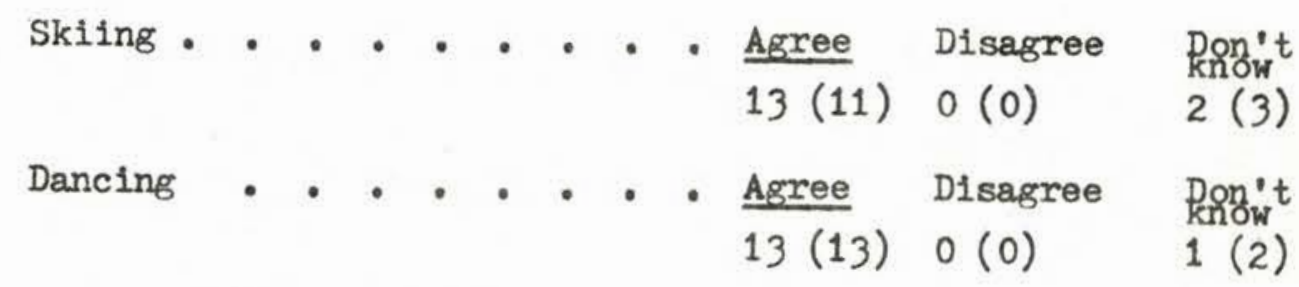

Music (1.e. band, orchestra). A Agree Disagree pon't $13(13) 0(0) \quad 1(1)$

Drama (i.e. public performances) Agree Disagree Ron't 14 (13) $0(0) \quad 1(2)$

Bicycling - . . . A Agree Disagree kon't 13 (14) 0 (0) 1 (1)

Track - . . - . 11 (11) $0(0) \quad 3(3)$

Chess - . . - . Agree Disagree kon't $15(15) \quad 0(0) \quad 0(0)$

Clubs (1.e. Boy Scouts, Girl Scouts, etc.) - . - Agree Disagree Ron't $15(15) \quad 0(0) \quad 0(0)$

Hiking or back packing - - Agree Disagree pon't $13(13) 0(0) \quad 2(2)$

Caring for animals - . - Agree Disagree Ron't 14 (15) $0(0) \quad 1(0)$

Babysitting - . - - Agree Disagree Pon't $12(10) 0(0) \quad 3(4)$

Lawn mowing - . - - Agree Disagree Pon't $14(14) 0(0) \quad 1$ (1)

7. An epileptic child should be kept under close supervision at all times.

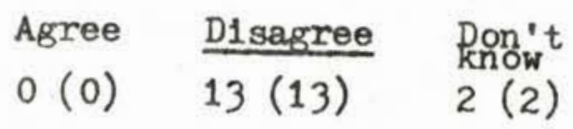


8. People with epilepsy should not marry .

\begin{tabular}{|c|c|}
\hline rree & Disagree \\
\hline (0) & $14(15)$ \\
\hline
\end{tabular}

9. People with epilepsy should not have children

$\begin{array}{lll}\text { Agree } & \frac{\text { D1 sagree }}{\text { Pon't }} \\ 0(0) & 12(15) & 3(0)\end{array}$

10. Epilepsy prevents learning

Agree
$0(0)$

11. Epilepsy is caused by bad genes
Agre
$\frac{\text { Disagree }}{8(14)}$
1 (0) 8 (14)
Ron't $6(1)$

Ron't 6 (2)

*12. Epileptic children require special attention

$\begin{array}{lll}\text { Agree } & \text { Disagree } & \begin{array}{l}\text { Pon't } \\ \text { know } \\ 4(8)\end{array}\end{array}$

13. A child with epilepsy should not be punished for misbehaving if such punishment aggravates his seizures
Agree
1 (2)
Disagree
pon't 6 (11)
9 (2)

14. The epileptic child's brothers and sisters should cater to him

$\begin{array}{lll}\text { Agree } & \frac{\text { Disagree }}{\text { Ron't }} \\ 1 \text { (0) } & 14(15) & \begin{array}{l}\text { know } \\ 1(0)\end{array}\end{array}$

*15. The epileptic child should be protected from ridicule or teasing by other children
$\frac{\text { Agree }}{2(5)}$
Disagree
pon't
6 (5)
$6(5)$

16. Only a qualified medical doctor

can diagnose epilepsy.

$\begin{array}{ll}\text { Agree } & \text { D1sagree } \\ 14(13) & 0 \quad(2)\end{array}$

know't $1(0)$

17. Epilepsy can be cured through the use of certain medications called anticonvulsants
Agree
D1sagree
1 (7)
?
(7) 
18. Medicines used in the control

of seizures are habit forming

2(6) 6 (7)

Ron't

7 (2)

19. I would trust an older epileptic child to handle his own medications

$\begin{array}{ll}\text { Agree } & \text { Disagree } \\ 8(10) & 2(3)\end{array}$

know't

$5(2)$

20. Proper rest and diet are essential in the control of epilepsy

$\begin{array}{ll}\frac{\text { Agree }}{9(12)} & \text { Disagree } \\ 2(1)\end{array}$

Ron't

4 (2)

21. More frequent but smaller meals

help to control the frequency of seizures.

1 Agree $\frac{\text { D1 sagree }}{6(8)}$

22. The programs offered by the

Epilepsy League of Oregon are

only for people with epilepsy

$\begin{array}{ll}\text { Agree } & \text { Disagree } \\ \text { o(0) } & 7(12)\end{array}$

Ron't

23. Every child who has seizures

should be given an explanation

of his problems

$\begin{array}{ll}\text { Agree } & \text { Disagree } \\ 11(12) & 3(3)\end{array}$

know "t

1 (0)

24. An epileptic child should

usually be placed in a special

classroom situation

$1(0) \quad \frac{\text { Disagree }}{14(10)}$

Ron't

25. Children with epilepsy

seldom fintsh high school

because they are not smart

enough

$\begin{array}{lll}\text { Agree } & \frac{\text { Disagree }}{\text { Don't }} & \begin{array}{c}\text { know } \\ \theta(0)\end{array}\end{array}$

26. Teachers are often anxious

about a child who has

epilepsy.

$\frac{\text { Agree }}{12(12)} \stackrel{\text { Disagree }}{0}$

Pon't
kn? 2 (2) 
27. I would be willing for my child to have a teacher who had epilepsy . . - . Agree Disagree 13 (15) 0 (0) pon't $2(0)$

*28. An epileptic person should be left alone during and after a seizure . .

$\begin{array}{lll}\text { Agree } & \frac{\text { Disagree }}{\text { Pon't }} \\ 1 \text { (3) } & 12(10) & \begin{array}{l}\text { know } \\ 2(2)\end{array}\end{array}$

*29. I am frightened when I see

a seizure . . . .

Agree 4 (3)

Disagree Ron't 11 (11) 1 (1)

30. I would feel embarrassed by having an epileptic child in the family . . .

$\begin{array}{lll}\text { Agree } & \text { Disagree } & \begin{array}{c}\text { Pon't } \\ \text { know } \\ 0(1)\end{array}\end{array}$

31. Epilepsy can cause heart trouble

1 Agree $\frac{\text { Disagree }}{6(13)}$

Ron't 9 (2)

*32. All people who have epilepsy have seizures . . . . . - Agree Disagree 5(6) 7 (9) know't $3(0)$

33. Most people who have epilepsy are of low intelligence.

$\begin{array}{lll}\text { Agree } & \frac{\text { Disagree }}{\text { Pon't }} & \begin{array}{l}\text { know } \\ 1(1)\end{array}\end{array}$

*34. Many people are afraid of an epileptic child. .

$\frac{\text { Agree }}{11(14)} \frac{\text { Disagree }}{3(0)} \quad \begin{aligned} & \text { Pon't } \\ & \text { know } \\ & 1(1)\end{aligned}$

35. People with epilepsy generally have good work records . .

$\begin{array}{lll}\frac{\text { Agree }}{6(6)} & \begin{array}{l}\text { Disagree } \\ 0(1)\end{array} & \begin{array}{l}\text { Pon't } \\ \text { know } \\ 9(8)\end{array}\end{array}$

36. Epilepsy is a handicap in getting a job

$\frac{\text { Agree }}{10(9)} \quad \begin{aligned} & \text { Disagree } \\ & 1 \text { (1) }\end{aligned}$


37. Very few people who have

epilepsy ever amount to

anything . - . - . Agree $\frac{\text { Disagree }}{\text { kon't }} \begin{aligned} & \text { know } \\ & 2(1)\end{aligned}$

38. Since people who have

epilepsy are almost always

poor in math, their best

vocations lie outside the

field of mathematics. .

Agree

Disagree

Pon't

0 (0) $11(11)$

$4(4)$

39. The types of vocations are

very limited for the epileptic

person

Agree

Disagree

0 (3)

11 (9)

pon't

4(3)

*40. Children with epilepsy should

be placed with other children

who have epilepsy . .

.

(1)

Agree Disagree

Ron't

$1(0)$

9 (12)

5(3)

41. Sometimes a child has a seizure deliberately .

$\begin{array}{ll}\frac{\text { Agree }}{2(4)} & \text { Disagree }\end{array}$

pon't

7 (2)

*42. All parents of children with

epilepsy are more understanding

of the epileptic child than

are other parents . . .

Agree $\frac{\text { Disagree }}{8(9)}$

Ron't
know
$2(0)$

43. Epileptic children generally

lead a long and healthy life

Agree

$3(8)$

Disagree

pon't

0 (1)

12(6)

44. It is difficult to plan for

the future of an epileptic

child... . . .

Agree

Disagree

$3(7)$

6 (5)

knon't

6 (3)

*45. A child who has selzures may die in one of his seizures

- A

Agre
Disagree

3 (13)
Ron't 9 (1) 
46. The child with epilepsy suffers no pain during his seizures . . .

$\begin{array}{lll}\text { Agree } & \text { Disagree } & \begin{array}{l}\text { Pon't } \\ \text { know }\end{array} \\ 5(8) & 0(2) & 10(5)\end{array}$

*47. The earlier the onset of epilepsy the more likely the person is to outgrow the condition

$\begin{array}{ll}\text { Agree } & \text { Disagree } \\ 4(9) & 1(3)\end{array}$

48. Certain types of emotional

situations increase the

frequency of seizures

$\frac{\text { Agree }}{9(12)} \quad 1(1)$

Ron't

5(2)

*49. Climate affects the frequency

of seizures . . . .

$\begin{array}{ll}\text { Agree } & \text { Disagree } \\ 1 \text { (2) } & 3(9)\end{array}$

Ron't

11 (4)

50. Screen doors have been known

to trigger selzures...

Agree Disagree

2(10) 4 (3)

Pon't

9 (2)

51. An epileptic child needs more

parental discipline than

other children . . . .

Agree

Disagree

Ron't

$1(0)$

11 (13)

$3(2)$

52. Males have more violent

seizures than females

Agree Disagree

know't

0 (0) $2(9)$

$13(6)$

*53. Epileptic children have fewer

seizures when playing quietly

alone than with a group of

noisy, active playmates.

Agree

Disagree

1 (1)

2(9)

Ron't

11 (5)

54. Some parents believe it is

their fault that their child

has epilepsy

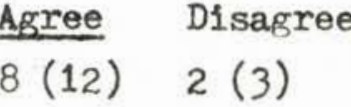

Ron't

$5(0)$

55. A child may swallow his tongue

durting a seizure

Disagree

Ron't

7 (1) $5(13)$ 
56. Never put anything between a person's teeth during a seizur

57. Children with epilepsy have lower resistance to infectious disease than the average normal child.

58. An epileptic child should be $\begin{array}{lll}\frac{\text { Agree }}{5(13)} & \begin{array}{l}\text { Disagree } \\ 3(0)\end{array} & \begin{array}{l}\text { Pon't } \\ \text { know } \\ 8(2)\end{array}\end{array}$ given less responsibility than

other children

Agree

o (1)

Disagree

8 (10)

Pon't

7 (4)

Agree

$0(0)$

Disagree

13 (15)

kon't $2(0)$

59. A child with epilepsy should be treated the same as any other child

60. Children with epilepsy should not associate frequently with other epileptic children lest they imitate their undesirable behavioral patterns

*61. A child with epilepsy will also $\begin{array}{lll}\text { Agree } & \text { Disagree } & \text { Pon't } \\ 4(13) & 8(2) & 3(0)\end{array}$ have many other problems 
The following films on epilepsy are avallable. Please circle those you have or have not seen, or are or are not interested in seeing.

$$
\text { * * * }
$$

Grand Mal Epilepsy: Diagnosis And Management $16 \mathrm{~mm}$ color, sound film, 30 minutes. A doctor is called in the early morning by an anxious parent announcing his teenage daughter has had some "sort of fit." The patient is hospitalized and a neurologist is consulted who institutes a complete diagnostic regimen. The film depicts medical management, treatment, and diagnosis as well as the personal reaction of the girl, her family and friends.

Not Without Hope - 23 minute color. Story of a child with epilepsy who faces a world still prejudiced by antiquated superstitions.

Have Not Seen

Interested

Not Interested

Only A Part of Life - 5 minute black and white. The story of epilepsy. Shows both pet1t mal and grand mal manifestations from grammax school into college.

Have Seen

Have Not Seen

Interested

Not interested

Benjamin - 5 minute color cartoon. The story of a young boy who is really no different from other boys and girls except that sometimes he has seizures.

Have Seen

Have Not Seen

Interested

Not Interested

The Dark Wave - 23 minute color. Story of a 12 year old girl with petit mal seizures. Shows the parents' shock, school board members' reactions, playmates' misunderstanding.

Have Seen

Have Not Seen

Interested

Not Interested

Boy In A Storm - 30 minute color. From the "Medic" television program. Story of a high school boy and his difficulties related to epilepsy.

Have Seen

Have Not Seen

Interested

Not Interested 
Please list below any comments you wish to make in areas that are of particular concern to you regarding epilepsy.

Please list below any specific problems or questions you may have about epilepsy in which we could be of further assistance to you. 
APPENDIX D

Evaluation Questionnaire 
EVALUATION QUESTIONNAIRE

Please answer the questions below. If you need more space, write on the back of the sheet.

1. Which parts of the Parent Seminar did you find most informative?

Physical condition of epllepsy, definition of epilepsy, history of selzure treatment, treatment limitations on the eplleptic child, types of seizures represented, videotaping and psychological assessment, some films. Guest speakers, group discussion, parent interaction, soclalization.

2. Did you feel emotionally disturbed by some parts of the seminar?

(Check one) Yes ? No 8

A. If yes, in what way?

Participants 1dealistic attitudes, initial apprehension, thought provoking, outdated movies, when session ended felt alone.

3. Did the seminars answer all of your questions concerning seizure disorders?

(Check one)

Yes

No 8

If no, what questions were not answered?

*Medications, other treatments avallable, not enough about specific individual case problems, more guest speakers, more on causes of epilepsy and selzures, why some side effects, *what happens during a seizure.

Indicates material was presented.

Items that were mentioned by more than half of the parents are underlined. 
4. Which of the material presented did you find most interesting?

Doctors' thoughts and experiences, informatio on individual cases, group discussion, the more severely 111--the more truthful the parent (and forthright), history of epllepsy, current work and research in epilepsy, staff interest in parents questions.

5. Which material did you find least interesting?

Outdated movies, chemical formulas of anti-convulsants, one of the speakers.

6. Did you find some of the material vague and confusing?

(Check one)

Yes

6

No

9

A. If yes, what?

Materlal was vague because the subject matter was vague. Certain specific points about epilepsy. Needed summary of information, point by point answers to questionnaire.

7. Do you think the number of weekly sessions wası (Check one) too few 1 too many 4 about xight 10

8. What material, if any, do you think could be eliminated?

Outdated movies

9. What kinds of information do you feel should be added?

* Practical ramifications of epilepsy (employment restrictions, insurance, eligibility, physical limitations), service obl1gations, specific case problems in the adult population (1.e. adulthood), study of the brain and its function, better films, parents as teacher aids in school, more time for discussion and questions regarding Epllepsy League of Oregon, public education and more information on special schools preschools, should the teacher be told, increase speakers, Include public education and Westside schools. *Kinds of seizures.

10. What do you feel is the best size of the group? (Circle one) $\frac{8}{2} \frac{10}{3} \frac{12}{2} \frac{14}{1} \frac{16}{5} \frac{18}{2} 20$ Other 
11. Would you recommend this type of seminar to other parents of children with selzure disorders?

$$
\text { (Check one) Yes } 15 \text { No }
$$

A. Why or why not?

Common problems, sharing, exchange of experiences, provides reference for resource material, can recognize possible problems and solutions, enhances perspective, develops friendships, exchange assistance, staff experience.

12. We would appreciate any additional comments (either positive or negative) you care to make.

Want testimonials from "successful" and "unsuccessful" epileptics, continue the meetings, more participation, group should continue to be mandatory, more information on convulsions, a session on legal and educational constraints.

Thank you very much for your cooperation.

George R. Jacobsen

Grant R. Kane

Joan Sacia 
APPENDIX E

Handicap Problems Inventory 


\title{
MANUEL
}

\section{for}

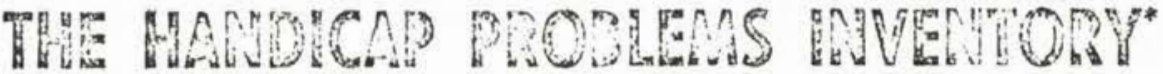

\author{
by
}

G. N. WRIGHT, PH. D. Program Director

National Epilepsy League, Inc.

and

H. H. REMMERS, PH. D.

Professor of Ps;cliology and Education

Purdue University

The Haudicap Probleins Irventory (II.P.I.) is a checklist of 2800 problems attributable to physical dis. ability. It is intended for use with nll kinds of physicolly handicapped teenagers and adults. By marking those problems for which he "blames" his handicap, the disabled person systematically rcveals the significance he attaches to his impairment. Scores, therefore, represent a quantification of the impact of the disability upon the person as he sees it.

A feature of the H.P.I. is that disability related problems are cate gorized into four life arcas: vocational, social, family, and personal (the latter refecting the internal press, i.c., factors not ascriberl to an environmental context). Thus four separate scores are obtained by simply counting the number of marks for each of the four kinds of problems the individual believes are related to his disability. In other words, the instrument provides an index of the verbalized impact of disability as it alfects personal (internal), family, social and vocational ad. justments.

\section{GENERAI. DESCRIPTION}

The 11.P.I. has been desiencal for the use of psycinologists, councelors and other professional people serving the disabled. It is the only instatin at of its hind copecially constructed for the disabled population. Norms are hased upon a sample of over 1000 individuals determined by thorough medical examinations to have substantial and permanent physical disability.

Practical considerations as to the intended use of the H.P.I. guided its construction. This is reflected in its simplicity of adtainistration and scoring. The four areas (personal, famil;; social and vocational) are wurkable divisions of the seats of handicaps resulting from disability; statistical evidence substantiating the reasunableness of this categorization is presented later.

Furthermore, the II.P.I. has been designed for a wide variety of situations. It is suitable for use with persons of low educational altainment (down to the fifth erade: level); this is a particularly important requirement in view of the inferior school experience of the disabled population. In this respect both the simplicity of test taking and casy vocabulary levei of the H.P.I. are nuteworthy. Also important is the fact it is intended for all kinds of substantial physical disabilities, whether sensory, orthopeilic, of whatever. Thic 11.1.1. is thus appropriate for clicnt; typically scen by agenries serving the disabled.

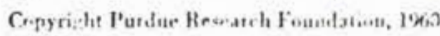

- This tesearch wav supposted in part by a gram frum the Fedatel Ofice of Joestional Kehabilitation and almo by the School of Science, Education atud the IJumanities of Purdue Eniversity. 


\section{PURPOSE}

Disablement is a relative term in that no individual is completely physically fit. It is generally af:reed, however, that ten per cent of the peneral population suffer disability suftcient to cause significant limitations in daily living. For this group of substantially handicapyed prople the II.P.I. is appropriate.

The enormity of the conditions of disablement in terms of incidence and personal conequences justifies the development and use of a special psycholocical imstrument. Measurement devices not tailored for the disaticd fail in at least three respects: 1) they do not emptasize the unique and powerful stimulus, the disablement, and its adverse effects upon adjustment; 2) norm scores are hased upon the general population or some sepment of it, rather than a disabled population; aud 3) items of general tests are frequently inappropriate and convey a different meaning to one suffering a physical handicap.

Counselors of the handirapped are well aware of the need to determine the impact of disablenent upon the counsclce. Disability can and does create a variety of handicaps or special problems which must be identified and dealt with in rehabilitation planning. The II.P.I. gives the counselor quickly and quantitatively an cstimate of the impact of disability as the client sees it and is able to verbalize it.

The four area scores provide in relative terms the mean. ing of the disability the client places upon the various aspects of his life. Additional information is had hy qualitative inspection of specific problems checked. Here in. sights may be obtained as to the adjustive mechanisms employed, e.g., withdrawal, aggression, denial, etc. Furthermore, discussion of problems checked provides an easy entry into interviews concerned with the psychological implications of the disablement.

Of course, HI.P.I. scores per se do not directly measure the personality adjustment of individuals. A very hiph score may reflect an exaggeration of the effects of the disablement indicative of a deep personality difficulty, or the checking of many problems may show an ob. jective and accurate appraisal of the multiple effects of serious disablement. Conversely, a low score may sugfest patholegical denial of the disability, or it may indicate healthy solution of problems associated with a minor limitation. The experienced counselor will readily recog. nize the underlying significance of the score and will thus be provided important adilitional diagnostic information on the individual.

In effect the administration of the H.P.I. is a structured interview. By systematical querying the clicnt is given opportunity to make known in a relatively painless way factors about his disability which bother him and impede adjustment. The 280 items are a comprehensic representation of problems related to physical disability.

\section{DEVFLOPMENT OF THE. INSTRLMENT}

Described here is the methed by which the II.P.I. was constructed: the collection of problems cuncomitant to physical disablement, i.e., H.P.I. items; the classification of items into four life areas; and the trial administrations of the H.P.I.

Initially a $70 \mathrm{item}$ sentence completion trst was devised to determine the problems phycically disabled people relite to impaiment. Of "open-end" type requiritin of the respondent a written completion, all sentence stems as well as the written instructions were designed to uncover the self-perccived results of disalility. The stems were constructed to permit projection of respondent's feclings by incorporating the terms "a handicapped person" or "handicapied people" instead of a personal pronoun. Stems varied widely as to degrce of structuring.

Administration of this sentence conpletion test was to a random sample of 100 disabled people seleeted from the case file of a district oflice of a state vocutional re. habilitation apency. Review of these cases revealed compreliensive variation according to these factors: ane (more than 16 years), occupational status, socio-economic level, education, sex and type of disability. In each instance nedical diagnosis had confirmed the disability.

The original list of problems was obtained from 2870 completiors of the above descrilied resporidents to the specially constructed sentence completion test. Eliminated were duplicates and unmeaningful problems and those only applicable to a specific impairment. This method resulted in the very comprehensive coverage of general handicap problems found in the H.P.I.

These problems statements sifted from the sentence completions were edited to make a total of 280 uniform and elear items. Changes were minitnal in order to preserve the meaning expressed by the disabled person. To prevent diff.culty for peopie with limited reading yocabu. laries all words used in the H.P.I. are at or easier than the fifth grade level (according to Thorndike's Teacher's IFord Book).

Itens were then randomized and submitted to 27 psychologists for assignment of each iten to one of four predetermined context catepurics. Of the total $2: 0$ items, the categotization is as follows: 96 personal items, 68 family items, 54 social itcms, 62 vocational items. A fifth caterory "too general" (to rlassify) was not found applicalile to any of the 280 items by a significant number of judpes. Agreement of the judges on all of the items was significant at or beyond the one per cent level (by an approximation of the binomial expansion indicating a probability of less than one in 100 of obtaining by chance alone one or more similar judgements when given five classification alternatives). Most itcms obtained such close agreement by judges as to be significant far beyond the one per cent level of crinfidence.

Furthe: development of the instrument included a try. out of the preliminary form of the II.P.I. using anotirer sample of 100 disabled individuals. Primary purpuses served by this trial administration were to further im. prove clarity of individual itrme and the mechanies of administration (directions), and to determine testee attitudes toward the instrument. 
Unstructured interviews with 35 of this trial croup, plus an additional 50 counselees who have taken the refined form of the H.P.I., indicate: a positive attitude toward test taking (reflected by care and sincerity), a high degree of understanding of instructions and individual itens, and completeness of the list of problems, i.r., no unlisted handicap problems were reporter.

It is to be noted that alministration of the sentence - completion test from which items were collected, the trial administration of the preliminary form of the problems list and the administration of the final form for reliability, normative and other data were all by mail. The per cent of return of the latter group excecded 86 per cent; this, and statistically derived information of a technical nature, leads to the conclusion that no important bias resulted from the nonparticipating group.

\section{RELIABHLITY AN'D VALIDITY}

Reliability coefficients from each of the four areas of the II.P.I. have been cstimated from the previousiy men. tioned sample of 1027 randomly selected physically dis. abled clients of the Iudiana Division of Vocational Rehabilifation." The internal consistency cocflicients of reliability (Kuder-Pichardson formula 20) are shown in Table 2. Reliability extimates range from .91 to .95 for the four areas. These high indices of internal consistency reliability suggest that the area scotes are a measure of a generalized homogencous collection of problems.

Scotes directly measure the phenomenological report of the individual. No claim is made for scores beyond the faet that they reflect self perceptions (and, of course, willingness to report). In this sense the "validity" is equivalent to the reliability coefficient.

TABLE 1

COMPOSITION OF SAMIPLE - INTERRELATIONSHIPS

(Given in Percentuges)

\begin{tabular}{|c|c|c|c|c|c|}
\hline Total $N=1027$ & $N$ & Percent & & $N$ & Percent \\
\hline SEX & & & MAIN DISABILITY & & \\
\hline 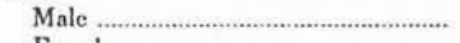 & 712 & 69.3 & Other & 141 & 13.7 \\
\hline 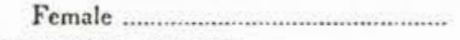 & 315 & 30.7 & Amputated Leg.......... & 85 & 8.2 \\
\hline MARITAL STATUS & & & Amputated Arm & 28 & 2.7 \\
\hline Married ……………………...... & 305 & 29.6 & 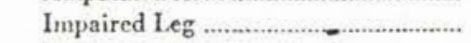 & 211 & 20.5 \\
\hline Single & 636 & 61.9 & Jimpaired Arm & 100 & 9.7 \\
\hline 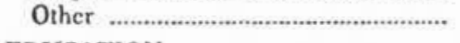 & 86 & 8.3 & Spinc & 131 & 12.7 \\
\hline EDUCATION & s. & & 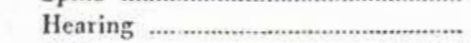 & 93 & 9.0 \\
\hline 0.8 & 143 & 13.9 & 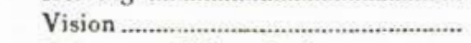 & 94 & 9.1 \\
\hline 9.12 & 461 & 41.8 & Pulmonary Tuberculosis ......................... & 75 & 7.3 \\
\hline 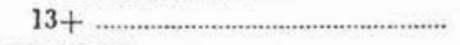 & 423 & 41.1 & 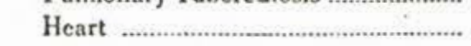 & 69 & 6.7 \\
\hline RELIGION & & $\cdot$ & SECOND DISABILITY & & \\
\hline Roman Catholic & 151 & 14.7 & $\begin{array}{l}\text { SECOND DISABILITY } \\
\text { Ycs }\end{array}$ & & \\
\hline $\begin{array}{l}\text { Protestant } \\
\text { Not Listed }\end{array}$ & 773 & 75.2 & Yes & 341 & 33.2 \\
\hline 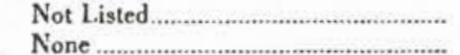 & 20 & 1.9 & No & 686 & 66.7 \\
\hline $\begin{array}{l}\text { None } \\
\text { RURAI-URBAN }\end{array}$ & 83 & 8.0 & YEARS DISABLED & & \\
\hline City & 319 & 31.0 & 0.5 & 297 & 28.9 \\
\hline 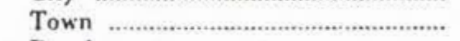 & 466 & 45.3 & $6 \cdot 10 \ldots$ & 189 & 18.4 \\
\hline 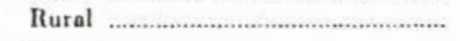 & 2.12 & 23.5 & $11.15 \ldots \ldots$ & 1.46 & 14.2 \\
\hline AGE $\cdot$ & & $\cdot$ & 16.20 & 229 & 22.2 \\
\hline $16-20$ & 410 & 39.9 & $21+\ldots \ldots \ldots$ & 166 & 16.1 \\
\hline $21 \cdot 30$ & 338 & 32.9 & & & \\
\hline $31+\ldots \ldots \ldots$ & 279 & 27.1 & SUPPORT SOURCE: & & \\
\hline HOW DISABI.ED & & & Earnings ........ & 337 & 31.8 \\
\hline Disease .................. & 523 & 50.9 & Family & 493 & 48.0 \\
\hline 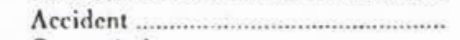 & 268 & 26.0 & Insurance & 85 & 8.2 \\
\hline 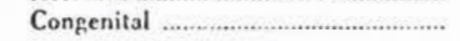 & 236 & 22.9 & 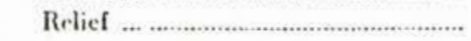 & 112 & 10.9 \\
\hline
\end{tabular}

- Clients for vreation rehalulitation ernices are selected nation-

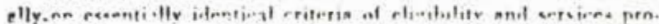
vided. Other gromura of disubled prople, such ax aren in ditferent kinds of agencurs, however, niay not be comparable. For this-reason other ärencies will necd to examine the appropriateness fot their own ernup of , latn teported im this maunal for state retiabilitation clienta For romparison purposes compostion of the nurn group is decrabed in detsil in Table 1. 
TABLE 2

\section{RELIABILITIES OF SUBTESTS \\ (Internal Consistency ${ }^{\circ}$ )}

Subtest
Personal
Family
Social

•Kuder-Richardson \#20.

It is acknowledged that there may be discrepancy be tween the frequency of problems checked by the respondent and the actual number of disability incurred problems. The, mechanism of denial of disability and, conversely, exaggeration of the linitation have been cited as phenomena which could influence the response set of a specific individual. The degree to which the H.P.I. scores represent the objective situations of the individual or how well it can predict future situations is not definitely known. His attitudes, however, as measured by the-H.P.I. are important data for the rehabilitation counselor.

The lack of correlational studies using outside criteria simply means that the H.P.I. should not be employed for screening purposes. Its uses should be confined to those outlined in the paragraphs on "interpretation." Bricfly stated, the H.P.I. provides the counsclor reliable (internally consistent) data about his client's present stated views concerning the effect of his disability.

\section{NORMS AND DEMONSTRATED RELATIONSHIPS}

Through the above mentioned final trial administra. tion of the refined H.P.l. to the 1000 -odd disabled people, several situations and characteristics of the handi. c-pped person have been shown to influcnce the kind and number of prohlems he experiences. Results of this study are reported in Table 3 . These data have two values:

1) The reports of statistical differences substantiate the assumption of concurrent validity in that the relation. ships found hetween H.P.I. scores and outside criteria are in the logically expected direction, e.g., a hiph H.P.I. score (many problems) is positively related to having a second disability, negatively related to amount of education, etc.

2) The report of mean scores in these tables provides the counselor a more detailed picture of the expectancy of an indivirlual's scure (on the basis of comparison to his subgroup membership viz., nge, sex, etc.) than the table of norms which averagey these factors.

Normative dnta are provided in Table 4. These are presented as percentile scores for the over 1000 participants in the final trial aduinistration. Only "subtest scores" should be used for counseling purposes; "total test" norms are reposted for technical reasons only and have no reliability estimates computed.

\section{ADMINISTTRA'TION}

The H.P.I. can be given either individually or to a group. Only abnut 30 minutes need be scheduled for administrntion; however, the slow testec should be allowed time to finish.

As with other self-report devices, it is important that good rapport be established before H.P.I. is administered. The individual must feel that his answers will be confi. dential and used in his interest.

In discussing the value of the H.P.1. before its administration, it is well to assess the rapport factor. Any lack of cooperation should be corrected before beginning. Generally the only introduction required will be the directions. 
TABLE 3

MEAN COMPARISONS FOR EACH SURTFST BY PFRSONAL BACKGROUND VARIABLES

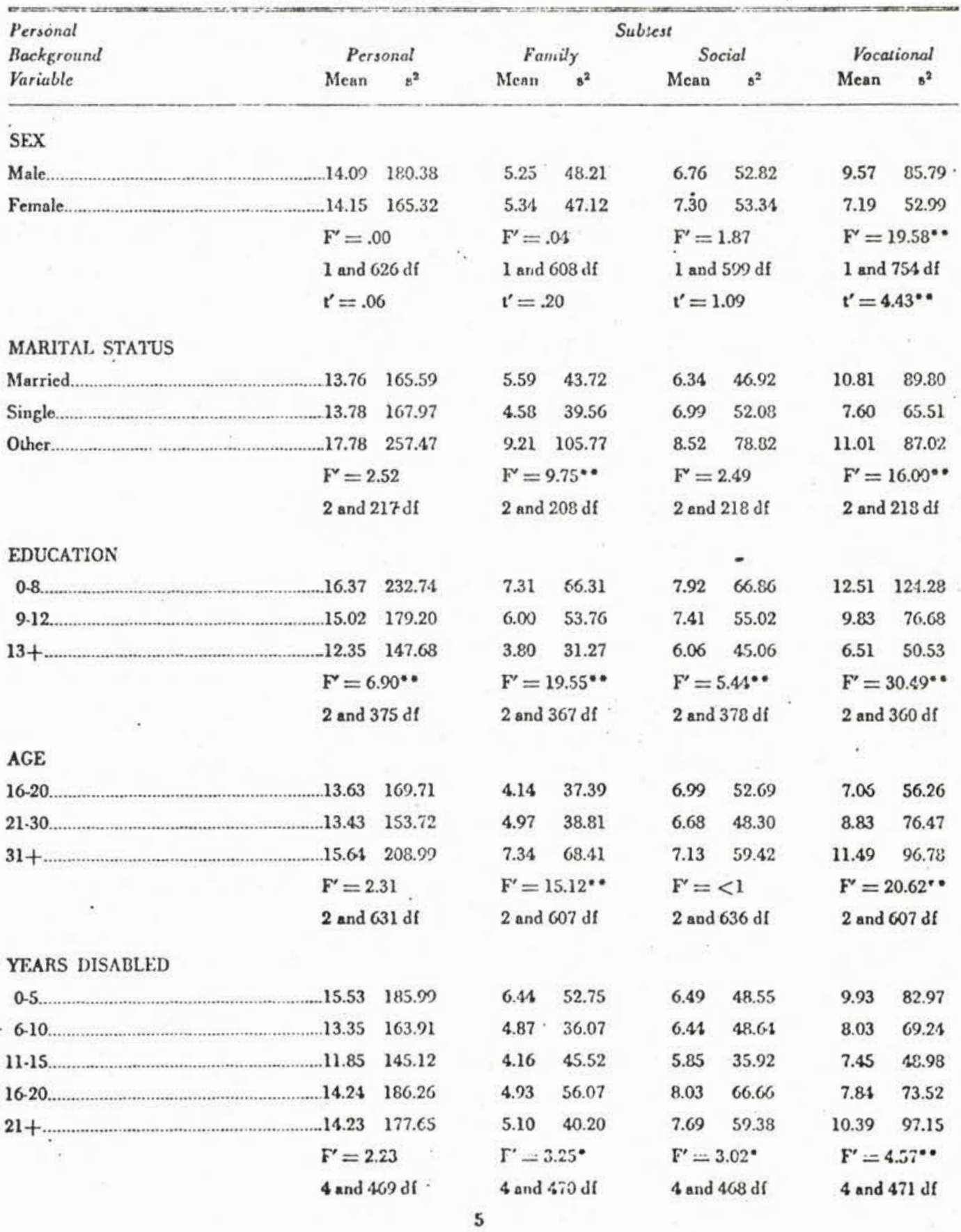


TABLE 3 (Cont.)

\begin{tabular}{|c|c|c|c|c|c|c|c|c|}
\hline \multirow{3}{*}{$\begin{array}{l}\text { Personal } \\
\text { Background } \\
\text { Variable }\end{array}$} & \multirow{2}{*}{\multicolumn{2}{|c|}{ Personal }} & \multicolumn{4}{|c|}{ Subtest } & \multirow{2}{*}{\multicolumn{2}{|c|}{ Vocational }} \\
\hline & & & \multicolumn{2}{|c|}{ Family } & \multicolumn{2}{|c|}{ Social } & & \\
\hline & Mean & $s^{2}$ & Mean & $s^{2}$ & Mean & $s^{2}$ & Mean & $\mathrm{s}^{2}$ \\
\hline \multicolumn{9}{|l|}{ SECOND DISABILITY } \\
\hline No & 12.52 & 137.11 & 4.27 & 32.44 & 6.17 & 41.73 & 7.48 & 56.10 \\
\hline \multirow{3}{*}{ PRIMARY DISABILITY } & .17 .29 & 238.95 & 7.29 & 72.31 & 8.14 & 72.37 & 11.55 & 107.75 \\
\hline & \multicolumn{2}{|c|}{$\begin{array}{l}1 \text { and } 541 \mathrm{df} \\
t^{\prime}=5.03 \%\end{array}$} & \multicolumn{2}{|c|}{$\begin{array}{l}1 \text { and } 495 \mathrm{df} \\
t^{\prime}=5.91^{\circ}\end{array}$} & \multicolumn{2}{|c|}{$\begin{array}{c}1 \text { and } 541 \mathrm{df} \\
t^{\prime}=4.33^{*} \\
.\end{array}$} & \multicolumn{2}{|c|}{$\begin{array}{l}1 \text { and } 522 \mathrm{df} \\
t^{\prime}=6.46^{\circ}\end{array}$} \\
\hline & & & & & & & & \\
\hline 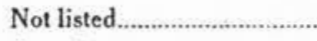 & $\ldots 13.68$ & 168.95 & 5.53 & 46.82 & 7.09 & 57.31 & 8.27 & 83.31 \\
\hline Amp. Leg & $\ldots 14.79$ & 237.40 & 7.07 & 87.51 & 7.49 & 82.45 & 10.37 & 102.57 \\
\hline Amp. Arm........ & .12 .79 & 126.40 & $3 . \$ 9$ & 38.99 & 7.00 & 41.47 & 8.71 & 56.29 \\
\hline Impair. Leg $\ldots . .$. & .14 .01 & 145.84 & 4.70 & 37.35 & 7.00 & 42.28 & 7.63 & 52.31 \\
\hline Impair. Arm.... & $\ldots 16.93$ & 243.26 & 5.87 & 50.40 & 8.18 & 67.30 & 11.00 & 98.69 \\
\hline Spine................ & $\ldots 16.09$ & 229.19 & 6.69 & 62.31 & 7.22 & 70.71 & 10.47 & 105.99 \\
\hline Hearing $\ldots$ &. .13 .57 & 148.10 & 4.44 & 32.08 & 8.52 & 51.51 & 9.48 & 74.73 \\
\hline Vision.... &. .10 .38 & 122.39 & 2.46 & 23.93 & 5.28 & 31.14 & 5.68 & 42.93 \\
\hline Pul. Tbc.... & $\ldots 12.40$ & 162.78 & 5.59 & 52.89 & 5.12 & 30.86 & 8.12 & 73.70 \\
\hline \multirow[t]{3}{*}{ Heart...... } & .14 .78 & 127.19 & 5.99 & 37.93 & 5.83 & 26.29 & 9.81 & 53.95 \\
\hline & \multicolumn{2}{|c|}{$F^{\prime}=1.98^{\circ}$} & \multicolumn{2}{|c|}{$F^{\prime}=4.60^{\cdots}$} & \multicolumn{2}{|c|}{$F^{\prime}=2.77^{*}$} & \multicolumn{2}{|c|}{$\mathrm{F}^{\prime}=4.15^{\cdots}$} \\
\hline & \multicolumn{2}{|c|}{9 and $302 \mathrm{df}$} & \multicolumn{2}{|c|}{9 and $300 \mathrm{df}$} & \multicolumn{2}{|c|}{9 and $303 \mathrm{df}$} & \multicolumn{2}{|c|}{9 and $300 \mathrm{df}$} \\
\hline \multicolumn{9}{|l|}{ INCOME SOURCE } \\
\hline 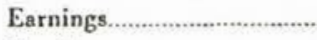 & 12.50 & 153.93 & 4.27 & 40.31 & 6.25 & 47.28 & 8.87 & 79.03 \\
\hline Family ............................ & .14 .05 & 167.07 & 5.08 & 45.71 & 7.16 & 53.52 & 7.87 & 66.81 \\
\hline Insurance.... & 14.09 & 142.85 & 5.95 & 33.57 & 5.62 & 37.48 & 8.62 & 42.09 \\
\hline Relief............. &. .19 .27 & 274.87 & 8.65 & 77.43 & 8.96 & 74.22 & 13.19 & 20.46 \\
\hline & $F^{\prime}=5$ & $30^{\cdots}$ & $F^{\prime \prime}=\varepsilon$ & $.47^{*}$ & $F^{\prime}=$ & $48^{*}$ & $\mathrm{~F}^{\prime}=$ & $7.81 \cdots$ \\
\hline & 3 and 2 & $57 \mathrm{df}$ & 3 and & $260 \mathrm{df}$ & 3 and & $63 \mathrm{df}$ & 3 and & $260 \mathrm{df}$ \\
\hline RURAL-URBAN & & . & & & & & & \\
\hline 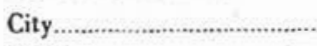 & 13.72 & 171.33 & 5.36 & 45.52 & 6.74 & 53.88 & 9.01 & 83.94 \\
\hline Town................ & .15 .35 & 19.13 & 5.65 & 51.85 & 7.36 & 56.82 & 9.38 & 81.49 \\
\hline Rural.... &. .12 .23 & 140.24 & 4.45 & 42.58 & 6.35 & 43.37 & 7.55 & 56.94 \\
\hline & $F^{\prime}=4$ & $97^{\bullet}$ & $F^{\prime}=$ & 60 & $F^{\prime}=$ & 78 & $F^{\prime}=$ & $4.22^{*}$ \\
\hline & 2 and 6 & $11 \mathrm{df}$ & 2 and & $502 \mathrm{df}$ & 2 and & $06 \mathrm{df}$ & 2 and & $611 \mathrm{df}$ \\
\hline 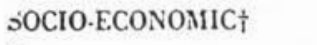 & & & & & & & & \\
\hline 0 & 13.41 & 191.43 & 4.61 & 21.22 & 6.65 & 56.09 & 9.25 & 97.33 \\
\hline $1 \ldots \ldots \ldots . . . .$. & 14.10 & 212.38 & 5.31 & 33.22 & 6.74 & 59.62 & 12.28 & 112.52 \\
\hline $2 \ldots$ & 13.83 & 191.36 & 6.27 & 72.76 & 7.52 & 52.72 & 10.26 & 94.03 \\
\hline $3 \ldots \ldots$ & $\ldots 15.97$ & 205.71 & 6.36 & 63.35 & 7.15 & 48.56 & 10.67 & 87.13 \\
\hline $4 \ldots \ldots$ & 16.25 & 211.51 & 6.21 & 58.51 & 7.96 & 68.50 & 9.41 & 68.35 \\
\hline $5 \ldots \ldots$ & $\ldots 13.11$ & 157.87 & 4.75 & 39.20 & 6.48 & 48.61 & 7.91 & 63.01 \\
\hline $6 \ldots \ldots$ & 13.42 & 142.17 & 4.36 & 31.57 & 6.58 & 43.17 & 7.19 & 58.31 \\
\hline $7 \ldots \ldots$ & $\ldots 14.43$ & 133.89 & 6.96 & 73.50 & 6.78 & 39.31 & 8.26 & 81.66 \\
\hline & $F^{\prime}=1$ & 16 & $F^{\prime}=$ & 83 & $F^{\prime}==$ & & $F^{\prime}=$ & $3.11^{\cdots}$ \\
\hline & 7 and 2 & $02 \mathrm{df}$ & 7 and & $201 \mathrm{df}$ & & & 7 and & $200 \mathrm{df}$ \\
\hline
\end{tabular}

- Significant at fivr perient level: *vignificant at one perient lesel.

1 The bigher the number, the higher the siatus. 
TABLE 4

PERCENTILE NORMS FOR TOTAL, TEST AND SUBTESTS

\begin{tabular}{|c|c|c|c|c|c|}
\hline \multirow[b]{2}{*}{$\begin{array}{c}\text { Percentile } \\
\text { Score }\end{array}$} & \multicolumn{3}{|c|}{ Rav Score Equivalent } & \multicolumn{2}{|l|}{. } \\
\hline & Total Test & Persanal & Fomily & Social & Vocational \\
\hline 99 & 149 & 57 & 34 & 32 & 37 \\
\hline 98 & 132 & 53 & 26 & $28^{\circ}$ & 34 \\
\hline 97 & 122 & 48 & 23 & 25 & 32 \\
\hline 96 & 110 & $45^{\circ}$ & 21 & 25 & 29 \\
\hline 95 & 104 & 43 & 19 & 22 & 27 \\
\hline 90 & 82 & 33 & 14 & 18 & 23 \\
\hline 85 & 64 & 27 & 11 & 14 & 17 \\
\hline 80 & 54 & 23 & 9 & 11 & 15 \\
\hline 75 & 48 & 19 & 7 & 9 & 12 \\
\hline 70 & 42 & 16 & 6 & 8 & 11 \\
\hline 65 & 36 & 15 & 5 & 7 & 9 \\
\hline 60 & 31 & 13 & 4 & 6 & - \\
\hline 55 & 28 & 12 & 3 & 5 & 7 \\
\hline 50 & 25 & 10 & 3 & 4 & 6 \\
\hline 45 & 22 & 9 & 2 & 4 & 5 \\
\hline 40 & 19 & 7 & 2 & 3 & 4 \\
\hline 35 & 16 & 6 & 1 & 3 & 4 \\
\hline 30 & 14 & 5 & 1 & 2 & 3 \\
\hline 25 & 10 & 4 & 1 & 2 & 2 \\
\hline 20 & 9 & 3 & - & 1 & 2 \\
\hline 15 & 7 & 3 & - & 1 & 1 \\
\hline 10 & 5 & 2 & - & 1 & 1 \\
\hline 5 & 3 & 1 & - & - & - \\
\hline 4 & 2 & 1 & - & - & - \\
\hline 3 & 1 & - & - & - & - \\
\hline 2 & - & - & - & - & - \\
\hline 1 & - & - & - & - & - \\
\hline
\end{tabular}


TobI. 5

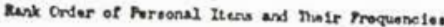

(by Jotal, Priakry and Sacondary Dioabliltty Crospo)

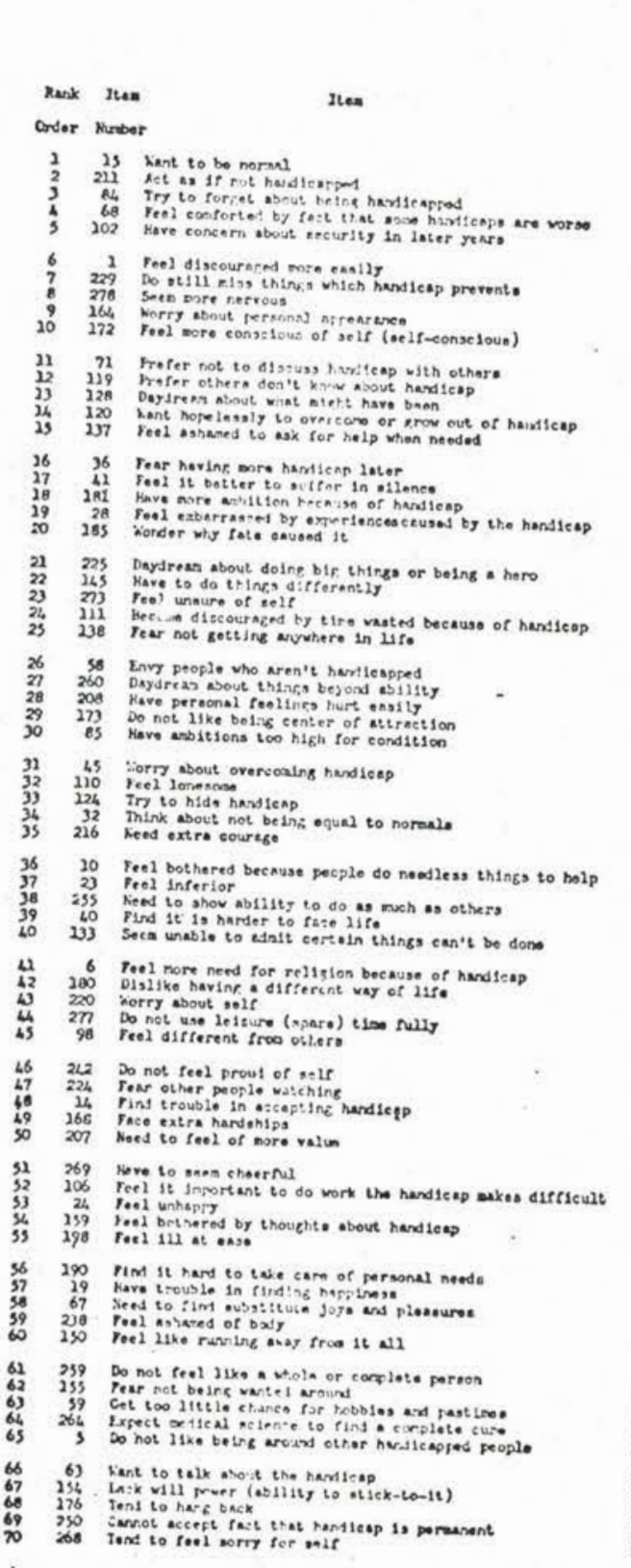

\begin{tabular}{|c|c|c|c|c|c|c|c|c|c|c|c|}
\hline \multirow[b]{2}{*}{ 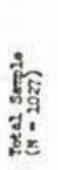 } & \multicolumn{4}{|c|}{ Yrequency } & \multicolumn{6}{|c|}{ 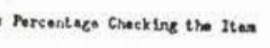 } & \\
\hline & 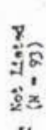 & $\begin{array}{l}52 \\
\dot{5}: 3\end{array}$ & $\begin{array}{l}\text { हैन } \\
\dot{2}:\end{array}$ & $\frac{s_{0}}{5}$ & $\frac{5}{5}$ & & & & $\begin{array}{l}8 x \\
23 \\
23\end{array}$ & $\sum_{2}^{\widehat{\lambda}}$ & हैं \\
\hline $\begin{array}{l}35 \\
43 \\
46 \\
42 \\
3 B\end{array}$ & $\begin{array}{l}54 \\
54 \\
23 \\
37 \\
29\end{array}$ & $\begin{array}{l}49 \\
i, 0 \\
4, \\
4 \\
6\end{array}$ & $\begin{array}{l}43 \\
52 \\
43 \\
37 \\
23\end{array}$ & $\begin{array}{l}57 \\
60 \\
35 \\
48 \\
27\end{array}$ & $\begin{array}{l}46 \\
46 \\
32 \\
48 \\
28\end{array}$ & $\begin{array}{l}60 \\
47 \\
43 \\
31 \\
40\end{array}$ & $\begin{array}{l}33 \\
31 \\
41 \\
37 \\
27\end{array}$ & $\begin{array}{l}41 \\
33 \\
4 \\
39 \\
21\end{array}$ & $\begin{array}{l}36 \\
45 \\
30 \\
33 \\
30\end{array}$ & $\begin{array}{l}58 \\
51 \\
51 \\
47 \\
40\end{array}$ & $\begin{array}{l}62 \\
4\end{array}$ \\
\hline $\begin{array}{l}34 \\
314 \\
31 \\
73 \\
25\end{array}$ & $\begin{array}{l}33 \\
25 \\
24 \\
25 \\
23\end{array}$ & $\begin{array}{l}32 \\
24 \\
37 \\
23 \\
23\end{array}$ & $\begin{array}{l}38 \\
24 \\
24 \\
24 \\
24\end{array}$ & $\begin{array}{l}22 \\
32 \\
18 \\
34 \\
26\end{array}$ & $\begin{array}{l}26 \\
35 \\
25 \\
30 \\
33\end{array}$ & $\begin{array}{l}26 \\
30 \\
23 \\
26 \\
22\end{array}$ & $\begin{array}{l}29 \\
30 \\
39 \\
12 \\
16\end{array}$ & $\begin{array}{l}31 \\
16 \\
23 \\
26 \\
24\end{array}$ & $\begin{array}{l}36 \\
21 \\
36 \\
13 \\
16\end{array}$ & $\begin{array}{l}30 \\
45 \\
49 \\
13 \\
17\end{array}$ & $\begin{array}{l}38 \\
32 \\
29\end{array}$ \\
\hline $\begin{array}{l}22 \\
21 \\
212 \\
21 \\
21\end{array}$ & $\begin{array}{l}26 \\
18 \\
16 \\
22 \\
23\end{array}$ & $\begin{array}{l}22 \\
21 \\
12 \\
17 \\
23\end{array}$ & $\begin{array}{l}20 \\
5 \\
24 \\
24\end{array}$ & $\begin{array}{l}22 \\
24 \\
24 \\
20 \\
16\end{array}$ & $\begin{array}{l}7 \\
31 \\
24 \\
19 \\
26\end{array}$ & $\begin{array}{l}31 \\
17 \\
25 \\
19 \\
17\end{array}$ & $\begin{array}{l}14 \\
34 \\
16 \\
10 \\
18\end{array}$ & & $\begin{array}{l}21 \\
23 \\
10 \\
14 \\
23\end{array}$ & $\begin{array}{l}21 \\
76 \\
20 \\
30 \\
25\end{array}$ & \\
\hline $\begin{array}{l}x 1 \\
x 0 \\
x 0 \\
x \\
x \\
0\end{array}$ & $\begin{array}{l}10 \\
22 \\
22 \\
27 \\
17\end{array}$ & $\begin{array}{l}23 \\
21 \\
22 \\
17 \\
15\end{array}$ & $\begin{array}{l}5 \\
14 \\
29 \\
19 \\
30\end{array}$ & $\begin{array}{l}17 \\
20 \\
22 \\
18 \\
20\end{array}$ & $\begin{array}{l}6 \\
13 \\
30 \\
19 \\
26\end{array}$ & $\begin{array}{l}22 \\
32 \\
17 \\
16 \\
19\end{array}$ & $\begin{array}{l}n \\
18 \\
24 \\
24 \\
16\end{array}$ & $\begin{array}{l}21 \\
10 \\
10 \\
11 \\
16\end{array}$ & $\begin{array}{l}36 \\
30 \\
10 \\
91 \\
21\end{array}$ & $\begin{array}{c}38 \\
13 \\
19 \\
6 \\
19\end{array}$ & $\begin{array}{l}21 \\
26\end{array}$ \\
\hline $\begin{array}{l}19 \\
19 \\
19 \\
19 \\
19\end{array}$ & $\begin{array}{l}22 \\
15 \\
15 \\
15 \\
28\end{array}$ & $\begin{array}{l}10 \\
19 \\
12 \\
n \\
29\end{array}$ & $\begin{array}{l}29 \\
46 \\
14 \\
24\end{array}$ & $\begin{array}{l}22 \\
14 \\
19 \\
10 \\
11\end{array}$ & $\begin{array}{r}22 \\
31 \\
7 \\
23 \\
22\end{array}$ & $\begin{array}{l}19 \\
18 \\
16 \\
10 \\
18\end{array}$ & $\begin{array}{l}16 \\
6 \\
20 \\
20 \\
20\end{array}$ & $\begin{array}{c}14 \\
6 \\
19 \\
14 \\
10\end{array}$ & $\begin{array}{l}23 \\
h \\
18 \\
21 \\
20\end{array}$ & $\begin{array}{l}23 \\
19 \\
23 \\
15 \\
23\end{array}$ & $\begin{array}{l}21 \\
26 \\
22 \\
21 \\
21\end{array}$ \\
\hline $\begin{array}{l}17 \\
17\end{array}$ & $\begin{array}{l}16 \\
12 \\
24 \\
20 \\
23\end{array}$ & $\begin{array}{l}17 \\
15 \\
10 \\
12 \\
12\end{array}$ & $\begin{array}{l}24 \\
10 \\
19 \\
19 \\
10\end{array}$ & $\begin{array}{l}22 \\
20 \\
14 \\
19 \\
13\end{array}$ & $\begin{array}{l}15 \\
13 \\
34 \\
20 \\
19\end{array}$ & $\begin{array}{l}18 \\
21 \\
16 \\
13 \\
24\end{array}$ & $\begin{array}{l}14 \\
20 \\
24 \\
16 \\
14 \\
\end{array}$ & $\begin{array}{l}10 \\
8 \\
16 \\
13 \\
10\end{array}$ & $\begin{array}{l}11 \\
16 \\
11 \\
11 \\
16\end{array}$ & $\begin{array}{l}25 \\
26 \\
19 \\
17 \\
25\end{array}$ & $\begin{array}{l}20 \\
21 \\
19 \\
19 \\
22\end{array}$ \\
\hline $\begin{array}{l}17 \\
17 \\
17\end{array}$ & $\begin{array}{l}18 \\
12 \\
11 \\
16 \\
16\end{array}$ & $\begin{array}{l}22 \\
23 \\
21 \\
13 \\
17\end{array}$ & $\begin{array}{l}20 \\
10 \\
10 \\
10\end{array}$ & $\begin{array}{l}11 \\
9 \\
16 \\
14 \\
11\end{array}$ & $\begin{array}{l}13 \\
33 \\
19 \\
12\end{array}$ & & $\begin{array}{l}6 \\
22 \\
24 \\
14 \\
18\end{array}$ & $\begin{array}{l}13 \\
120 \\
15 \\
11 \\
13\end{array}$ & $\begin{array}{l}14 \\
26 \\
5 \\
13 \\
14\end{array}$ & $\begin{array}{l}15 \\
13 \\
9 \\
17 \\
15\end{array}$ & $\begin{array}{l}24 \\
24 \\
20 \\
20 \\
22\end{array}$ \\
\hline 26 & $\begin{array}{l}18 \\
16 \\
16 \\
13 \\
11\end{array}$ & $\begin{array}{l}23 \\
8 \\
12 \\
13 \\
23\end{array}$ & $\begin{array}{l}57 \\
19 \\
5 \\
21 \\
29\end{array}$ & $\begin{array}{l}13 \\
11 \\
16 \\
9 \\
18\end{array}$ & $\begin{array}{l}20 \\
20 \\
17 \\
19 \\
19\end{array}$ & $\begin{array}{l}22 \\
20 \\
23 \\
9 \\
26\end{array}$ & $\begin{array}{l}12 \\
20 \\
31 \\
18 \\
10\end{array}$ & $\begin{array}{r}6 \\
16 \\
10 \\
5 \\
8\end{array}$ & $\begin{array}{r}12 \\
9 \\
7 \\
y \\
5\end{array}$ & $\begin{array}{l}9 \\
13 \\
19 \\
13 \\
21\end{array}$ & $\begin{array}{l}19 \\
21 \\
18 \\
23 \\
17\end{array}$ \\
\hline 1s & $\begin{array}{l}11 \\
15 \\
10 \\
15 \\
16\end{array}$ & $\begin{array}{l}13 \\
13 \\
13 \\
12 \\
13\end{array}$ & $\begin{array}{l}3 \\
39 \\
3 \\
3 \\
4\end{array}$ & $\begin{array}{c}11 \\
10 \\
7 \\
11 \\
8\end{array}$ & $\begin{array}{l}u 1 \\
31 \\
11 \\
13 \\
7\end{array}$ & $\begin{array}{c}27 \\
10 \\
9 \\
12 \\
14\end{array}$ & $\begin{array}{l}16 \\
12 \\
10 \\
12 \\
22\end{array}$ & $\begin{array}{l}9 \\
5 \\
13 \\
13 \\
9\end{array}$ & $\begin{array}{l}25 \\
11 \\
16 \\
11 \\
5\end{array}$ & $\begin{array}{l}11 \\
13 \\
19 \\
21 \\
11\end{array}$ & $\begin{array}{l}19 \\
21 \\
23 \\
17 \\
19\end{array}$ \\
\hline $\begin{array}{l}23 \\
13 \\
13\end{array}$ & $\begin{array}{l}12 \\
10 \\
13 \\
14 \\
23\end{array}$ & $\begin{array}{c}10 \\
13 \\
8 \\
13 \\
6\end{array}$ & $\begin{array}{c}14 \\
3 \\
34 \\
3\end{array}$ & $\begin{array}{c}11 \\
16 \\
7 \\
? \\
8\end{array}$ & $\begin{array}{r}19 \\
22 \\
6 \\
? \\
9\end{array}$ & $\begin{array}{l}10 \\
21 \\
17 \\
10 \\
12\end{array}$ & $\begin{array}{l}12 \\
6 \\
22 \\
12 \\
12\end{array}$ & $\begin{array}{c}11 \\
21 \\
6 \\
6 \\
21\end{array}$ & $\begin{array}{r}9 \\
2 \\
14 \\
4 \\
21\end{array}$ & $\begin{array}{l}23 \\
6 \\
21 \\
11 \\
8\end{array}$ & $\begin{array}{l}18 \\
16 \\
16 \\
21 \\
1 n\end{array}$ \\
\hline 22 & $\begin{array}{r}10 \\
8 \\
5 \\
6 \\
23\end{array}$ & $\begin{array}{l}23 \\
13 \\
13 \\
10 \\
12\end{array}$ & $\begin{array}{l}24 \\
3 \\
10 \\
20\end{array}$ & $\begin{array}{c}10 \\
23 \\
7 \\
6 \\
9\end{array}$ & $\begin{array}{l}9 \\
19 \\
9 \\
\text { y } \\
23\end{array}$ & $\begin{array}{l}12 \\
12 \\
83 \\
13\end{array}$ & $\begin{array}{l}12 \\
12 \\
18 \\
14 \\
12\end{array}$ & $\begin{array}{r}\text { g } \\
8 \\
9 \\
21 \\
13\end{array}$ & $\begin{array}{c}7 \\
5 \\
7 \\
13 \\
11\end{array}$ & $\begin{array}{l}\underset{1}{15} \\
13 \\
{ }_{6}\end{array}$ & $\begin{array}{l}29 \\
14 \\
19 \\
16 \\
15\end{array}$ \\
\hline$u$ & $\begin{array}{r}20 \\
20 \\
3 \\
3 \\
21\end{array}$ & $\begin{array}{l}5 \\
12 \\
15 \\
17 \\
12\end{array}$ & $\begin{array}{l}19 \\
35 \\
10 \\
10 \\
4\end{array}$ & $\begin{array}{c}6 \\
7 \\
3 \\
11 \\
6\end{array}$ & $\begin{array}{l}21^{2} \\
11 \\
19 \\
7\end{array}$ & $\begin{array}{l}16 \\
\text { है } \\
14 \\
14\end{array}$ & $\begin{array}{l}10 \\
12 \\
12 \\
10 \\
10\end{array}$ & $\begin{array}{l}5 \\
9 \\
4 \\
1 \\
3\end{array}$ & $\begin{array}{l}33 \\
23 \\
35 \\
16\end{array}$ & $\begin{array}{l}\frac{6}{12} \\
11 \\
22 \\
27\end{array}$ & $\begin{array}{l}16 \\
15 \\
16 \\
114\end{array}$ \\
\hline $\begin{array}{c}10 \\
10 \\
10\end{array}$ & $\begin{array}{r}3 \\
3 \\
36 \\
17 \\
10\end{array}$ & $\begin{array}{r}13 \\
10 \\
6 \\
6 \\
6\end{array}$ & $\begin{array}{l}L_{1} \\
10 \\
5\end{array}$ & $\begin{array}{l}3 \\
6 \\
6 \\
5 \\
3 \\
3\end{array}$ & $\begin{array}{c}9 \\
9 \\
6 \\
1 \\
23\end{array}$ & $\begin{array}{c}12 \\
5 \\
20 \\
5 \\
6\end{array}$ & $\begin{array}{c}12 \\
12 \\
12 \\
6 \\
6\end{array}$ & $\begin{array}{c}6 \\
21 \\
5 \\
9 \\
9\end{array}$ & $\begin{array}{l}21 \\
3 \\
\frac{14}{21} \\
4\end{array}$ & $\begin{array}{c}31 \\
8 \\
29\end{array}$ & $\begin{array}{l}27 \\
15 \\
21 \\
11 \\
21\end{array}$ \\
\hline 0 & $\begin{array}{l}92 \\
12 \\
12 \\
\text { 20 }\end{array}$ & $\begin{array}{l}13 \\
8 \\
2 \\
2\end{array}$ & $\begin{array}{cc}3 \\
20 \\
3 \\
3 \\
3\end{array}$ & $\begin{array}{l}\text { \& } \\
\text { ये } \\
? \\
7\end{array}$ & $\begin{array}{l}10 \\
6 \\
9 \\
6 \\
25\end{array}$ & $\begin{array}{l}6 \\
6 \\
8 \\
3\end{array}$ & $\begin{array}{l}20 \\
20 \\
20\end{array}$ & $\begin{array}{l}3 \\
20 \\
20 \\
20\end{array}$ & $\begin{array}{ll}? & 1 \\
9 & \\
? & 1 \\
9 & 1\end{array}$ & $\begin{array}{l}13 \\
8 \\
6 \\
23 \\
17\end{array}$ & $\begin{array}{l}13 \\
99 \\
12 \\
13 \\
11\end{array}$ \\
\hline
\end{tabular}

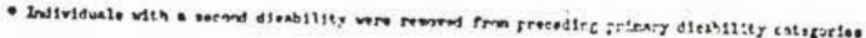


Tables (cont.)

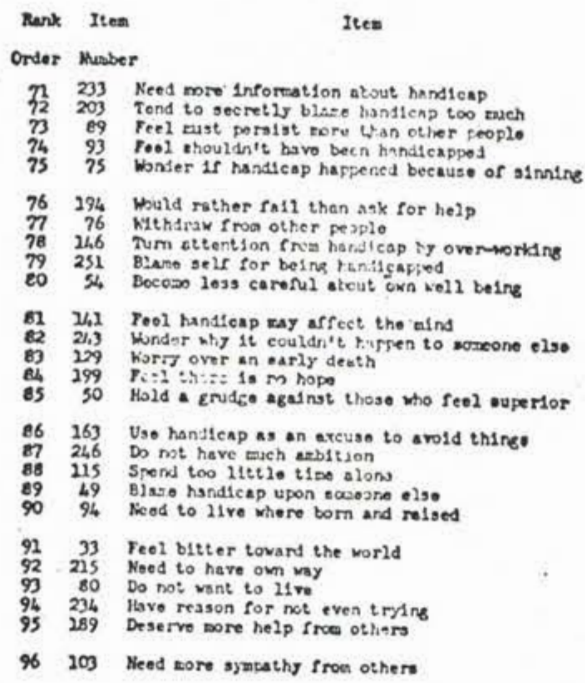

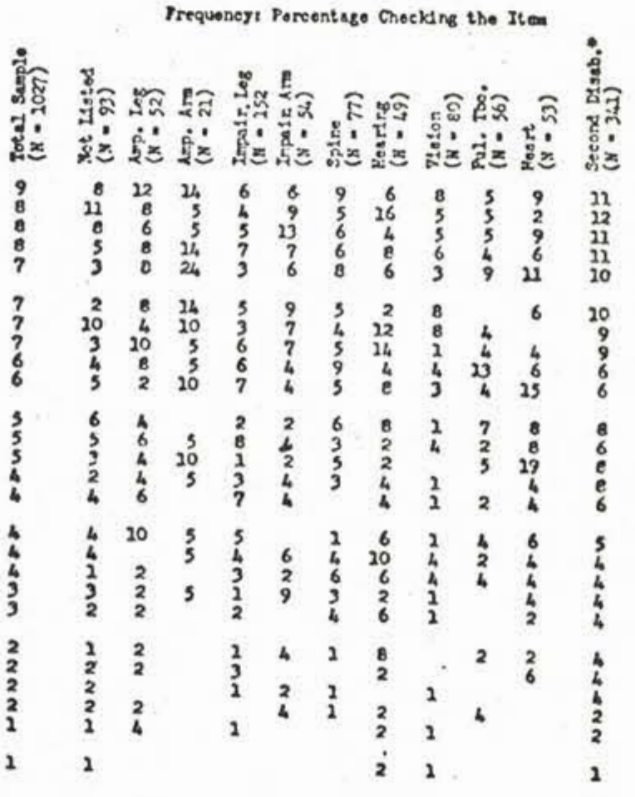


Tablo 6

Rank Onder of Far1ly Iters and Tho1r Froquencles

(by Total, Primarz and Socondary odsabluty Croupo)

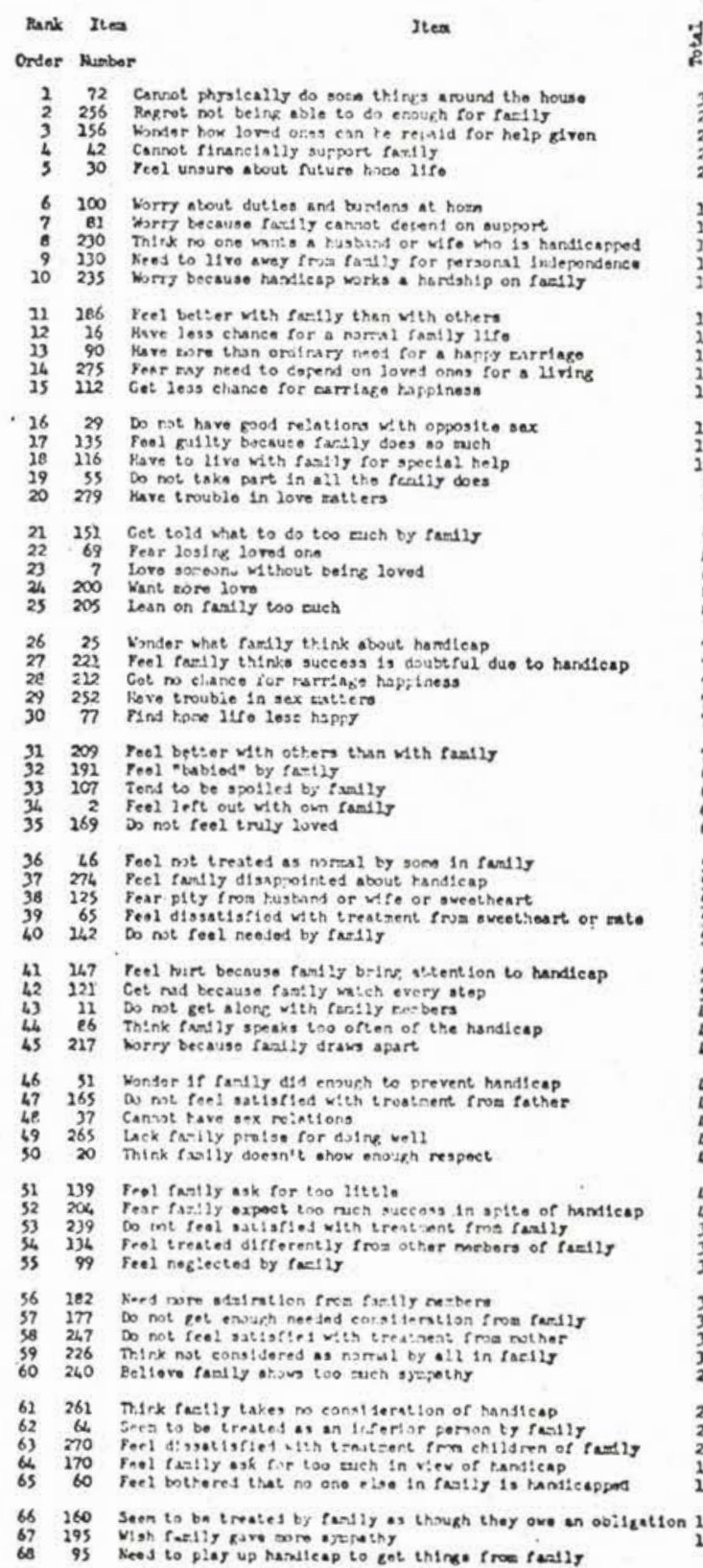

Irequencyt Percentago Checklrg the Itom

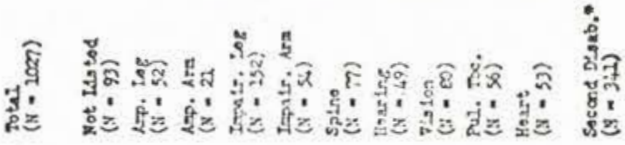

$\begin{array}{lllllllrllll}33 & 20 & 37 & 43 & 21 & 39 & 44 & 4 & 6 & 29 & 49 & 45\end{array}$

$\begin{array}{lllllllrllll}24 & 25 & 21 & 5 & 23 & 15 & 29 & 12 & 10 & 32 & 25 & 30 \\ 20 & 18 & 23 & 19 & 10 & 13 & 23 & 8 & 1 & 32 & 17 & 30\end{array}$

$\begin{array}{llllllrrrrr}18 & 23 & 19 & 10 & 13 & 23 & 8 & 1 & 32 & 17 & 30 \\ 25 & 29 & 5 & 16 & 11 & 21 & 18 & 9 & 29 & 25 & 25\end{array}$

$\begin{array}{rrrrrrrrrrr}8 & 27 & 5 & 11 & 12 & 18 & 6 & 9 & 16 & 21 & 20 \\ 10 & 27 & 5 & 3 & 13 & 18 & 6 & 4 & 27 & 17 & 21\end{array}$

$\begin{array}{lllllllllll}9 & 13 & 10 & 3 & 13 & 18 & 6 & 4 & 27 & 17 & 21 \\ 13 & 13 & 16 & 16 & 5 & 7 & 4 & 22\end{array}$

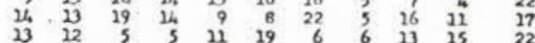

$\begin{array}{llrllllllll}11 & 8 & 10 & 6 & 13 & 10 & 24 & 6 & 14 & 8 & 21 \\ 14 & 8 & 5 & 7 & 4 & 17 & 8 & 2 & 9 & 8 & 22\end{array}$

$\begin{array}{rrrrrrrrrrr}14 & 15 & 5 & 7 & 4 & 17 & 8 & 1 & 9 & 8 & 22 \\ 6 & 10 & 14 & 12 & 13 & 8 & 10 & 8 & 11 & 15 & 16\end{array}$

$\begin{array}{rrrrrrrrrrr}10 & 17 & 10 & 7 & 4 & 13 & 8 & 6 & 14 & 19 & 16\end{array}$

$\begin{array}{rrrrrrrrrrr}10 & 10 & 5 & 7 & 7 & 6 & 8 & 10 & 2 & 4 & 19 \\ 9 & 8 & & 3 & 7 & 12 & 16 & 5 & 21 & 11 & 36\end{array}$

$\begin{array}{rrrrrrrrrrr}10 & 4 & 5 & 7 & 7 & 14 & 2 & 3 & 9 & 11 & 16 \\ 9 & 10 & 5 & 7 & 4 & 23 & 10 & 3 & 9 & 8 & 16 \\ 6 & 8 & 5 & 9 & 9 & 8 & 10 & 6 & 11 & 4 & 13\end{array}$

$\begin{array}{llllllllll}12 & 8 & 5 & 6 & 5 & 10 & 4 & 11 & 11 & 11\end{array}$

$\begin{array}{rrrrrrrrrrr}6 & 6 & 5 & 7 & 11 & 9 & 12 & 5 & 7 & 6 & 11 \\ 3 & 12 & 5 & 8 & 11 & 6 & 8 & 5 & 7 & 4 & 11 \\ 8 & 8 & 5 & 7 & 9 & 6 & 12 & 5 & 2 & 8 & 11 \\ 22 & 4 & 5 & 6 & 23 & 5 & 8 & 5 & 4 & 8 & 10\end{array}$

$\begin{array}{llllllllll}4 & 6 & 5 & 7 & 8 & 6 & 3 & 9 & 8 & 11\end{array}$

$\begin{array}{rrrrrrrrrrr}8 & 12 & 5 & 5 & 7 & 6 & 6 & 4 & 7 & 8 & 9 \\ 4 & 4 & 5 & 3 & 21 & 5 & 8 & 2 & 4 & 6 & 12 \\ 4 & 4 & 10 & 5 & & 9 & 4 & & 5 & 4 & 21 \\ 6 & 4 & 5 & 4 & 7 & 10 & - & 1 & 5 & 4 & 21\end{array}$

$\begin{array}{lllllllllll}8 & 10 & 5 & 7 & 7 & 4 & 22 & 4 & 4 & 4\end{array}$

$\begin{array}{rrrrrrrrrrr}6 & 4 & 10 & 5 & 9 & 5 & 8 & 5 & 4 & 11 & 7 \\ 9 & 2 & 5 & 3 & 9 & 4 & 8 & 3 & 9 & 11 & 8 \\ 8 & 6 & 5 & 5 & & 4 & 12 & 1 & 4 & 4 & 9 \\ 4 & 8 & 10 & 3 & 7 & 1 & 8 & 5 & 5 & & 9\end{array}$

$\begin{array}{rrrrrrrrrrr}11 & 4 & 5 & 1 & 4 & 3 & 4 & 6 & 2 & 6 & 8 \\ 4 & 10 & & 1 & 6 & 5 & 4 & 4 & 7 & 4 & 8 \\ 2 & 8 & 5 & 7 & 2 & 3 & 8 & 5 & 2 & 4 & 7 \\ 1 & 4 & 5 & 3 & 6 & 5 & 6 & 3 & 7 & 2 & 8 \\ 10 & 2 & 5 & 1 & 4 & 1 & 6 & 2 & 5 & 4 & 8\end{array}$

$\begin{array}{lllllllllll}4 & 2 & & 5 & 7 & 3 & 8 & 6 & 4 & 9 & 5 \\ 6 & 2 & 5 & 2 & 6 & 3 & 6 & 5 & 7 & 8 & 5\end{array}$

$\begin{array}{lllllllllll}3 & 2 & 10 & 3 & 4 & 2 & 6 & 5 & 7 & 8 & 4 \\ 8 & 2 & & 6 & 4 & 2 & 6 & 5 & 2 & 21 & 6 \\ 4 & 8 & 5 & 3 & 2 & 3 & 4 & 3 & 7 & 8 & 5\end{array}$

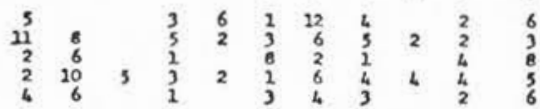

$\begin{array}{lllllllllll}2 & 2 & & 1 & 2 & 4 & 2 & 3 & 9 & & 6 \\ 2 & 2 & 5 & 2 & 2 & 1 & 4 & 1 & 5 & 2 & 6 \\ 4 & 4 & 5 & 1 & 2 & 1 & 4 & 3 & 5 & 2 & 5 \\ 4 & 4 & 5 & 1 & 2 & 1 & 2 & 2 & 4 & 8 & 5 \\ 2 & 10 & 30 & 3 & & 3 & 4 & & & & 4\end{array}$

$\begin{array}{lllllllllll}2 & 6 & & 3 & 2 & 2 & 6 & 3 & 2 & & 5 \\ 4 & 4 & & 3 & & & 4 & 2 & 2 & & 4 \\ 4 & & 5 & 2 & 4 & 2 & 4 & 3 & 4 & 4 & 3 \\ 4 & 2 & & 1 & & 3 & & 3 & 4 & 4 & 3 \\ 3 & 2 & & 2 & & 2 & 4 & 2 & 2 & 9 & 3\end{array}$

$\begin{array}{lllllllllll}3 & & 5 & 1 & 2 & & & 1 & 5 & 2 & 2 \\ 6 & 2 & 5 & 1 & 2 & & 2 & & 2 & 2 & 2 \\ 2 & 4 & & 1 & & 4 & 4 & & 2 & & 2 \\ 1 & 2 & & 1 & & & 4 & & 4 & & 2 \\ 1 & 2 & & & 2 & 1 & 2 & & 2 & & 1 \\ 1 & & & & & 2 & & & & & 2\end{array}$

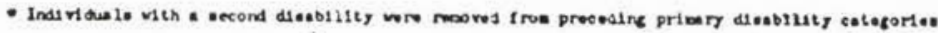


รable?

Rank Onfer of Soclel Itees axd thelr Prequencies

(by Totol, Primery and Secondery Dlasuluty Croupa)

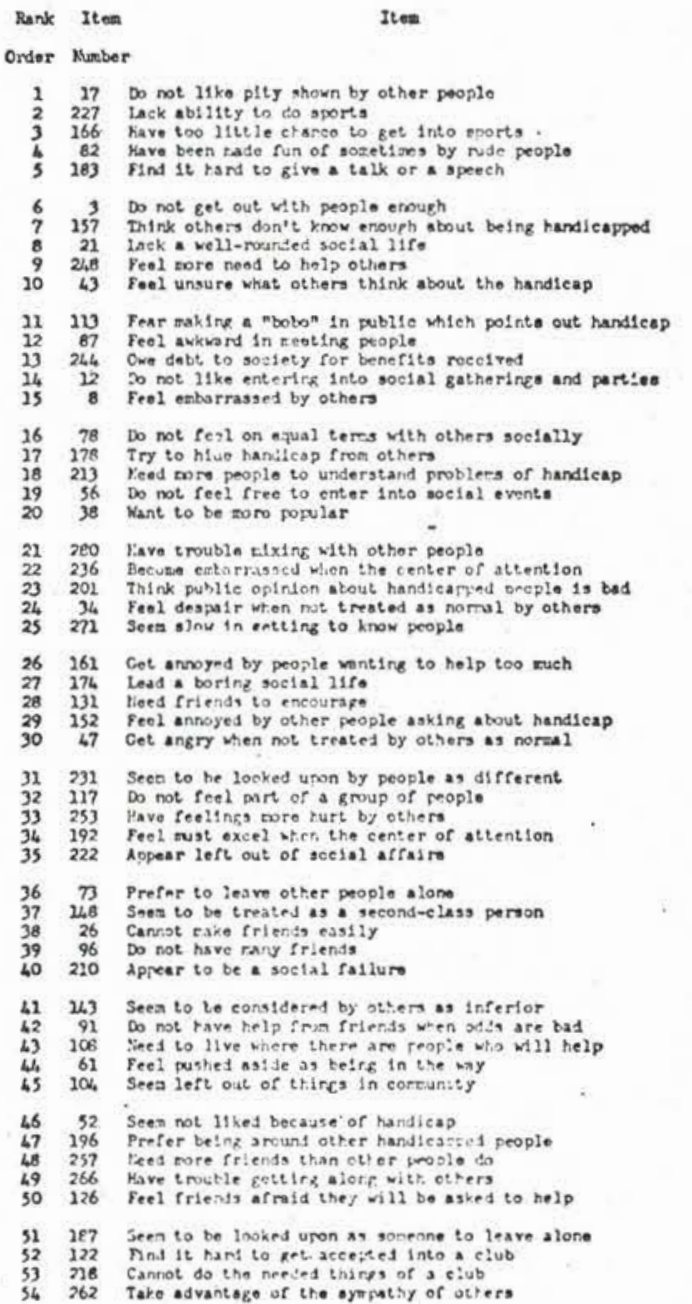

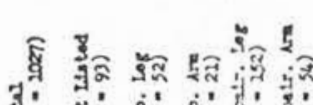

Frequemyt Poreort ece checking the Item

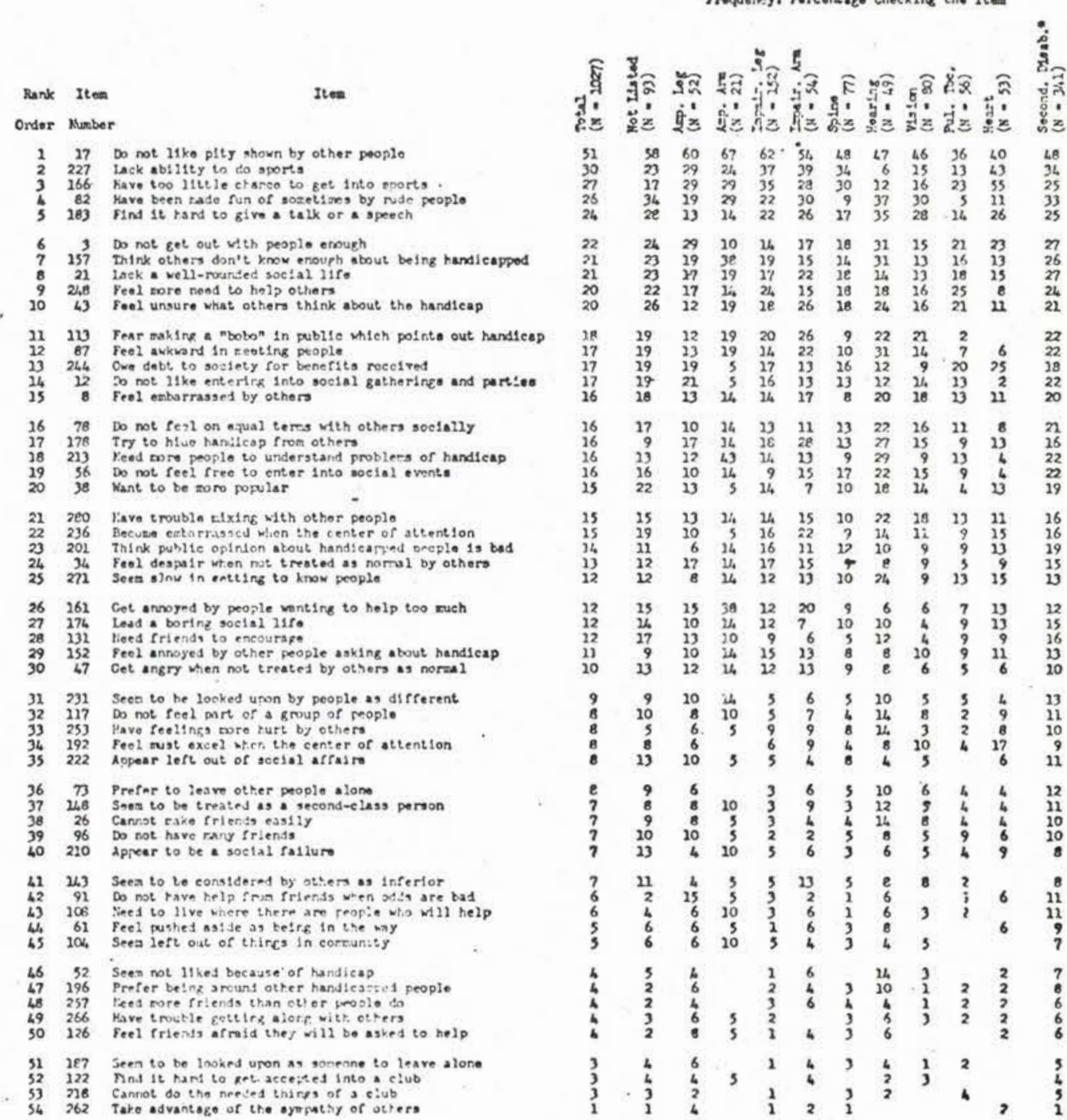

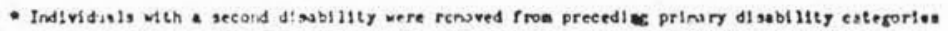


Tablo 8

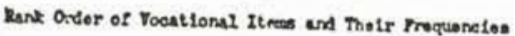

(by roul, Primary and Socontary Dianta 21ty Groups)

Prequencyi Porcentaze Choek1ng the Itea

Rank Itoe

Order Musber

228 Noed to got oxtra education for mitable Job

2149 Find sono jobs aro binjond phygloal abli1ty

13 Find two otrikeo acainat a hanslenppos parron fos hunting

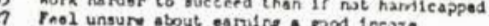

6263 Noed to get work eilled to phyoleal linits

$7205 \mathrm{Try}$ to eot decant job

8 172 Cannot be surs atout future work chances

10 57 Cot discouragnd becauso not fit for 411 vork

11275 Work hardor to provo handlesp is not Isportent

$32 \quad 253$ Horry about success in 21 re's work

2324,9 Noed help in riridine wik

15101 Dislike dopending on others at wrk

26284 Cannot do things an woll as ablo-bodled workere

1797 rind it hard to take a linlne.

28219 Feol unjustly turied domn for a job because of handicap

19 it loso confidence in work ahlisty

24 Craro suctess in work wore than othera do

21202 Wrrs about gotting a bettor job

22 272 Miss out on getting outtablo wotk dus to handieap

2374 Koed to get an oasy job

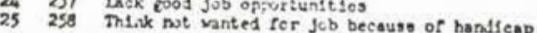

26254 Want work whore handleap vil1 be loss noticed

27 Teer job fallure die to handicap

232 Koed to misk iardar in order to keep up

30116 Awold jobs mich are mate hand by the hanticap

31228 Cannot apply full erount of knowledge and telent

3239 Tear loss of ability to vork

33127 Try harder to plesen "bosg"

35192 Cet low vages bezause of handleap

36245 Have mo chance to prove job abluty

3770 Rejul re change of job plans

38279 Mavn to take $1 \mathrm{t}$ eagy at work breause of handicap

3935 Fear losing Job to one who den't handicapred

Sace proverted by handicap froe eattire ahead in career

$42 \quad 193$ Worry becauge soce others are dolng botler work

320 thick inserior stien others do a better job

31 Thirk others dislike vorkite with a handicapred person

45 6o Prefer work with o:her handicarped peoplo

4622 Rozulro special privilegns on the job

47276 Lack opirit to kees tryire for a good job

Le 83 seen to be expected to vork too rard

29 214 Do not like present job

51 es Cannot feel irmrtant in present job

53 Hold no chnnco of rakine prod in $11 \mathrm{f}_{0}$ 's mork

55 109 Need relp of fellow meknrs

56123 Carnot sake up for work 1Latuation

57 is Fel terptel to usn handicap to eake work easter

3679 Fear boro tib dity

39223 knod nuro csnsideration fros follow workere

Use handicap as an excuse for nut gotting work

61262 Tend to one manilicap as an excuse to be lazy at work

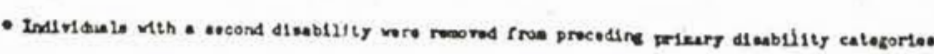

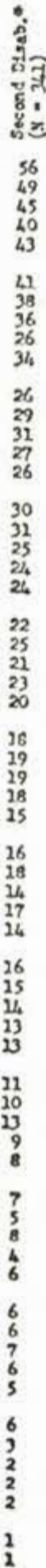




\section{SCORING}

For hand scoring items have been arranged so that a single hand scoring template for each of the four sub. tests can be applied to the four separate pages of the test, i.e., the first item of pages one, two, three and four is a personal subtest item; the second item on every page is a family item; eic. (The one exception is that the-last item on pages one and two is vocational and on pagers

- three and four is social.) This scoring order facilitates ease in hand scoring. Items were placed successively into these scoring positions according to their original random order, the exception being item one which was arbitrerily placed in that position for subjective reasons.

Use of four scoring templates-one for each of the four areas-70 items long, provides the raw scores. Raw scores for the four areas are quickly converted to percentile scores by referral to the table of percentile norms, Table 4. "Total test" scores should not be used as they cannot give the valuable differentisl information contained in area scores and do not have computed reliability coefficients.

\section{INTERPRETATION}

The higher the percentile score in each separate area, the greater the indication of impact of the disability in that area. Psychological meaning of the area scores is demonstrated by the high internal consistency of the four separate areas. Althouph these areas are accurately defined by the terms personal, family, social and vocational (as established statistirally by agroement of judges who categorized itcms on the sole basis of these four terms), users of the test may obtain more definitive understanding of the four terms by reading through items in each of the areas. Items in each area are listed in Tables 5 to 8 along with average scorcs. for several disability groups.

Area scores indicate which life situations bear the brunt of the greatest impact of the disablement. A relatively high number of family type problens, for example, would be the counselor's clue that special attention should be given to the adjustment situation in that area.

On the other hand, it does not necessarily follow that only high scores are to be inspected for adjustment dif. feulties. The tendencies to either exagkerate or to minimize one's handicap have been pointed out. Then, too, people vary as to how big the problem seems before checking it. The level of score should be confirmed by other sources of infurmation about the person. Inconsistencies-either unexpectedly hich or low score areasare especially illuminating and warrant further investiga. tion. Assistance in identifving or rutionalizing inconsistencies may also be oltained by inspecting the tables of mean scores for various orfanismic variables isee "Demonatrated Relationships" and Th!le 3).

Study of individual provicats ciecined also pives the counselor valuable information. The intensity with which the problem is felt must, of course, be determined by per. sonal discussion. Frequently the client reveals problems in the impersonal setting of the H.P.I. that he would not bring up in personal conversation. Naturally the systematic method of inquiring sbout 280 common disability related problems is a highly efficient and thorough covernge.

The client may reveal a problem that would never occur to the counselor to explore. For example, a young epileptic man checked item 129, "Worry over an early death." Thus identified, this important source of anxicty could be removed by the counselor's explaining that epilepsy does not cause death.

The counsclor should look over individual items checked and plan his interview accordingly. As indicated before, the typical defense mechanism employed or other person. ality cues may be suggested by the pattern of the items checked.

The counselor must be particularly sensitive to items and to areas which are not cheched due to a desire to cover up serious problems. Avoidnnce of known problems or problern areas suggests the posvilility of intense cmotional feelings which must be handled with great caution. Only counsclors well treined in clinical psychology should attempt to probe into such defenses. Otherwise it is best to limit discussion to those problems which the client is ready to scknowledge.

Tables 5, 6, 7, and 8 list the frequency of response by cach of several kinds of disability-groups for each individual problem. The counsclor may wish to refer to these tables to learn whether any particular problem checked by his client is one which is commonly experienced by those of his disability group.

Just the act of thinking about and verbalizing his prob. lems in taking and discussing the H.P.I. has direct value to the disabled person. Sudden insights are not uncom. mon. It may be the first time the client has nllowed him. self to admit the cxistence of the dificulty. Stating the problem is, of course, the first step in arriving at a solution. It also provides a natural way to get the interview started. People are usually willing to discuss the checked problems.

\section{SUCGESTED RESEARCH}

Many new areas of research are opened up by the publication of the II.P.I. A few suggestions for such study are mentioned below:

1. The relationship between H.P.I. item or area scores and personality adjustment.

2. The predictive validity of H.P.I. scores in reference to the success or failure of rehabilitation outcomes.

3. The concurrent validity of H.P.I. scores in terms of outside criteria such as rating scale judgments.

6. Niethuds and effectiveness of usc of II.P.I. in the counseling function. 
5. Dynamics of the mechanisms of denial and exaggera. tion of disability.

6. Groups of disabled not included in studies to date, viz. blind, emotionally disturlicd, younger and older age groups, clients of other agnencies serving the disabled and other segments of the handicapped population.

7. Effectiveness of various types of rehabilitation serv. ices in reducing problems (by retest procedures).

8. Stability (reliability) of H.P.I. scores by test-retest methods.

9. The relationship of II.P.I. scores to variables not yet studied, e.g., degrec of impairment, intelligence, personality test scores, etc.
10. Underlying reasons for relationship thus far demonstrated.

11. Empathy with the disabled person by his family, counselor and others through dual administration of the H.P.I.

12. Factor analytic study.

Special pricing considerations are given those who wish to use the H.P.I. in connection with research and are willing to make results available for publication. Applications should be addressed to:

The Purdue Research Foundation, Lafayette, Indiana. 


\section{HANDICAF PRORIEMS INVENTORY}

\section{Instructions:}

This is a list of difficulties reported by physically handicapped people. Your responses to this list will enahle us to hetter visualize the problems you feel result from your child's disability. By giving us a better picture of how you feel your child's disahility bothers him, something may be done about them. Your answers will be confidential. Some of the items were written for older individuals than your child may be. Answer thern anyway as to how you expect they may or may not affect him in the future.

Mark with a soft nencil the snace between the vertical lines all problems which you internret as caused by, added to, or related to your child's disability. Skin over, do not mark, those problems which your child does not have or which you feel have nothing to do with his being handicapped. The way you feel is the "right" or best answer.

Your Gender: $\quad M \quad F$

Your Child's Gender: M F 


\title{
HANDICAP PROBLEMS INVENTORY
}

\author{
GEORGE N. WIRIGHT and H. H. REMMERS
}

INSTIUCTIONS: With a soft pencil, blacken the space between the vertical lines, in back of all problems caused by or added to by your disability. Skip over, do not mark, those problems which you do not have or which you feel have nothing to do with being handicapped. The way you truly feel is the "right" or best anawer. As you read through the Handicap l'roblems Inventory mark between the two lines (il) after the items which have something to
do with your handicap.
1. Feel discouraged more easily
2. Feel left out with own family
3. Do not get out with people enough
4. Lose confidence in work abllity
5. Do not like beink around other handirajped people
6. Yoel more need for relligion because of handicap
7. Love someone without being loved
8. Feel embarraased by others
9. Do not apply welf at work
10. Peel wothered because people do needless things to belp
11. Do not get along with family memlers:

12. Do not like entering into soclal catherings and parties

18. Find two strikes arsinst a handicapped person job hunung

14. Find trouble in accepting handicap

15. Want to be normal

16. Hare less chance for a normal family life

17. Do not like plty abown by other people

18. Need to get extra education for uitable job

19. IIave trouble in finding happines:

20. Think family doesn't nhow enough reosect

81. Lack a well-rounded social lifo

22. Require special privileges on the job

23. Feel inferior
24. Feel unhappy

25. Wonder what family think about handicap

26. Cannot tunke friendo easily

27. Yeel unsure about earning a good inconio

28. Feel emhinrranad by experiences caused by the handieap

29. Do nut have good relations with opposite sex

30. Fecl unsure about futuro bome life

s1. Think othern dislike working with a

32. Think about not being oqual to normals

23. Feel bitler toward the world

34. Feel despair wben not troald as normal by others

85. Fear losing fob to one who isn't

36. Fear having more handicap later

37. Cennot have sex relations

38. Want to be more popular

39. Fear loss of ability to work

40. Find it is harder to face tife

41. Feel it better to suffer in silence

42. Cannot fnancislly support famils

43. Feel unsure what others think about the landicap

41. Find follow workers take advantenge of handicapped peoplo

45. Worry about overeoming handicap 46. Frel not trented as normal by nome
47. Get ankry when not treated by others as normn!

48. Fold no chnnce of making good in life's work

49. Blame hondicap upon someone the

50. Hold a grudge against those who feel superior

61. Wonder if family did enough to prevent handicap

82. Seem not liked becaure of handicap

63. Work harder to succeed than if not handicapped

54. Become leas careful about own well

65. Do not lake part in all the famlly does

58. Do not feel free to enter Into socin| oventa 87. Get dincourn cod because not at for

\footnotetext{
63. Envy people who aren't handicapped |

s9. Got wo little chance for bobblet and pastimes

60. Feel bothered that no one eloe in family is handicapped

61. Feel pushed aside as being in the way

62. Fear baving to take up. "pantandling" (begring)

63. Waat to talk about the handicap

C4. Snem to be treated as an Inforior person by inmily

65. Peel dinnatlafied with treatment from aweetheart or mate

66. Prefer work with otber handicapped people

67. Need to find substitute foys and pleasurea

68. Feel comforted by fact that some handicaps are worse

69. Fear losing luved one

70. Roquire change of job plans
} 

71. Prefer not to discuss handieap with
others

72. Cannot physically do wome thing: around the house

73. Prefer to leave other people alone

74. Need to get an easy fob

78. Wonder if handicap happened becaves of ainning

7a. Withdraw from other people

77. Find bome life leas beppy

78. Do not foel on equal terms with others occially

79. Fear mare fob duty

80. Do bot want to live

81. Worry because family eannot depend on support

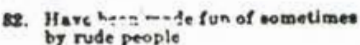
83. Seem to be expected to work too
hard

34. Try to forzet about being bandicapped

85. Heve ambitions too Migh for condition 86. Think family opeaks too often of the
handicap

87. Feel awkward in meeting people

88. Cannot feel important in present job

89. Feet must persist more than other peoplo

90. Have more than ordinary need for a happy marriage

91: Do not have help from friends when odda are bad

92. Get low wagres because of handicap

93. Feel shouldn't have been handicapped
94. Need to live where born and raised

95. Need to play up handieap to get things (rum family

96. Do not have many friends

97. Find it hard to make a living

98. Feel different from others

09. Feel negleeted by famlly

100. Worry about duties and burdens at

101. Dislike depending on others at work

102. Have coneern about security in later

103. Need more aympathy from others

104. Seem left out of things in eommunity

\section{Try to get dreent fob}

106. Peel it important to do work the bandicap makes dimeult

107. Tend to be spoiled by family

108. Nined in live where there are people who will help

109. Need belp of fellow workers

110. Feel lonesome because of handicap

112. Fiet less chance for marriage happiness

113. Fear making a "bobble" in public which points out handicap

114. Feel job nbility is overlooked

115. Spend too littio time alone

116. Have to live with family for speciai
117. Do not feel part of a group of people

118. Avoid fobs wliteh are made hard by the handicap

119. Prefer othera don't know about handicap

120. Want hopelessly to overeome or srow out uf hatidicap

121. Giet mad becautr fanilg wateh every atep

122. Find it hard to set accepted into a club

123. Cannot make up for wurk limilations

124. Try to hide handicap

125. Fear pity from husbend or wife or sweethenrt

126. Feel friends afraid they will be asked to heip

127. Try harder to pleane "hoos"

128. Deydream about what might have been

129. Worry over an early death peraonal independence

131. Need friends to encourage

132. Try to work beyond a bility

133. Seem unable to admit certain things can't be done

134. Feel trealed differently from other members of family

136. Feel guilty berause family does so

136. Think "boss" should make work easier

137. Feel anhamed to ask for help when needed

138. Fear not getting anywhere in lifo

139. Feel family ask for too little

140. Think must hold own at work with 


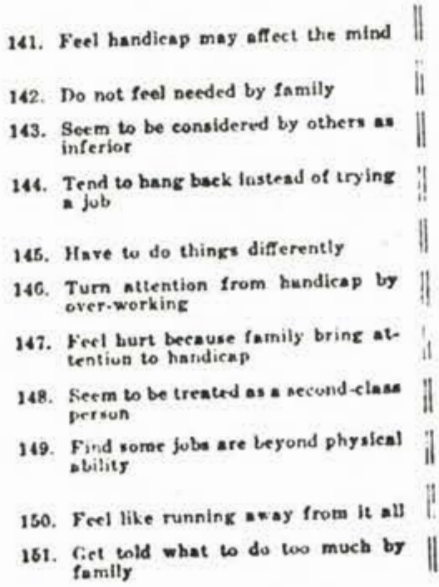
152. Ferl annoyed by other people

133. Worry about success in life's work

164. Lark will power (ability to stick.

165. Fear not being wanted around

136. Wander how loved ones can be repaid for help given

157. Think others don't know enougb about being handicapped

158. Foel templed to use handicap to make work easier 169. Feel bothered by thoughts about if
handicap

160. Scem to be treated by family as though they owe an obligation 161. Get annoyed by people wanting to
help too much 162. Tend to use bandicap as an exeuse
to be laxy at work 163. Use handicap as an excuse to avoid
things
164. Worny about personal appearance

1C5. Do not feel satisfied with treatment from father

166. Have too little chance to get into sports

107. Want to prove grealer ability on tho job

168. Face extre hardshlys

169. Do not feel truly loved 170. Feet family ask for wo much in view
of handicap

171. Cannot be zure about future work chances

172. Feel more conscious of self (celf-eonscious)

173. Do not like beine center of attraction

174. Load a boring social life

175. Work harder to prove handicep is not important

176. Tend to hang beck

177. Do not ret enoukt needed consideration from family

178. Try to bide handicap from othera

179. Have to take it eary at wurk because of handicap

180. Thalike baving a different way of life

181. Have mnte ambition because cf bandicap

182. Need more admiration from inmily menbers

183. Find it hard to give a talk or a speech

184. Cannot do things as well as able-bodied worker

185. Wonder why fate cauned it 186. Feel better with family than with
others
187. Seem to bo looked upon an someone to leave alone

188. Fear job fallure due to handicap

189. Deserve more belp from others

190. Find it hard to take care of versonal needs

191. Feel "babied" by familly

192. Feel must excel when the center of attention

193. Worry because some others are doing betler work

194. Would rather fall than ask for belp

195. Wish family gave more sympathy

196. Frefer being aruund other handicapped people

197. Use handicap as an excuse for not getung work

205. Feel III at eane

199. Feel there is no hope

200. Want mors love

201. Think public opinion about handicapped people ia bad

202. Worry about getting a betler job

203. Tend to secretly blame handicap too Year family expect wo much success
in ipite of handicap

205. Lean on family too mueb

206. Feel inferior when otbers do a bether job

207. Need to feel of more ralue

208. Have personal feelinga burt easily 209. Feel better with others than with

210. A ppear to be a social failure 


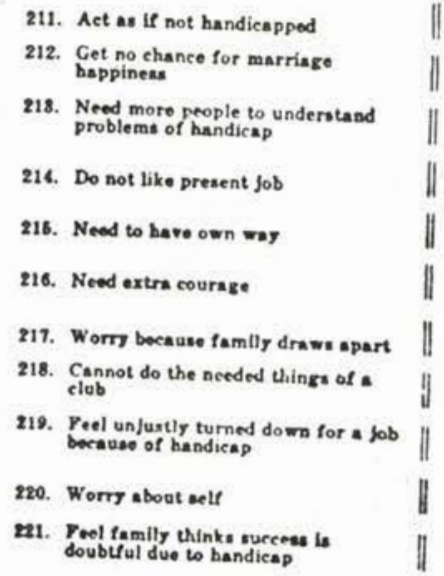

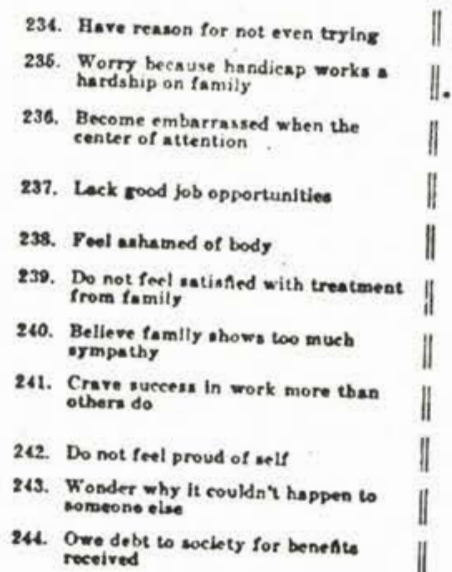

234. Have reason for not even trying 235. Worry because handicap works a
hardship on family

236. Become embarrassed when the center of attention

237. Leck rood fob opportunitiee

238. Fool ashated of body

239. Do not feel satinfied with treatment
from fomily

240. Belleve famlly thows too much ermpachy 241. Crave success in work more tban
others do

212. Do not feel proud of self

243. Wonder why it couldn't happen to nomeono else 244. Owe debt to society for benente
roceived

\footnotetext{
222. Appear left out of social aff atrs 228. Nned more conalderation from
fellow worken

224. Fear other people watching

225. Daydream about doing big thine a bero

226. Think not considered ao normal by all in family

227. Lack ability wo do sports

228. Cannot apply full amount of knowledge and talent

229. Do atill mina thinge which bandicap preventa

230. Think no one wants a hunbend or wife who is handicapped

231. Seem to be looked upon by people as different

232. Nieed to work harder in order to keep up

233. Need more information about handieap
}

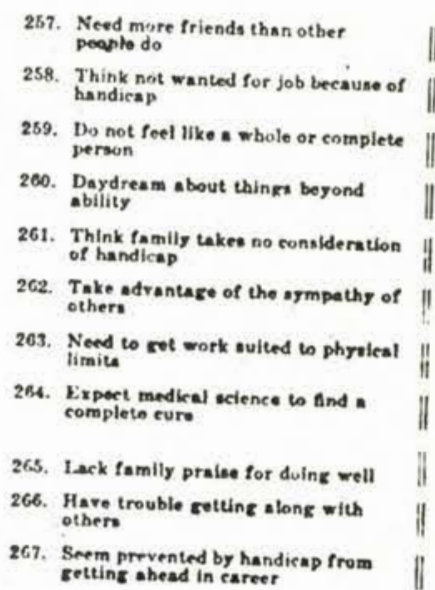

267. Seem prevented by handicap from getting ahead in eareer
245. Have no chance lo prove fob ability
246. Do not have much ambition
247. Do not feel satisfied with treatment from mother
248. Feol more need to help others
249. Neod help in Anding work 250. Cannot accept fact that handicap is
permanent
251. Blame self for being bandicapped
252. Have trouble in sex matters
263. Have feelings more burt by others 254. Want work where handicap will bo 255. Need to show ability to do al much
as others
256. Regret not being able to do enough
for family
268. Tend to foel worty for melf
269. Have to neem ehoerful
270: Feel dissatiafed with treatment from children of family
271. Seem slow in getting to know people
272. Miss out on retting sultable work due to handicap
273. Feel unsure of sels
274. Frel family dianppointed abou handicap
275. Fear may need to depend on loved ones for a living
278. Lack opirit to keep trying for a grood job
277. Do not une leisure (spare) time fully
278. Seem more nervous
279. Have trouble in love matters
280. Have trouble mixing with other people


APPENDIX F

Letters of Introduction And Contract 


\section{GDQD $\stackrel{+}{+}$ SAMARITAN}

Children's Clinic

Dear

Good Samaritan Hospital and liedical Center, Epilensy League of Oremon, Oregon Mental Health Division, and Multnomah County have, in one capacity or another, pranted funds to be used in developing an effective educational experience for preschool children who are experiencing some degree of developmental difficulty because of neurological impairment. The program will be administered by Good Samaritan Hospital Children's Clinic for Neurolorically Impaired Children.

The preschool prorram is planned to provide selected children with many positive, encouragino school experiences. It is intended to produce sionificant development in the areas of academic, social and. emotional srowth. The basic annroach includes individualized academic instruction and a well-nlanned irtensive period of intervention designed to promote appropriate behavior. An effective program is possible when parents become interested and active participants in the work done wi.th their child.

has been recommended by Mrs. Jill West, M. Id., as a child who micht benefit from our orogram. We would like to make this opportunity available and solicit your cooperation in attendins required conferences and group neetings. Because the parents' influence is considered so important to a child's progress, unsatisfactory parental involvement in this program may make continuation of the child's classroom enrollment impossible.

Your signature on this letter indicates consent for your child's' participation in the preschool prorram and your willingness to cooperate with the staff. Please call if you wish further clarification.

$$
\text { Sincerely, }
$$

Tames R. Schimschock, M.D. iroject Director 


\section{GOLD+ + 4 HDSPITAL \& MEDICAL CENTER}

Children's Clinic

PARENT GROUP CONTRACT

The Children's Clinic staff strongly believes that both the preschool and the family must cooperate in helping children who are havino developmental difficulties. The Cheldren's Clinic staff feels that without such cooperation their chances of successfully working with a child are small. Therefore, in addition to scheduled individual conferences, it is required that parents attend a parent discussion group which will meet every Wednesday evening beginning October 4 , 1972, from 7:00 to 3:30 n.m. in the Cafeteria Conference Room, on the third floor of the main building at Good Samaritan Hospital.

Parent attendance is required for the first six sessions and a re-evaluation session at a two month interval from the date of the sixth session. At the end of the sixth session, the parent(s) has the option of taking part in a second group or withdrawing from the group.

If a child's parent(s) fails to attend two consecutive group meetings without calling the Children's Clinic secretary, Sandy Withrow, at 229-7220, their child may be withdrawn from the preschool program. The child can then be readmitted only after the parent(s) schedule a conference with a Clinic staff member and begin attending group meetings.

Date

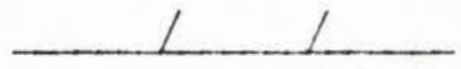

Simned

Parent

Simned

Group Facilitator 


\section{GDOD+5AMARITAN HOSPITAL \& MEDICAL CENTER}

Children's Clinic

NOTIFICATION OF THE RESEARCH IMPLICATIONS

OF THE PARENTS' DISCUSSION GROUP

I consent to participate in the Parents' Discussion Group as a member of the research population described in "The Research Aspects of the Children's Clinic Parents' Discussion Group."

Date

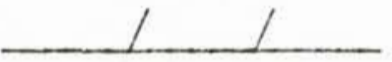

Signed

Date Signed

I consent to participate in the Parents' Discussion Group but not as a member of the research population described in "The Research Aspects of the Children's. Clinic Parents' Discussion Group."

Date

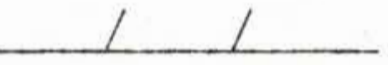

Date

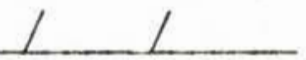

Signed

Signed 


\title{
PARENT DISCUSSION GROUPS
}

Planning For Cooperation Between Parent And Child

An Experimental Research Project With The Focus of Discovering And Discussing Some Of The Difficulties In Parenting A Child With A Seizure Disorder

\section{Sponsored By}

Good Samaritan Hospital \& Medical Center

\author{
Children's Clinic \\ For \\ Neurologically Impaired Children \\ James R. Schimschock, M.D. \\ Program Director
}


INTRODUCTION

New experiences, especially new group experiences, create anxious moment's for many people. In a majority of cases this expectational anxiety can be overcome, in varying degrees, if the particlpants are aware of what the new experience has to offer. In response to this supposition, the following information is available on our plans for Parent Discussion Groups, held in conjunction with the preschool program at the Children's Clinic. Many of the ideas and statements recorded below have been extracted from two resource books. 1,2

WHY PARENT DISCUSSION GROUPS?

Preschool education is an extension of parental care. The preschool years, so important for the development of a child's personality, demand from parents considerable skill and understanding. Inasmuch as the preschool child needs opportunity for free play, skilled help and contact with other children, he also needs parents who are secure in their knowledge and their feelings of adequacy to face and cope with the unique problems he presents. It is the feeling

${ }^{1}$ Auerbach, Aline B., Parents Learn Through Discussion: Principles And Practices of Parent Group Education, The Child Study Association Of America (New Yorki John Wiley and Sons, Inc.), 1968.

2Stern, H. H., "Parent Education: An International Survey," The Journal of The Institute of Education (Hamburg, Germany: The University of Hull And The UNESCO Institute For Education), 1960. 
of our staff that these two demands can be reconciled in the Pre-School program at the Children's Clinic.

We are committed to a close cooperation with the parents. We realize that in spite of all the external educational resources available to a family, the immediate and most potent educational area in any family is still parents. Our program, like any other system of education, is powerless in the face of parental indifference, opposition or serious and unreconcllable divergence of opinion. We need your commitment!

\section{WHAT IS A PARENT DISCUSSION GROUP?}

A parent discussion group, only one of many kinds of group educational services for parents, aims to help parentss

1. Become more familiar with basic concepts of child growth and development and parent-childfamily interaction from a dynamic point of view as well as problems specifically related to raising a child with seizures.

2. Recognize some of the crisis points in different stages of child development.

3. Learn to approach problems and situations with new skills and discrimination.

4. Gain a better understanding of the complexities of their everyday situations so that they will have a broader background against which to make choices.

In short, a parents' discussion group involves the exchange of concepts, personal knowledge, feelings, opinions, attitudes, emotions and skills which contribute to the physical, emotional and mental 
health of participant parents as well as their children.

A parents' discussion group, as an integral part of the preschool program, is conceived as being an exchange of help, ideas and information between parent participants, between parents and clinic staff and between clinic staff members, rather than as an opportunity for a one-way, formal instruction given by the staff and recelved by parents. In summary, this is an opportunity for every participant to teach others as well as learn from others.

WHAT CAN THE DISCUSSION GROUP ACCOMPLISH?

Parents learning from the experiences of other parents with children who have similar problems gives each group member a broader base of information which can serve as a background against which they can look at their own children and themselves. Hopefully, the group experience can assist parentsi

1. To a better understanding of their children's needs at different stages of their growth, recognizing their basic similarities, yet appreciating the individual differences that make each child a unique person with his own constitutional make-up, his own rate of growth, his own wishes and his own drives, hopefully erasing misconceptions about epilepsy and child rearing.

2. To examine what they expect of themselves as parents and how their goals have been influenced by their earlier experiences, their social and economic environment, and previous knowledge about children and family life.

3. Gain further knowledge of the interaction that takes place between parent and child, sibling and child, child and the total family by selfassessment of their own attitudes and practices 
not as "good" or "bad" but dynamically in terms of what is actually happening.

4. Appreciate the many influences on their child and on themselves as parents by using new insights to sort out the particular influences to which they are responding, and thus to understand their significance and learn to deal with them.

5. Develop a realization that other parents have similar problems in child rearing.

WHAT THE GROUP CANNOT ACCOMPLISH,

Even with specific recommendational input from participants, this group cannot function to give explicit help in solving individual problems. Parents and staff members may, however, realize a need for individual professional intervention, outside of the group experience, and these services will be available through the Clinic on a consultant basis. These consultant services include, but are not limited to, psychiatric, psychological, social work, educational and medical assistance. 
The Specifics of the Children's Clinic

Parents' D1scussion Group

\section{GUIDELINES FOR GROUP PARTICIPATION:}

1. Each participant will be required to commit himself to attending the first six sessions of the parent discussion group by signing the contract of commitment. The meetings will be held in accordance with the information presented in the letter of invitation to the program.

2. The group will not be presented with any set curriculum but will develop its own "agenda" in relation to seizures during the first group meeting and as each session progresses.

3. Because of the wide differences in individuals, there will be no pressure on an individual member to move into the discussion any faster than he is prepared to or to come to any set conclusions. Rather, participants are encouraged to expand their horizons at their own rate of speed; free to pick up what they feel is meaningful.

4. At no time will there be any pressure toward group concensus or conformity; on the contrary, each member is encouraged to come to his own decisions. An open exchange of related experiences and opinions is encouraged, as well as careful listening to the comments of other group members.

5. When possible, members are encouraged to be specific when they pose their questions or concerns and to describe in some detall the immediate occurrences which brought the issues to the fore.

6. This experience can be as much of an emotional experience as it is an intellectual one. Expression of feelings are encouraged, not just for their own sake in a vacuum, but in relation to the substance of parent-child relationships and family living.

Parents as well as professionals have a wealth of materlal that 
can be put "on the table" for discussion. Parents will be encouraged to respond freely to one another, questioning, observing, explaining, agreeing, adding, commenting, disagreeing as they examine their own ideas and convictions and progressively assume new positions for themselves. Hopefully, there will be an exchange of information by group members and/or the contribution of additional information by outside sources.

WHO MAKES UP THE DISCUSSION GROUP?

The group will be comprised of the parents whose children are enrolled in Good Samaritan Hospital and Medical Center Children's Clinic preschool program. There will be nine couples who will meet with a neurologist, special educator, psychologist, social worker, or other specialists as requested. At one time or another, each of these consultants will co-facilitate (lead) the group discussions.

\section{WHAT ARE THE GOALS?}

1. To help parents better deal with their child's seizure disorder.

2. To help parents feel more comfortable with their child who has seizures.

3. To help parents better understand and deal more effectively with their child's:
a. Needs
b. Level of functioning
c. Potential
d. Limitations
e. Future

4. To allow parents a secure environment in which to talk 
about their own needs and feelings which may contribute to prejudicial misunderstandings about their child.

5. To help parents gain a better understanding of their own strengths and how to benefit from these.

6. To give parents an opportunity to express their feelings in relation to the handling of selzures.

7. To help parents better understand themselves and other parents within the group.

8. Provide an opportunity for parents to obtain accurate information relating to epilepsy and child rearing.

WHAT WILL BE EXPECTED OF THE PARENTS?

1. To share experiences, insights, and problems of their child and family.

2. Make an effort to talk about the things that concern them the most (fears, suspicions, worries, embarrassment, etc.).

3. To be willing to listen to the others.

4. To be honest and become involved.

5. To keep all discussion of the group confidential and show respect for others in the group.

6. To be to the group meetings on time.

\section{IS THE PARENT DISCUSSION GROUP MANDATORY?}

Yes, and all invited parents are encouraged to participate. The Parents' Group is part of the educational curriculum being offered your child when he is enrolled in the preschool program, and attendance at the Parents' Discussion Group can possibly aid your child's development in the classroom and at home. 


\section{TOPICS FOR DISCUSSION:}

The agenda for discussion is open for parental input. While the topics for discussion are not yet determined, hopefully some of the topics will center around the discussion of seizures. The major focus of the group, however, will be dependent upon parental interest and active participation. 
The Research Aspects of the

Parents' Discussion Group

As with most programs funded by public and/or private grants of monies, an accounting for program expenditures is required. The accounting requirement for the Children's Clinic is met in two ways:

1. Through financial statements

2. Through research findings

The research requirements of the Children's Clinic encompasses two major areas. These areas are the collection of numerical data on its patients and programs, and the development of new programs. One of the Children's Clinic's responses to these requirements is the funding and evaluation of the Parents' Discussion Group. 
The Children's Clinic research committee that developed and will evaluate the Parents' Discussion Group is composed as follows:

Research Committee Coordinator James R. Schimschock, M.D. Program Director, Children's Clinic Good Samaritan Hospital

Statistical Consultant \begin{tabular}{|c|}
\hline Quentin D. Clarkson, Ph.D. \\
Faculty Consultant \\
Graduate School of Social Work \\
Portland State University
\end{tabular}
Research Advisor Mrs. June Dunn, M.S.W. Faculty Advisor Graduate School of Social Work Portland State University

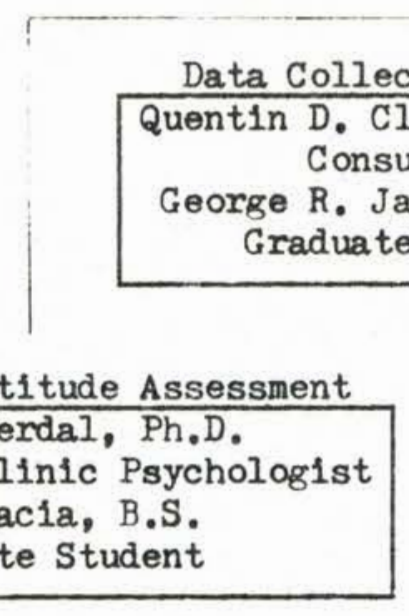

Parental Attitude Assessment

$$
\text { Llef Terdal, Ph.D. }
$$

Consultant Clinic Psychologist

J oan Sacia, B.S.

Graduate Student
Parents' Discussion Group

Russell Jackson, Ph.D. Consultant Clinic Psychologist Grant Kane, B.A. Graduate Student

\section{SPONSORS,}

The primary sponsoring agency for this research is the Good Samaritan Hospital and Medical Center Children's Clinic for Neurologically Impaired Children. Additional sponsoring agencies are the Epilepsy League of Oregon, and Portland State University. 
OBJECTIVES:

The proposed research by this committee has two major objectives:

1. To obtain information for future program development concerning parental expectations, needs, and interpretations of parenting a child, in terms of their child's selzure activity.

2. To fulfill the research requirements for three members of the committee for their Masters Degrees in Social Work, Graduate School of Social Work, Portland State University.

\section{PARTICIPANT PROTECTION:}

Before continuing with a detailed description of your involvement in the research aspects of the Parents' Discussion Group, let us explain the protections of anonymity and confidentiality we assure each participant member in the group and their families.

All research findings, including numerical data which is part of the ongoing clinic reporting system, will not divulge any identifying information of participants or their children. The research findings will be recorded in a non-published thesis, submitted to the Graduate School of Social Work, Portland State University, as partial fulfillment of the requirements for a Masters Degree in Social Work by George Jacobsen, Grant Kane, and Joan Sacia, members of the research committee. Additional copies of this thesis will be available to the Epilepsy League of Oregon and the Children's Clinic with the express understanding that the information be used for future program development. 
Any other use of the material gathered during the research on the Parents' Discussion Group or the written thesis summary thereof without the express written permission of the participants will not be authorized.

ELBMENTS OF THE RESEARCH PROGRAM:

Prior to the first group session, the parent(s) will meet individually with the group facilitator (leader). This meeting will provide the parent(s) time to express their individual concerns about their child's range of problems. The parent(s) will be encouraged to make their desires known about what they would like to obtain from the parent group sessions. Also, at this time, the following will be dones

1. Information from the Group Explanation Sheet will be discussed.

2. The Socio-Economic Inventory used for gathering baseline information will be issued.

3. The Epilepsy Questionna1re will be administered.

4. The Handicap Problems Inventory will be administered.

5. The Brochure For Parents and other related material will be distributed to allow the parents an opportunity to read and discuss the information presented before the first group session.

6. The Parents' Discussion Group meetings will be audio tape recorded for use in assessing the value of the group sessions.

7. At some time during the period in which the group meets, and in close cooperation with the scheduled attendance of your child in the preschool program and parents' personal schedules, a team of clinical 
psychologists will observe and chart the interaction of mother and child in a play situation. Part of the charting process will include a video tape of the interaction.

\section{SUMMARY:}

Any changes in the afore described research design should be submitted to the group participants in writing for authorization.

George R. Jacobsen

Grant R. Kane

Joan Sacia 
APPENDIX G

Review of The Literature On The Value of Parent Groups 
REVIEW OF THE LITERATURE ON

THE VALUE OF GROUP INFLUENCE

In numerous areas dealing with groups for parents, many published findings reveal how the various types of treatment techniques used within each group are successful after several sessions, while others ${ }^{1}$ are successful from the onset. In a group of people brought together for any purpose, the degree in which the anticipated goals are successfully realized is dependent upon the capacity of the member's purpose and need plus the amount of appropriate knowledge and experience proposed. The use of groups is not a substitute for other types of psychotherapy, but may be effective with specific clients.

\section{Group Approach Preferred Over Individual Approach}

Crow discovered the effectiveness of discussion groups in helping parents with the task of child rearing. ${ }^{2}$ Durkin experienced the use of the group approach with mothers who were given a chance to gain insight into their attitudes instead of having to try to make futile conscious attempts to improve individually their way of handling their children. ${ }^{3}$

Scheidlinger and Pyrke feel that groups should be tried simultaneously with individual contact to appreciate what influence the group discussion has upon its members. When geared to the unique problems of adults, groups may hold a promise for a speedler and more 
effective way of helping the participants. ${ }^{4}$ Lewin found that discussion proved more effective than lectures or individual conferences in alding a speciflc group of people to change a mode of behavior. 5

One group education study in particular, outside of the United States, was approached with seven epileptic patients at Heemstede (the Netherlands). Brullerman's findings revealed thats

$$
\begin{aligned}
& \text { - group therapy can serve to support or } \\
& \text { even make possible medical treatment, even if it } \\
& \text { does not directly combat epllepsy. Even if the } \\
& \text { functioning of an epileptic patient in a group } \\
& \text { proves to be unsatisfactory, group discussion } \\
& \text { can still be an important means towards a better } \\
& \text { integration and therefore a better functioning } \\
& \text { of that patient. }
\end{aligned}
$$

Wittenburg reports that groups offer such encouraging

results that:

The application of psychiatric and casework knowledge and concepts to all fields of human behavior... necessitate the inclusion of group work courses and practice in the training of case workers, and more psychiatric knowledge and practice for group workers.

The getting together and sharing with one another has advantages. The dynamics and general characteristics of nearly any goal-directed and facilitated parents group can have impact if even to a limited degree. Slavson believes the mere influence of the group experience is in a sense therapeutic in effect, even if it were not so intent. ${ }^{8}$ Grunwald and Casella found that getting together brought success in learning where other efforts had not been so rapidly successful. 9 Their report states that the father's 
attitude was at a disadvantage when involved in individual contact. The result was resentment upon the mother. Groups were then inst1tuted to help overcome the parental difficulties with the goal of dealing with the resentment and impressing upon the parents minds the purpose of the "get together."

The collection of individuals into a group provides a setting In which the group atmosphere can minimize the amount of individual feelings of isolation and difference, the hypothesis being that the parent derives a feeling of strength and solace from discovering that he is not unique in his situation. ${ }^{10}$ hallowitz and Stephens report how the group approach enabled fathers to particlpate in discussions and to become both emotionally involved and to attain unity. ${ }^{11}$

Experiences With Parent Groups

Parent groups have been attempted with varying success in numerous areas, educational as well as therapeut1c. While Schilder first used this form over thirty years ago, ${ }^{12}$ Amster pioneered in applying the technique to mothers of children with behavioral problems; ${ }^{13}$ Lowry found groups to be surprisingly successful; ${ }^{14}$ Milman reports of her group approach to the parents of physically disabled children; ${ }^{15}$ Wittes and Radin discussed their two group approaches to parents of preschool children (to improve child-rearing attitudes and practices). These two groups were experimental while the third, a control group, was a prediction that preschool and 
parent discussions being programmed simultaneously would have greater impact. ${ }^{16}$ Day and Rosen worked with groups with mothers of schizophrenic children; ${ }^{17}$ Bakwin and Bakwin worked with a group of parents whose children were schizophrenic and dealt with childhood schizophrenia in general; ${ }^{18}$ Durkin described his group experience with mothers of disturbed children; ${ }^{19}$ Durkin, Glatzer and Hirsch introduced the group methods to the mothers whose children were receiving psychiatric work; ${ }^{20}$ Speers and Lansing dealt with simultaneous groups for the mothers with groups for their psychotic children; ${ }^{21}$ Wiener reported success with groups for parents of autistic children; ${ }^{22}$ Funt objectively tells of three different discussion groups, one with parents of preschool children, the second with parents of adolescents, and the third, discussion groups with older adults; ${ }^{23}$ Bergen and Kris engaged parents in a group in a hospital setting; ${ }^{24}$ Papademetriou used parent discussion groups with a focus upon unwed daughters; ${ }^{25}$ Driscoll and Lubin worked with groups for parents of children with cystic fibrosis; ${ }^{26}$ McPherson and Samuels held groups for parents of hyperactive and aggressive children; ${ }^{27}$ Laibman offered groups for parents of adolescents; ${ }^{28}$ and more recently is the work of Frisbie who is finding simultaneous groups for parents and groups for their children with physical handicaps to be adequate treatment when time and funds are apparent (some children whose handicaps were obvious and some which were not so obvious were in attendance, while some of them may or may not have had epilepsy). 29 
Still in other areas is the work of Goodman and Rothman; 30 Siegel; ${ }^{31}$ Bice; ${ }^{32}$ Veingold and Normouth; ${ }^{33}$ White; $^{34}$ Nadal; ${ }^{35}$ Appell, Williams and Fishell; ${ }^{36}$ HoGriff; ${ }^{37}$ Coleman; ${ }^{38}$ Cunnins; $^{39}$ and French and levbarg, 40 who have all held parent groups. Groups for parents of children with emotional, learninf, and behavioral mroblems are highly recommended by others. 41,42

\section{The Value of Parent Groun Education}

Parents of children with handicapping conditions need to understand not only their children, their needs, potentials and motivations at each stare of development, but also themselves as parents, their ow attitudes, feelinfs, and expectations, and the role they play in the narent-child relationship. $43,44,45,46$

Parent rroup education offers a methodolony which may be anplice flexibly to further the rowth and learnin of the particular parents who attend. 47 Auerbach, in a joint study with the Child Study Association of Anerica, reports:

We are convinced that various tyoes of roups for
narents of handicapnod children are a valid and
important part of promrams of service to these
parents and that different kinds of grouns may
serve different kinds of needs. Parents can sain
2. jreat deal, according to the purnose of the
project, skills which are used ard the way in which
the promrams are related to the essential concoms
of parents and their readiness to move ahead to new
knowled and insirhts. 4 .

Parent rroup education has a value, not as a suhstitute, nut, in and $\sigma^{\circ}$ itself, contributin in a very positive sense to the 
parents' growth and increased strength in a way that often cannot be achieved in other ways. Through parent group education, parents gain much of the factual knowledge they want about their children and the immediate situations they are facing in dealing with them. 49

As parent group education stresses primarily the need to understand the meaning of behavior and communication within a family so that parents may respond more freely, parent group education must not prescribe curriculum but proceed from the interests and concerns of the parent members as they emerge in their daily lives with their children. This process allows parents to be dellberately encouraged to develop independent thinking, which in turn, coincides with the goal of parent group education, of helping the parents find their own place in their individual thinking and come to their own conclusions. 50 Mann states that the primary goal of any group should be the attainment of group unity for the purpose of mutual exploration, analysis, and synthesis. 51

Since "a discussion group is a group of people of equivalent status meeting deliberately to discuss a previously agreed-upon subject and to learn together," 52 along w1th building of the parents strength and helping them improve through an experience of guided group discussion, the effective handling of a child with seizures necessitates changes in parental attitudes which enter into the child's development. $13,43,44,45,53,54,55$ This Clinic agrees with Lowry, that "with preschool children (where) the mother-child 
relationship is the primary consideration, "56 both parents can utilize the group experience even more to gain additional understanding of their preschool children, their family relationships, their knowledge of epilepsy, communication patterns, child growth and development, and the emotional strain under which they are living. 57 Because of both parents' own active role in the group educational process, they should have an opportunity to respond and digest the matters discussed, which hopefully allows the content of the discussions to closely meet both of their developing interests and concerns. Together they have the opportunity and responsibility to see that the learning is directed toward the realities of their daily lives and therefore has meaning for them as they need it. Social/Emotional Behavior of The Child

The child who has a severe and frequent seizure disorder: -. may be unable to experience comfort and normal feelings in early childhood. Later he may be affected by inconsistency, hostility, rejection, overprotection and many detrimental influences symptomatic of the adjustment of the parents to the problem. 58

Bridge has described the child's feelings regarding his seizure disorder as obtained from interviews with parentsi

After the world is no longer black, he awakens to find himself surrounded by excited, agitated adults, who are unusually solicitous about him. In addition to the fear of death, children with seizures experlence feelings of hopelessness and resentment against the attitudes which others show toward them. Emotional difficulties in the child with seizures arise as a result of awareness that he is different from peers and because of the need to adjust hopes and ambition to the limitations set by the seizure activity. 59 
Parental attempts to meet these difficulties are frequently met with confusion and feelings of anxiety and inadequacy, as well as fear, rejection and isolation. Because of the child's difficulties in being allowed to develop independence (learning from structured or constantly supervised experience, perceiving his emotional environment appropriately, and conceptualizing), behavior is often aberrant and tends to arouse antagonism or enforced 1sloation. The parents have not been prepared by their past experience to respond with understanding to this behavior. Eventually the child is likely to experience progressive restriction in social contacts, inadequate training facilities, difficult community attitudes, and limited opportunities for employment and recreation. Innumerable influences in the life of the child with epilepsy, therefore, tend to create social/emotional disturbance. Ultimately, intellectual and social limitations may make it impossible for him to find a solution to conflicts between his instinctual needs and social adaptation. With the onset of seizures, however, parents frequently describe a change in behavior. Though some children appear unaffected by the disorder, the majority become unstable, dissatisfied, restless and distractible, demanding, resentful, quarrelsome, and disobedient. Outbursts of temper are frequent. Interest in school lags and they may become disturbing and annoying in the classroom. Continuance of these symptoms is likely to exaggerate the epilepsy as time goes on. 60 Deutsch and Wiener studied a group of children with epilepsy in 
their homes. Behavior and personality varied widely. Although narcissistic behavior was found in some it was not characteristic of the entire group, and the same was true for aggressive behavior. Some of the children, especially those with petit mal and psychomotor attacks, inhibited their aggression because of fear of retallation. 61

Sullivan and Gahagan found that almost half of the children with epilepsy exhibited conduct disorders of various degrees. Most of them were hyperkinetic, antisocial, cruel, stubborn, and destructive. Their problems took the form of rage, temper tantrums, lying, stealing, nailbiting, and speech difficulties. Many of these children came from homes where siblings also had problems. 62

Much of the aggressive behavior of children with epilepsy has been thought to be the reaction to rejection by the parents and by society. Feelings of guilt may produce antisocial behavior. Demands for attention or frustration have in some instances caused children with seizures to simulate clinical seizures. 63

Bradley divides the bahavior difficulties associated with epilepsy into two general groups. The first are those which are direct and primary expressions of disordered cerebral function. Since such symptoms arise, presumably, from the same alterations in brain function as produce the convulsions, a certain similarity in symptoms is to be expected. In the second group, the symptoms are expressions of the patient's own reactions to his illness. Such reactions will de- 
pend on the child's personality and on the way his illness is regarded by the people around him. Since these vary from child to child, the secondary symptoms will also vary in different individuals.

According to Bradley, the general behavior that is primarily characteristic of the child with selzures consists of a cluster of five traits. No one or two of these are characteristic but the presence of several gives a general pattern. The traits are (1) erratic variability in mood or behavior, (2) hypermotility, (3) irritability, (4) short and vacillating attention span, and (5) a rather selective difficulty in mathematics as a school subject.

He also states that erratic variability in mood or behavior expresses 1 tself by fluctuations in social adaptability with apparent cause or purpose, occurring, usually, at irregular intervals. The child has good days and bad days at home and at school and he may be puzzled and frustrated by them as are his parents and teachers. The hypermotility or overactivity and the distractibility or short attention span are similar to that seen in other children with organic brain disease. It tends to decrease as the child matures. Irritability is a frequent symptom of many sorts of emotional maladjustment but it is often developed to a high degree in the child with seizures. Its occurrence without any relationship to c1rcumstances in the child's environment sometimes makes it difficult to understand. ${ }^{64}$

\section{Characteristic Symptoms}

A certain number of children have been described who show the grouping of symptoms considered by Bradley to be characteristic of the 
child with epilepsy, yet have no convulsions. A considerable proportion of these children show electroencephalographic changes resembling those found in epilepsy!

According to Bakwin and Bakwin:

Parental mishandling, especially overprotection and oversolicitousness, is not uncommon. A number of parents believe that epileptic children are more vulnerable to the risks of everyday life than others and they therefore $11 \mathrm{mit}$ normal social relationships and play. Dependency and infantilism are encouraged in this way.

When the convulsions persist over a long period the child is often rejected because of the difficulties involved in caring for $\mathrm{him}$. He may react to the rejection with feelings of guilt and shy, sensitive, and antisocial behavior. This is intensified when he is unable to attend school or when he is not accepted in the community. Other children react to parental rejection with hostility, aggressiveness, and incessant demands for attention. 65

Fortunately, the outlook for the child with epilepsy is now more optimistic than ever. This may be attributed to more widespread interest in epilepsy and the recent advances in diagnostic techniques, together with remarkably vigorous pharmacologic research and greater appreciation of the necessity for comprehensive evaluation and management of related problems in the child with seizures, in whom epilepsy may be the major, but not the only, problem.

\section{Primary Parental Reactions}

Few events are so frightening to parents as is expressed in their first reaction to a diagnosis of epllepsy in their child. Some are frightened that death may occur, that subsequent seizures will 
ensue, and mental deterioration may take place. The general idea that epilepsy is a shameful disease--a stigma--is of ten foremost in the minds of the parents. $43,45,46$

Several authors have found psychological and social complications to be puzzling, ${ }^{10}$ frustrating, ${ }^{53}$ subtle, ${ }^{54}$ severe, 55 and long lasting, 60 Others found the first reaction of parents to a diagnosis of epllepsy in their child is one of horror and frequently disbelief. 66,67 In many cases it was found that the development of epilepsy in their child was considered to be "punishment for their sins."68 In other cases it was not surprising to find parents class epilepsy with Frankenstein and vampire bats. 69

As epilepsy is one of the last of the "hush-hush" diseases, 70 the prevalling attitude of fear, misunderstanding and prejudice is still hampering many of these parents. $45,71,72,73$ Parents of children with seizures are not always free of these fears, suspiclons, and misunderstandings, and doctor-parent discussions about the motional and behavioral problems created in the family are not always conclusive.

The occurrence in one way or another of defect or damage of the central nervous system in a child is a difficult realistic problem which is likely to be of sufficient nature to cause an unlimited amount of distress in the parents. The most that can be expected of any prolonged application of professional skills to the management of the problem usually is some degree of improvement within the limitations imposed by the basic seizure disorder. Such 
a problem places heavy demands on the capacities of parents and produces feelings and reactions which are important factors in the lives of the parents and the child. In the majority of instances the lives of both the parents and the child tend to be adversely affected. Garrard and Richmond, in pointing this out, said,

Once defect or damage of the central nervous system is identified, parents do not feel toward the affected child as they would toward a normal child. How profoundly parental feelings are altered influences the extent to which healthy relations are present or absent for the child. Some parental feelings may be symptomatic of unsatisfactory adaptation to the disorder and may tend to impair effective integration of the problem into the daily ilfe of the family.

Acceptance is a term which is often used, but which does not adequately describe the process of adaptation of parents to a child diagnosed as having epilepsy. It is possible that some parents may never succeed in arriving at a complete understanding of the problem, and a neurologically handicapped child does not present a single problem for which there is a single or final solution. Problems continually arise at different developmental stages as the full extent of the process unfolds.

Groups For Parents Of Children With Epilepsy

The primary purpose in the therapy of any disability is the rehabilitation of the patient to a life as nearly normal as possible within the limits of the disability. ${ }^{75}$ The need for such a consistent and well-organized group program has long been recognized. ${ }^{76}$ 
Those who have published their findings on parent discussion groups 1 , 72, 73, 77 (where the common focus of the group has revolved around selzure disorders in their children) all agree that group discussion in this type of situation also makes for better and sometimes more rapid improvement in their adjustment. Direct discussion of seizures in a group can also make for rapid improvement in the parent-child relationship. 78

The use of groups as a method for giving parents the opportun1ty to discuss their child's selzure disorder, and related behavioral difficulties, first dates back twenty years when defries and Browder found group psychotherapy with children who had epilepsy and their mothers to be an effective and useful part of the therapy of the child suffering from both selzures and personality disturbances. By using the common problem of seizures in their children to bring the mothers and the children together in a group, they reported moving forward with surprisingly successful results. 73

In another study, 77 similar results were obtained. Parents whose life revolved around superstitions about and fears of seizures in their children were partially effectively cleared up in doctorparent talks, reading of pamphlets, and listening to professionals. After the parents were part of groups aimed at educating themselves, in which they discussed common problems and fears and shared indiv1dual successes, the parents could then be more optimistic. By having teenagers who had selzures address the group and tell of playing football and dating, the parents' optimism was encouraged. When 
the grouns had later dissolved, each parent had gained in learning about his child's problens and how to cope with them. The parents' expressions of enthusiasm and gratitude made the discussion groups seem even more worthwhile.

others ${ }^{1}$ reported such encouraping results with the parents of children sufferinf from seizures that their group discussions continued for over two years. They felt that they had actually fulfilled all of the objectives for which the grouns were originally desimned.

other education rroups have been reported, several outside of the United States, one of which was specifically dealing with seizures. DeColon, Trent and I on ${ }^{72}$ made an attempt in Puerto Rico to hold discussion mroups which involved ten mothers of adolescents who suffered from seizure disonders. The mothers were able to overcome many of their fears and misconceptions about seizure activity, emotional tension, and a reduction of anxiety. In nine of the ten cases it appeared that the rroup sessions had also led to a general reduction of tension within the home.

\section{The Process of Education}

Nuthes and abbour 43 feel that one of the first priorities in the treatment of a child who has a seizure disorder is to indoctrinate his parents so thoroughly in the nature of his condition that the need for continuous, discreet sunervision is fully appreciated, and the peneral fears, suspicions, and misheliefs are dispelled. Iennox 
feels that, more than with most other diseases, the only unit of treatment is the family. 44

In addition to his primary symptoms, the child shows behavior which reflects his feelings about himself, his adequacy and the special problems which his seizure disorder creates for him. Realizine the anxiety created in the parents of a child with seizures, concerm over parental attitudes about the child's seizures are of extreme importance as these attitudes prevail over and influence the behavior of the child. The child's attitude in turn reflects the way the parents feel about him and his seizures, and are to a large extent influenced by the way simnificant other people deal with him. $18,44,45,72$

As Bradley has stated:

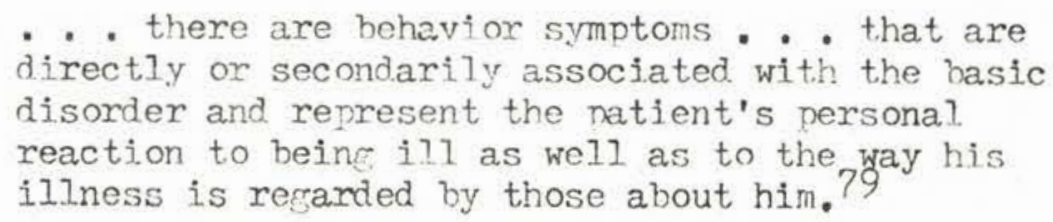

Sunmary

Group discussion as an education and leaming experience has been reported of considerable value ${ }^{80}$ in the treatment of the child with a seizure disoder. Furthernore, topical mroup discussion of enilepsy with the child's narents heneficially affects the attitudes of the parents.

Group discussions do have some precedence over other approaches, because of the favorable ratio of participant to professional, but their ultimate effectiveness hinmes on the active participation of 
the individual group members. This participation is motivated by the emotional needs of the participant, and the relevance of the group discussion. 81

With lasting results measured in reduction of parental anxiety and greater parental knowledge of their child's condition, the parent group education and discussion method appears to be a successful approach in accomplishing these goals. ${ }^{1}, 72,73,77$ Since emotional factors are among the most potent agents precipitating seizures in children, $18,44,45,58,60,82,83,84,85,86,87$ the family attitudes must be dealt with by first educating the parents to the medical and emotional needs of their child. $43,54,55$ 


\section{FOOTNOTES}

1. Gaston J. Baus, L. LaVerne Letson, and Ed1th Russell, "Group Sessions For Parents Of Children With Epilepsy," The Journal of Pediatrics, 52:3 (March 1958), pp. 271-273.

2. Maxine S. Crow, "Preventive Intervention Through Parent Group Education," Social Casework 48:3 (March 1967), pp. 161-165.

3. Helen E. Durkin, Group Therapy For Mothers of D1sturbed Children (Springfield, Ill.1 Charles C. Thomas, 1954), p. 212.

4. Saul Scheldlinger and Marjorie Pyrke, "Group Therapy Of Women W1th Severe Dependency Problems," American Journal Of Orthopsychiatry 31 (October 1961), pp. 775-785.

5. Kurt Lewin, "Frontiers In Group Dynamics I-Concept, Method And Reality In Social Sclence; Social Equilibria And Social Change," Human Relations 1:1 (June 1947), pp. 5-41; and "Frontiers In Group Dymamics II-Channels Of Group Life; Social Planning And Action Research," Human Relations 1:2 (November 1947), pp. 143-153.

6. L. H. Brullerman, "Group Therapy W1th Epileptic Patients At The "Instituut Voor Epilepsiebestrijding," Epilepsia 13 (1972), p. 231 .

7. Rudolf Wittenburg, "Psychiatric Concepts In Group Work," American Journal of Orthopsychiatry $14(1944)$, p. 83.

8. S. R. Slavson, Child Centered Group Guldance Of Parents (New Yorkı International Universities Press, Inc., 1958), p. 73.

9. Hanna Grunwald and Bernard Casella, "Group Counseling With Parents," Child Welfare (January 1958), pp. 11-17.

10. Doris H. Milman, "Group Therapy With Parentsi An Approach To The Rehabilitation Of Physically Disabled Children," The Journal of Pediatrics 44,1 (July 1953), pp. 113-116.

11. Emmanuel Hallowitz and Bermice Stephens, "Group Therapy W1th Parents," Social Casework 40,4 (April 1959), pp. 183-192.

12. P. Schilder, "Analysis of Ideologies Psychotherapeutic Method, Especially In Group Treatment," American Journal Of Psychlatry 93 (1936), pp. 601-613.

13. Fanny Amster, "Collect1ve Psychotherapy Of Mothers Of Emotionally Disturbed Children," American Journal Of Orthpsychiatry 14 (1944), pp. $44-46$. 
14. Lawson G. Lowry, "Group Therapy," American Journal of Orthopsych1atry $13(1943)$ p. 648.

15. Milman, pp. 113-116.

16. Glorlanne Wittes and Norma Radin, "Two Approaches To Group Work With Parents In A Compensatory Preschool Program," Social Work 16.1 (January 1971), pp. 42-50.

17. Max Day and Irving Rosen, "The Group Behavior Of Mothers of Schizophrenics," Journal of Nervous And Mental Disease 119 (1954), 366367.

18. Harry Bakwin and Ruth Morrls Bakwin, Clinical Management of Behav1 or Disorders In Children (Philadelphias W. B. Saunders Co., 1967), p. 154.

19. Durkin, p. 14.

20. Helen E. Durkin, Henrlette T. Glatzer, and Jeanette S. H1rsch, "Therapy of Mothers In Groups," American Journal of Orthopsychlatry 14 (1944), pp. 68-75.

21. Rex W. Speers and Cornelius Lansing, Group Therapy In Childhood Psychosis (Chapel Hill, University of North Carolina, 1965).

22. Louise L. Wiener, "Group Work With Parents," in Hubert S. Coffey and Lou1se L. Wiener (eds.) Group Treatment of Autistic Children (Englewood Cliffs! Prentice-Hall, Inc., 1967), pp. 89-92.

23. Irene Funt, "The Application of Casework Principles In Family Life Education," Soc1al Gasework XIII,3 (March 1962) 130-137.

24. Helen M. Bergen, and Anton O. Kris, "Services To Parents Of Adolescent Mental Patients," Soc1al Casework 53,2 (February 1972) 85-90.

25. Marguerite Papademetriou, "Use of A Group Technique With Unwed Mothers And Their Familles," Social Work 16,4 (October 1971) 85-90.

26. Chancellor B. Driscoll, and A. Harold Lubin, "Conferences With Parents of Children With Cystic Fibrosis," Social Casework 53.3 (March 1972) 140-146.

27. Sandra B. McPherson, and Cyrille R. Samuels, "Teaching Behavioral Methods To Parents," Social Casework 52,3 (March 1971) 148-153.

28. Erwin M. La1bman, "Group Counseling W1th Parents In An Agency Serving Adolescents," Social Work 6:2 (April 1961) 67-73. 
29. Personal contact with Dennis Frisbie, M. D., University of Oregon Medical School, Psychiatry Department, Portland, Oregon, 1972.

30. L. Goodman and R. Rothman, "The Development of A Group Counseling Program In A Clinic For Retarded Children," American Journal of Mental Deficiency 65 (1961) 781-795.

31. Ernest Siegel, Helping The Brain Injured Chlld (New Yorks Assoclation For Brain Injured Children, 1961).

32. Harry V. Bice, and Margaret C, Davitt Holden, "Group Counseling With Mothers Of Children W1th Cerebral Palsy," Soc1al Gasework $30: 3$ (March 1949) 104-109.

33. J. T. Weingold and R. P. Hormouth, "Group Guidance Of Parents of Mentally Retarded Children," Journal of Clinical Psychology 9 (1953) 118-124.

34. B. D. White, "Clinical Team Treatment of Mentally Retarded Child And H1s Parentsi Group Counseling And Play Observation," American Journal of Mental Deficiency 63 (1959) 713-723.

35. Robert M. Nadal, "A Counseling Program For Parents Of Severely Retarded Preschool Ch1ldren," Social Casework 42.2 (February 1961) 78-83.

36. Melville V. Appell, Clarence Williams, and Kenneth N. Fishell, "Changes In Attitudes of Parents Of Retarded Children Effected Through Group Counseling," Amerlcan Iournal of Mental Deficiency 68.6 (May 1964) 807-812.

37. Dorothy McGriff, "Working With A Group Of Authoritative Mothers," Soc1al Work 5:1 (January 1960) 63-68.

38. James C. Coleman, "Group Therapy With Parents of Mentally Deficient Children," Amerlcan Journal of Mental Deficiency 57 (1953) 700-704.

39. S. Thomas Cummins, "Brief Group Therapy Of Mothers Of Retarded Children Outside of The Specialty Setting," American Journal of Mental Deficlency 66 (1962) 739-748.

40. A. C. French, M. Levbarg, and H. Michal-Smith, "Parent Counseling As A Means of Improving The Performance of A Mentelly Retarded Boyi A Case Presentation," in C. L. Stacy and M. F. Demartino, (eds.) Counseling And Psychotherapy W1th The Mentally Retarded (Glencoe, IIl.1 The Free Press, 1957), pp. 438-445. 
41. Bakwin and Bakwln, "Clinical Management of Behavior Disorders In Children," p. 154.

42. Hyman S. Lippman, Treatment of The Child In Emotional Conflict (New Yorks MoGraw-H111 Book Co., 1962), p. 351.

43. J. G. Hughes and J. T. Jabbour, "The Treatment of The Epileptic Child," The Journal of Pediatrics 53:1 (July 1958) 66-68.

44. William G. Lennox, "The Social And Emotional Problems of The Epileptic Child And His Family," The Journal of Pediatrics 44,5 (May 1954) 591-596.

45. Samuel Livingston, "The Social Management of The Epileptic Child And H1s Parents," The Journal of Pediatrics 51:2 (August 1957) 137-145.

46. M1lman, p. 115.

47. Aline B. Auerbach, Parents Learn Through Discussion: Principles And Practices Of Parent Group Education (New Yorks John Wiley and Sons, Inc., 1968), p. 15-16.

48. Aline B. Auerbach, "What Can Parents Of Handicapped Children Gain From Group Experience," Helping Parents Of Handicapped Children (Boston: Children's Hospital Medical Center And Child Study Association Of America, October 1959), p. 16.

49. Auerbach, "What Can Parents Of Handicapped Children Gain From A Group Experience," p. 18.

50. Auerbach, "Parents Learn Through Discussion," p. 32.

51. James Mann, "The Theoretical Concepts Of The Group Process," Journal of Nervous And Mental Process 119 (1954), p. 365.

52. Valerie Graves, "The Discussion Group," The Postgraduate Medical Journal 40,459 (January 1964) 1-3.

53. J. Beasley, "Social Aspects Of Epilepsy In Ch1ldhood," Postgraduate Medical Journal 40,464 (June 1964) 34,4-345.

54. D. A. Pond and B. Bidwell, "Management of Behavior In Epileptic Children," British Medical Journal 2 (December 1954) 1520-1523.

55. Sterling D. Garrard and Jullus B. Richmond, "Psychological Aspects Of The Management of Children With Defects Or Damage of The Central Nervous System," Pediatric Glinics of North America (November 1957) 1033-1048. 
56. Lowry, p. 648 .

57. Auerbach, Parents Learn Through Discussion," p. 21.

58. Garrard and Richmond, p. 1040.

59. E. M. Bridge, Epilepsy And Convulsive Disorders In Children

(New York; McGraw-Hill Book Co., 1949) p. $434-435$.

60. R. M. Bakwin and Harry Bakwin, "Epilepsy," The Journal of Pediatrics 39,4 (December 1951) 775 .

61. L. Deutsch and I. I. Wiener, "Children With Epilepsy: Emotional Problems And Treatment," American Journal of Orthopsychiatry 18 (1948) p. 65.

62. E. B. Sullivan and L. Gahagan, "On Intelligence Of Epileptic Children," Genetic Psychology Monographs 17 (1935) 309.

63. Bakwin and Bakwin, "Epilepsy," p. 779.

64. Charles Bradley, "Characteristics And Management of Children W1th Behavior Problems Associated With Organic Brain Damage," Pediatric Clinics Of North America (November 1957) 1049-1060.

65. Bakwin and Bakwin, "Epilepsy," p. 780.

66. Ruth Gerofski, "The Patient Faces Epilepsy," Social Casework 29:5 (May 1948) 183.

67. Frances F. Schwentker, "Social Management of Epilepsy," in Samuel Livingston, The Diagnosis And Treatment of Convulsive Disorders In Children (Springfield: Charles C. Thomas, 1954) 236.

68. Livingston, p. 139.

69. Beasley, p. 345 .

70. Jerry Price Seizure Clinic, Brochure For Parents (Los Angeles! Children's Hospital, November 1963) 10 pages mimeograph.

71. Lennox, p. 593.

72. Lydia Santiago DeColon, Richard D. Trent, and Luis Sanchez Longo, "A Group Work Experience For Mothers Of Adolescents With Epilepsy," in Robert F. Noland, Counseling Parents Of The IIl And Handicapped (Springfield, Charles C. Thomas, 1971) 219-240. 
73. Zira deFries and Sue Browder, "Group Therapy With Epileptic Children And Their Mothers," Bulletin Of The New York Academy Of Medicine 28 (Apri1 1952) 235-240.

74. Garrard and Richmond, p. 1037.

75. Livingston, p. 137.

76. Baus, et al., p. 270 .

77. Sheldon H. Kamin, Charley Jackson Llewelleyn, and Winnie L. Sledge, "Group Dymamics In The Treatment Of Epilepsy," The Journal of Pediatrics 53 (October 1958) 410-412.

78. defries, et al., p. 235.

79. Bradley, p. 1055.

80. Kamin, et al., p. 410.

81. Ruth Mallison, Education As Therapy: Suggestions For Work With Neurologically Impaired Children (Seattles Special Child Pubilcations, 1968).

82. R. A. Jensen, "Importance of The Emotional Factor In The Convulsive Disorders of Children," American Journal of Psychiatry 104 (1947) 126-131.

83. William G. Lennox, and Margaret A. Lennox, Epilepsy And Related D1sorders (London: Churchill Press, 1960).

84. Frank Fremont-Smith, "The Influence of Emotion In Precipitating Convulsions," American Journal of Psychiatry 13:90 (1934) 717723. Also In Archives of Neurology And Psychiatry 30 (1933) $234-236$.

85. J. R. Stevens, "The Emotional Activation Of Electroencephalogram In Patients With Convulsive Disorders," Journal of Nervous And Mental Disease 128 (1959) 339.

86. Elabe M. Davidson, and Joan C. Thomas, "A Social Study of Epileptic Patients," Social Casework 3:9 (November 1949) 380-384.

87. Jean Cummins, "The Family As A Factor In The Epileptic's Social Ad justment," Social Casework 3,9 (November 1949) 384-387. 
APPENDIX $\mathrm{H}$

Session Questions 


\section{SESSTON QUESTIONS}

\section{First Session}

$\underline{\text { Sex }}$

$\mathrm{F} \quad$ What is the problem with the funds? Do they want you to cut down on teaching time? Less students? Or what?

F Where did the toys come from?

Ni How do you determine what will be measured of the child?

M What scales or tools do you use?

M What is their position if parents have their own objectives?

F Do they want him to achieve in both verbal and motor skills?

F Do they take the chronological age into consideration?

M. Is the criteria reasonable?

M. How can you measure in comparison to his being enrolled in another place?

V Do we have objectives that need emphasis?

M Do you ever use video-taping with both parents?

F Are you really natural during this situation?

F Has this technique ever been used with siblings?

F These meetings are going to adjourn on a prescribed time?

F Could the doctor more fully explain the EFG to us?

F Otherwise, how can she explain his prohlem to others?

1. I would like to be better informed about this, but will it help me to become a more effective parent?

II What level or degree of seizure activity is within this group?

F What causes the different kinds of seizures? 
F Did the increase in knowledore help you?

F Would specific information be helpful?

F How do you handle a child when he has a seizure?

F What makes people scared?

M Who made out the questionnaire?

\section{Second Session}

M Is participation in sports a relative issue for each child?

F What about the intake of excessive liquids?

F What about the stimulants and depressants? What are they that they cause a seizure?

Do little seizures often turm into bif seizures?

1 If a child with petit mal seizures goes on unchecked, can they develop into grand mal seizures?

Did you mention your condition when you applied for a job or driver's license?

When was your first seizure?

To what degree is epilepsy hereditary?

Is it possible that stimulation of attacks dies out or can there be a fluctuation where at times attacks may be stimulated by the environment, and other times not?

$H_{1} \quad$ Where can we look for more scientific information about epilepsy?

F Do you feel as a group that each child represented here is representative of all types of seizures that a child might have?

F Are the seizures occurring at the same time?

F What kinds of seizures are they having?

M. What age did they start seizuring?

1. Did both start seizuring about the same time? 
Are you as a parent goine to tell the schools that she has seizures?

Have you noticed any develommental delay in your children?

With what frequency does your child have seizures?

Is this a consistent pattern?

Do his eyes roll back or just stare?

Does he have a fear that he is going to have a seizure?

Does he have trouble walkind?

How old was he when he started seizuring?

Is he afraid iust before he has a seizure?

Does he have brothers and sisters?

There speech is concerned, do you find yourself comparino your son to his older sister?

1) How do you account for the older sister beins so capable of handling the seizures?

Do you wish that adults could accept his seizures as easily?

What medication is he on?

What is the significance of these different medications?

Would you classify your child as an epileptic?

I'm wondering if the physician does not brand the seizure condition for the parents sake, or is it to make the condition more nalatable for the parents sake or so the parent will attach no stigma to the child?

F Would it help parents to have a label?

I wonder if some status is assumed ahout the child?

I.

Why do doctors "beat around the bush" rather than pive us a diamosis?

F T wonder if the physician knows himself? 

black and white extreme?

\section{Third Session}

F

$\mathrm{F}$

F

F

F

F

$\mathrm{Ni}$

At what are do seizures usually berin?

Does it show on the $E E_{G}$ where somethine is wrong?

Was this a first premnancy?

What was the weight gain during the first year?

Was your labor prolonfed or difficult?

Do you feel from your own experience that problems can happen if you tell the school district?

Does it help to take an EFG both while asleep and awake?

Does she have muscle contractions with sejzures?

Has she ever done any physical damage to herself while seizuring?

You mean they were questioning you about how she got the bruises?

You said you were not goins, to inform the school? Why?

If the child's seizures are under control, why should the school have to know?

What difference would it make?

Does valium control his seizures?

Are you saying, he is slow in motor development as well as being small in size?

Is he an affectionate child?

Does he have seizures in his sleep?

Has he been a healthy child?

How does he behave around other children other than his baby brother?

What objectives do you have for him in his schooling?

What things are you hopin to see?

What is his primary problem now, seizures or prowth problem? 
F Why is there such a high percentase of children who are adopted that have selzure problems?

F Was one of your children adonted?

M Have her sisters and brothers seen her have a seizure in puhlic?

M Were they ever embarrassed?

\section{Fourth Session}

M Will we have any conflicts with official things, such as insurance, federal draft, and so on?

M Do we still have to classify them?

M Do different leagues lobby? Especially regarding insurance?

Mi Does the doctor know any more than we do?

M Why don't you perform a 24 hour observation and take a total approach?

$M \quad$ Don't you think it would be damaging to us to tell us that the problem is one of definition?

II Should you feel out each individual parent as a more practical approach?

F Does a different severity of seizures affect parental reaction to classification used?

M Are there any problems with parents who get turned off when they discover the doctor does not have all the answers?

F What is the principle behind the emotional build-up prior to a seizure and release of emotion afterwards?

F Are brain cells destroyed during a seizure?

li What is the connection between heredity and epilepsy?

M What about things that cause or induce seizures such as stimulants?

F Why is sleep disturbed because of some stimulants?

F Are there emotional factors which can induce seizures?

N What are your observations regarding activity? 
N How is it possible to run these kids through your program to get them ready for the schools if the consenses definition of epilepsy is not changed?

F

M

F

F

F

M

F

M

N.

$\mathrm{F}$

H

F

$\mathrm{M}$

$\mathrm{Ii}_{1}$

F

\section{Fifth Session}

F

Is it a question of educating our boy to the extent of helpine him explain to other people or are we hurtine him by informing him?

F

$\mathrm{F}$

Is epilepsy a static condition relative to maturity nervous system?

Is the Epilepsy League of Oregon under United Good Neighbors?

If you won't say the word, how can we say it?

How can we clean up the word epilepsy before we try to change it or group it with something else?

What if we are trying to get medical insurance and need a medical reference?

How do you respond to letters asking about risk factors?

You mean you leave it up to them to interpret?

How is the word epilepsy interpreted then?

Seizure sounds better than epilepsy, so is the difference only in social acceptance?

Should we say seizure disorder or epilepsy?

How will this affect kids in the future?

Who makes up the membership of the Epilepsy League?

Is epilepsy a static condition or isn't it?

Shouldn't parental efforts be more focused on static diseases rather than transient illness like epilepsy?

What is the incidence that epilepsy might get worse?

Do you think it will ever happen that epilepsy will become a clean word?

What would you recommend we do to chanre the attitudes of this community? 
Should each and every teacher behave in such a manner as to force us to move to another school district, where do we stand when in this kind of situation?

$M \quad$ Do you get any feedback from speaking to schools?

F Do you reach many people at high school age?

M Do some medications lose their effectiveness?

F Can too much penicillin have dire affects, like on an insensitive person?

F Should young adult epileptics have children?

N Are there hereditary implications in the Gibbon Ape colony?

F Do our children feel anything from the druss they take?

F Is it a normal feeling?

F Is it anything different from droggy, dizzy, drunk or sleepy?

F Are seizures painful?

\section{Sixth Session}

F Are any parents interested in contacting any other parents?

F Do any of these other parents have children with epilepsy?

M Could some of these parents join us and allow us to split into two groups?

M Does anyone here prefer a smaller or larper sroup?

F Should we limit our program only to the parents of the children in the classroom?

F Since this was a program scheduled for six weeks, was this set down this way for a purpose?

F What if we did have a new roup come and Dr. Schimschock and Watson spoke to them, and they saw the movies and everything, would this bring them up to where we are?

F Would this prevent it from be renetitive to us?

M Can we have this as our facility?

M Can you give us the bill number which is at Salem? 
What can we do as a group?

F

Before we complete our program this evening, can we find out about the Epilepsy League of Oregon and where to obtain money to send to the Clinic or any other service?

$M$

What can we do to help the Ieasue?

F

What can we do to erase the stigma?

$\mathrm{F}$

Would Betty Stokes be willing to be one of our speakers?

$\mathrm{Ni}$

Sould she support us in any bill pushing or lobbying at the Legislative process?

M Was there any decision made as to who you're going to invite into the group?

F

$\mathrm{M}$

$\mathrm{M}$

$M$

M

$\mathrm{M}$

F

F

F

$\mathrm{M}$

Is it fair for us to hold anyone out of our group?

Aren't we defeating our own purposes if we bring in too many?

How many couples are we talking about?

Shouldn't we invite people to social things first?

Can we get them to come to the meetings later on?

Wouldn't this be a good "in" with the schools too?

Where can we get facilities?

Should we limit ourselves to epilepsy children or include all others?

Could we get other people who are merely interested in attending?

Is any funding coming from the State? 
APPENDIX I

Soc10-Economic Inventory And Instruction 
The Socio-Economic Inventory is being developed for use as an investigative tool in the diagnostic evaluation of children suspected of having neurologically based learning and behavioral problems. This inventory takes the form of a structured questionnaire, administered to the child's parent during an interview.

Although any form of structured interview has the obvious fault of confining one's investigation to circumscribed areas of inquiry, the requirements for (1) collectino relevant diagnostic information in a single two-hour interview, and (2) the maintenance of some degree of consistency in the diagnostic information collected from differing sources, precluded the use of an entirely open-ended, unstructured interview.

This questionnaire focuses on the identified child in his or her social milieu at home, at school and in the immediate neighborhood. It is intended merely to obtain a number of facts about the child, each fact being covered by a single question or by several related questions. The several related questions, bearing on a single area of information or Field, are intended to cover different dimensions of the area.

\section{Administration of Inventory}

1. Allow a minimum of two hours for the completion of the inventory.

2. This inventory is not self-administered. The interviewer 
keeps possession of the schedule, reading the questions to the respondent, who is then requested to make verbal responses to the questions. No questions should be omitted, and the questions should always be asked in the same order. If a subject does not understand the question, it may simply be repeated. If the respondent gives an answer which the interviewer does not understand, or which he thinks is beside the point, the interviewer may merely ask the subject what he meant, and continue asking this until the answer appears appropriate and clear. If a question cannot be successfully handled in this way, it shoulc be marked for further investigation and possible deletion.

3. Maximum effort should be made to have the child's biological mother (or female guardian) respond to the questionnaire. If, however, the situation indicates that both parents should resnond to the questionnaire, then the questionnaire may be administered during a joint interview with both biological parents (or legal guardians).

\section{Detailed Instructions}

SECTION ONE: (identifying information) This section comprises Fields 1-12d, and with the exception of Fields 5, 12c and 12d, this section can be completed by the interviewer prior to the commencement of the interview. However, the information recorded prior to the interview should be verified by the respondent before beginning section two.

Field

1

2

8
Special Instructions

Case number is assigned by Clinic secretary. (biological, step, foster - mother, father)

Example: 5 years 4 months

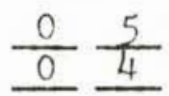


$12 a$

If more than one referral source, check the basic letter of referral.

This requires two responses. Card column 9 can be filled in from the information received on the letter of referral. Card column 10 can be filled in only by asking the informant which of the three reasons or combination thereof, are the reasons for having their child evaluated.

12c Filled in by interviewer without asking the informant. 12d Careful consideration should be piven this question. Iist pediatricians, neurologist, clinics, state, county, city and private agencies.

SECTION TWO: (current functioning) This section is the heart of the interview, and is comprised of the subsections, child's health history, child's problems areas, parental assessment of the child, and a review of areas including school, vocational, avocational, social and emotional ad.justment.

Subsection (health history)

Field Special Instructions

13a. Read the question to the respondent, but modify it for proper usage. If the respondent is not the biological parent of the child and there is no information, check response number 9 and explain.

$13 \mathrm{~b} \& \mathrm{c}$ Same instruction as $13 \mathrm{a}$. 
This section provides the respondent with an opportunity to tell what areas of the child's functioning concern the parent at the present time. (Detailed verbatim descriptions required)

Problem: As the respondent sees it; record the statement verbatim.

Frequency: How often does it occur and how long has it persisted.

Intensity، Is it static or does it change with different environments?

Conditions: What is the general atmosphere of the problem situation?

Precipitating: What brings it on?

14a-f Read the questions to the respondent, modifying the question for proper usage. Example: "Are Sally's behavior problems a major concern, secondary concern, etc." Amplify the responses by using the blank space in the columns.

$15 \mathrm{a} \& \mathrm{~b}$ If the child acts his age, reflect his or her chronological age. If he acts older or younger than their chronological are, reflect that age in years.

$15 \mathrm{c}$, d \& e Read the questions substituting the child's name for (your child). Read all the responses and let the respondent choose and explain the choice.

$15 f \& g$ After the question is read to the respondent, the 
respondent's first word will be the key to the selection of the appropriate response. The use or nonuse of qualifiers in the explanation will assist the further classification of the response.

Subsection (review of areas)

This section provides some difficulties in completion when the identifled child is very young (preschool) or when the identified child has a very low mental age (retardation). Carefully weigh the relevance of each question in this area before presenting the question to the respondent.

$16 \mathrm{a} \& \mathrm{~b} \quad$ For preschool-aged children, response 6 is an appropriate response. Those children unahle to attend school because of a very low mental age (mental retardation) response 6 is again an appropriate response. However, indicate the condition by specifying MR after the response.

16c If a child is retarded and attending either a Trainable Mentally Retarded or an Educable Mentally Retarded classroom setting, response 3 is the appropriate response. Indicate the type of classroom by TMR or ENR.

16d If the child is not attending school, specify Not In School.

16e This response is the total years in school, discounting preschool and kindergarten. For preschool-aged children, 00 is the appropriate response. 
For mentally retarded children in non-graded classes, as well as preschool children never attending classes, 00 is the appropriate response.

$16 \mathrm{~g}$ For preschool-aged children the appropriate response is 8 , but use the explanation to indicate the child is too young to attend any school

$16 \mathrm{~h} \& \mathrm{i}$ After reading the response areas to the informant, circle all responses indicated. Then total the number and place this number in the appropriate card column. $16 j$ Nany parents are able to discem academic readiness deficiencies in their child at an early age. This is a workable question for parents of all aged children, including preschool and mentally retarded children.

\section{Field (vocational) Special Instructions}

$17 \mathrm{a} \& \mathrm{~b}$ If the child is too young to have responsibilities at home or away then indicate the child is Too Young in the card column and select response 8.

$17 \mathrm{c}, \mathrm{d} \& \mathrm{e}$ Listen very closely for inconsistencies in responses, which at first indication one might infer that the child manages his own money, but upon closer examination it becomes evident that the parent actually manaes the child's money. If the child is actually too young to know the meaning of money or because of a retarded condition, cannot realize the meaning of money, then response $?$ is appropriate. Complete (why?) 
by indicating either MR or Too Youns

\section{(Avocational)}

$18 a$

Stress the word PRTMARILY.

$18 \mathrm{~b}$

Activity (what he/she does)

Delete $\%$ of time spent.

Activity level (physical activity)

18c Often because of the limitations of available children to play with, some children are forced to play in either a group made up of youner or older children. If this is the case, indicate your findings in the card column. Ohtain the average are of all the children the child plays with.

$18 \mathrm{~d} \quad$ Same as $18 \mathrm{~b}$

1. Se \& $f$ Stress RECREATTONAL on the child's terms.

Never: Once a month or less

Sporatic: Scattered sessions, but usually don't play together.

Frequent: Play together often or habitually play together.

Scheduled: Routinely planned play activities.

\section{(Social)}

19a-e The determination of appropriate or inappropriate behavior must he made hy the respondent and not the interviewer. Special notes should be made if the 
Field

interviewer feels there is a gross inconsistency between the respondent's explanation and his choice of appropriate or inappropriate behavior.

\section{(Emotional)}

$20 \mathrm{a} \& \mathrm{~b}$ Description provided must be in the words of the respondent.

\section{SFCTION THREE: (family history)}

This section is comprised of fields 21 through 23 which provides ceneral information on the living environment of the child by looking at the composition of the family, siblings with similar problems, parental background, status of marriage and family economics.

Field

\section{Special Instructions}

$21 \mathrm{~b} \& \mathrm{c} \quad \mathrm{Can}$ be completed by the interviewer.

$21 \mathrm{e} \quad$ Include neighbors, scout masters, baby sitters, etc.

22a-i Read question to the respondent, modifying (your

$$
\text { child) for proper usage. }
$$

23a-i Read question to the respondent, modifying: (your

$$
\text { child) for proper usape. }
$$

25a-27d Discuss the marriare history of both spouses but primarily in terms of the responses listed. 
SECTION ONE! Identifying Information

Field Field Name And Description

Card Column

1. Case number:

$1-3$

2. Child's name:

last first initial

3. Date of interview:

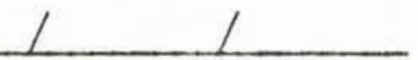

4. Interviewer:

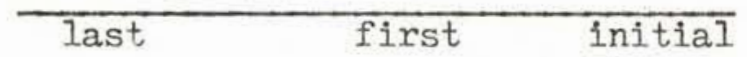

5. Informant:

last first initial

relationship to child

6. Sex of child:

4

$1=$ Male

$2=$ Female

7. Child's date of birth:

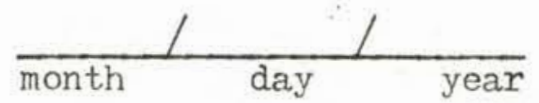

8. Child's current age:

years months

$5-6$
$7-8$

Child's present address:

number street city state zip

10. Telephone number:

11. Child's legal guardian:

last

first

initial

address (if different from number 9) 
Field Field Name And Description

12a Referring person or agency:

name

address

contact person

12b Reason for referral:

$1=$ Academic evaluation

$2=$ Medical evaluation

$3=$ Psychological evaluation

$4=$ Combination 1,2 and 3

$5=$ Combination 2 and 3

$6=$ Combination 1 and 2

$7=$ Combination 1 and 3

$8=$ Don't know

$\varphi=$ No information

12c Does the informant's interpretation of the reason for referral concur with the referral source?

(from letter of referral)

(from the informant)
10

$1=$ Yes

$2=$ No

$Q=$ No information

$12 \mathrm{~d}$ Is (your child) currently receiving services

12

or has received services from any other public

11

or private agency?

$1=$ Yes

\begin{tabular}{|l|l|l|}
\hline Agency & Worker & Phone \\
\hline & & \\
\hline & & \\
\hline & & \\
\hline
\end{tabular}

$2=$ No

$\varphi=$ No information 
(Health History)

13a Prenatal: While carryin the child, did the

$1=$ German measles

$2=$ Viral Episode

$3=$ Other

$8=$ Normal

9 No information

(Explanation)

$13 \mathrm{~b}$ Natal: At or around birth, did (your child) experience any of the following:

1= Prolonged labor, cord around neck, difficult delivery

$2=$ Premature

$3=$ Congenital anomaly

$8=$ Normal delivery

$g=$ No information (Explanation)

13c Postnatal: Since birth, has (your child) experienced any of the following:

$1=$ Severe illness, possibility of brain impairment from meningitis, encephalitis, high fever, dehydration

$2=$ Sever illness, prolonged hospitalization with surgery

$3=$ Sever illness, prolonped hospitalization without hospitalization without surgery

$Y=$ Normal

So No information (Further information) 
(Child's Problem Areas)

$14 \mathrm{a}$ In a hierarchy of concerns about (your child), listed in descending order of importance, what would they be?

1a Problem:

b Frequency,

c Intensity:

d Conditions of onset:

e Precipitating situation:

2a Problem:

b Frequency!

c Intensity:

d Conditions of onset:

e Precipitating situation:

3a Problem:

b Frequency:

c Intensity:

d Conditions of onset:

e Precipitating situations

14b Behavior problems as seen by the parents are:

$1=$ Major concern

$2=$ Secondary concern

$7=$ Not applicable

$8=$ State report of no concern

$9=$ No information 


\section{(Child's Problem Areas)}

$14 \mathrm{a}$ In a hierarchy of concerns about (your child), listed in descending order of importance, what would they be?

1a Problem:

b Frequency,

c Intensity:

d Conditions of onset:

e Precipitating situation:

2a Problem,

b Frequency:

c Intensity:

d Conditions of onset:

e Precipitating situation:

3a Problem:

b Frequency:

c Intensity:

d Conditions of onset:

e Precipitating situations:

14b Behavior problems as seen by the parents are:

$1=$ Major concern

$2=$ Secondary concern

$\eta=$ Not applicable

8 State report of no concern

q No information 
14c Hyperactivity as seen by the parents is:

$1=$ Ma.jor concern

$2=$ Secondary concern

$7=$ Not applicable

$8=$ Stated report of no concern

$g=$ No information

14d Short attention span as seen by the parents is:

$1=$ Major concern

$2=$ Secondary concern

$7=$ Not applicable

8 Stated report of no concern

$\varphi=$ No information

$14 \mathrm{e}$ Inability to concentrate and complete assigned

19 tasks as seen by the parents is:

$1=$ Major concern

$2=$ Secondary concern

$7=$ Not applicable

$8=$ Stated report of no concern

go No information

$14 \mathrm{f}$ Health problems as seen by the parents are:

20

$1=$ Ma jor concern

$2=$ Secondary concern

$7=$ Not applicable

$8=$ Stated report of no concern

$g=$ No information

$14 \mathrm{~g}$ Seizure control problem as seen by the parents is:

$1=$ Major concern

$2=$ Secondary concern

$\gamma=$ Not applicable

$8=$ Stated report of no concern

$q=$ No information

(Parental Assessment of Child)

15a Viewing (your child) in terms of other children

22 his/her age, would you say he/she:

$1=$ Acts younger than his/her age (con't.) 
$2=$ Acts his/her age

$3=$ Acts older than his/her ape

$g=$ No information

(Explanation)

$15 \mathrm{~b}$ What age is (your child) most like?

Projecting (your child) into adulthoor, how

would you assess his/her potential for a successful marital relationship?

$1=$ Severely restricted

$2=$ Somewhat restricted

$7=$ Too young; don't know

$8=$ Normal (unrestricted)

$g=$ No information

(Explanation)

$15 \mathrm{~d}$ How would you assess his/her ability to find suitable employment?

$1=$ Severely restricted (will need institutional setting)

$2=$ Somewhat restricted (will need sheltered workshop)

$3=$ Average (laborer, housewife)

$4=$ Above average (skilled laborer/white collar)

$5=$ High (professional)

$6=$ Too young; don't know

$?=$ Don't know

$g=$ No information

15e Looking back over (your child's) life, what do you see as the primary cause of his/her current problem?

$1=$ Health related

$2=$ Related to home environment

$3=$ Poor schools

$4=$ Poor teachers

$5=$ Other (specify)

$6=$ Don't know

$q=$ No information 
$15 f$ Do you see (your child) as being delayed

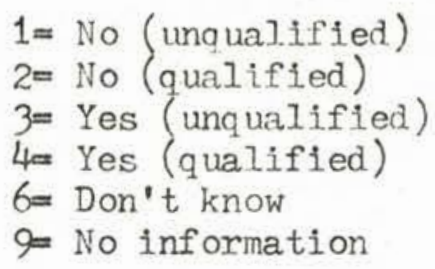

158 Do you see (your child) as bein mentally retarded in any way?

$1=$ No (unqualified)

$2=$ No (qualified)

$3=$ Yes (unqualified)

$4=$ Yes (qualified)

$6=$ Don't know

$g=$ No information

(Review of Areas)

Child's School Backround

$16 \mathrm{a}$ At what age did (your child) enter kindergarten?

$1=$ Never a.tended

$2=$ Age four

$3=$ Age five

$4=$ Age six

$5=$ Age seven

$6=$ Too youno (not yet attending)

O No information

16h What type of kinderoarten did (your child) attend?

$1=$ Public school

$2=$ Private school

name

$6=$ Too young (not applicable

$\varphi=$ No information 
16c In what type of school setting is (your child) now participating?

$1=$ Preschool

$2=$ Kindergarten

$3=$ Special Education

$4=$ Regular classes

$8=$ Not in school (specify)

$q=$ No information

$16 \mathrm{~d}$ What is the name of (your child's) current school?

name district area

1he How many years has (your child) attended public or private elementary or high school?

$00-98$

$99=$ No information

$16 \mathrm{f}$ How many years of school has (your child) repeated?

$0-8$

$9=$ No information

$16 \mathrm{~g}$ Has (your child) ever been placed in special education classes?

$1=$ Yes

$2=\mathrm{No}$

$8=$ Not applicable

$q$ No information

(Explanation)

16h In what academic areas do you feel (your child) excells?

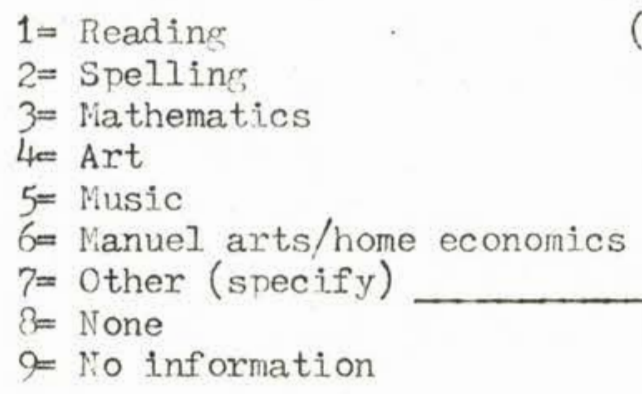


$16 i$ In what academic areas do you feel (your child) is deficient?

$1=$ Reading

(total \# of areas)

$2=$ Spelling

$3=$ Mathematics

$4=$ Art

$5=$ Music

$6=$ Manual arts/home economics

$\eta=$ Other (specify)

$8=$ None

9 No information

$16 j$ At what age did (your child's) academic deficienties become apparent?

16k How much formal education do you hope (your $39-40$ child) will be able to complete?

$1=$ Elementary education

$2=$ High school or equivalent (GED, etc.)

$3=$ Some college or trade school

$4=$ College degree

$5=$ Advanced college degree

$6=$ Other (specify)

$9=$ No information

\section{(Vocational)}

17a Does (your child) have responsibilities or chores at home?

$1=$ Household (garbage, room, general cleaning, etc.)

$2=$ Yard work

$3=$ Pets

$4=$ Child care

$5=$ Combination 1 and 2

$6=$ Combination 1,2 and 3

$7=$ Combination 2,3 and 4

$8=$ None

$9=$ No information

$17 \mathrm{~b}$ Does (your child) have responsibilities or jobs away from the home?

43

1= Paper route

$2=$ Seasonal harvest

$3=$ Baby sitting

$4=$ Gardening (con't.) 
$5=$ Housework

$6=0$ ther (specify)

$7=$ Errands

$8=$ None

$q$ No information

17c Does (your child) receive an allowance or 44 earn money at home?

$1=$ Yes

$2=\mathrm{No}$

$\eta=$ Not applicable (why?)

$\varphi=$ No information

17d Who manages (your child's) money?

$1=$ The child

$2=$ The parents

$7=$ Not applicable (why?)

o No information

17e How does (your child) manage his own money?

46

$1=$ Spends it all

$2=$ Saves it all (toward what goal?)

$3=\overline{\text { Saves part and spends part (what goal?) }}$

$\eta=$ Not applicable (why?)

$\varphi=$ No information

(Avocational)

18 Looking at the full ranse of (your child's) play activities, who does (your child) primarily play with?

$1=\operatorname{Self}$ (alone)

$2=$ Self and one peer (includine stblings)

$3=$ Self and groups of peers (including siblings)

$4=$ Self with mother alone

$5=$ Self with father alone

$q=$ No information

$18 \mathrm{~b}$ When (your child) plays by him/her self, what does he/she do?

$$
\text { (con't.) }
$$




\begin{tabular}{|l|l|l|}
\hline Activity & द Time & Activity Level \\
\hline & & \\
\hline & & \\
\hline & & \\
\hline
\end{tabular}

$18 \mathrm{c}$ What are the average ages of (your child's) playmates?

$1=1$ year or less older

$2=2$ years or less, hut more than 1 year older

$3=2$ or more years older

$4=1$ year or less youncer

$5=2$ years orless, but more than 1 year younger

$6=2$ or more years younoer

$7=$ Same age

$\delta=$ Does not play with other children (Why?)

$Q=$ Ho information

$18 d$ When (your child) plays with other children, what do they do?

\begin{tabular}{|l|l|l|}
\hline Activity & \% Time & Activity Level \\
\hline & & \\
\hline & & \\
\hline & & \\
\hline
\end{tabular}

$13 \mathrm{e}$ When (your child) plays with mother alone (STRICTLY RECREATTONAI TN TERUS OF THE CHTID), what do they do together?

$1=$ Never play together

$2=$ Sporadic play topether

$3=$ Frequently play together

$4=$ Scheduled play periods together

$9=$ No information

\begin{tabular}{|c|c|}
\hline Activity & Time Spent /Week \\
\hline & \\
\hline & \\
\hline & \\
\hline
\end{tabular}


(STRICTLY RECREATIONAL IN TERNS OF THE CHTLD),

what do they do together?

$1=$ Never play together

$2=$ Sporadic play together

$3=$ Frequently play together

$4=$ Scheduled play periods together

Q No information

\begin{tabular}{|l|l|}
\hline Activity & Time Spent / Week \\
\hline & \\
\hline & \\
\hline & \\
\hline
\end{tabular}

$18 \mathrm{~g}$ What recreational activities does your family do together?

$1=$ Many ( 4 or more)

$2=$ Few ( 3 or less)

$3=$ None

o No information

\begin{tabular}{|l|l|}
\hline Activity & Time Spent / Week \\
\hline & \\
\hline & \\
\hline & \\
\hline
\end{tabular}

(Social Adjustment)

19a How does (your child) relate to his/her parents in the family settine? (parental interpretation)

$1=$ Appropriate behavior for age

$2=$ Inappropriate behavior for age

(Explanation)

9 No information 
Field Field Name And Description

19c How does (your child) relate to adults in his/her extended family (like grandparents, cousins, etc.)? (parental interpretation)

1= Appropriate behavior for age

$2=$ Inappropriate behavior for age

(Explanation)

$9=$ No information

$19 \mathrm{~d}$

$\mathrm{He} / \mathrm{she}$ acts most like what age?

$(00-99)$

$56-57$

$19 \mathrm{e}$ How does (your child) relate to adults outside of the family? (parental interpretation)

$1=$ Appropriate behavior for ape

$2=$ Inappropriate behavior for age

(Explanation)

$g=$ No information

$19 f$

$\mathrm{He} /$ she acts most like what age?

(00-99) $\quad 59-60$

$19 \mathrm{~g} \quad$ How does (your child) relate to other children in his/her nuclear or extended family?

(parental interpretation)

$1=$ Appropriate behavior for age

$2=$ Inappropriate behavior for age

(Explanation)

$q=$ No information

$19 \mathrm{~h}$

$\mathrm{He} / \mathrm{she}$ acts most like what age?

How does (your child) relate to other children outside of his/her nuclear and extended family?

1= Appropriate behavior for age

$2=$ Inappropriate behavior for age

(Explanation)

$9=$ No information 
$19 j \mathrm{je} / \mathrm{she}$ acts most like what are?

(Emotional Adjustment)

20a How would you describe the current emotional

67 disposition of (your child) in the home environment?

$1=$ Cannot describe

$2=$ Inadequate description

$3=$ Adequate description

$\varphi=$ No information

$20 \mathrm{~b}$ How would you describe the current emotional disposition of (your child) in the school environment?

$1=$ Cannot describe

$2=$ Inadequate description

$3=$ Adequate description

$9=$ No information

\section{(Health)}

21 What health problems does (your child) have which require a doctor's care outside of this Clinic?

$1=$ Physical problems

$2=$ Neurological problems

$3=$ Psychological problems

$4=$ other (specify)

$5=$ Combination 1 and 2

$6=$ Combination 1 and 3

$7=$ Combination 2 and 3

$8=$ None

$9=$ No information 
$19 j \mathrm{He} / \mathrm{she}$ acts most like what are?

(Emotional Adjustment)

20a How would you describe the current emotional disposition of (your child) in the home environment?

$1=$ Cannot describe

$2=$ Inadequate description

$3=$ Adequate description

9 No information

$20 \mathrm{~b}$ How would you describe the current emotional disposition of (your child) in the school environment?

$1=$ Cannot describe

$2=$ Inadequate description

$3=$ Adequate description

$\varphi=$ No information

\section{(Health)}

21 What health problems does (your child) have which require a doctor's care outside of this 69 Clinic?

$1=$ Physical problems

$2=$ Neurological problems

$3=$ Psychological problems

$4=0$ ther (specify)

$5=$ Combination 1 and 2

$6=$ Combination 1 and 3

$7=$ Combination 2 and 3

$8=$ None

$9=$ No information 
SECTION THREE: Family History

Field Field Name And Description

Card Column

22a In rank order of age, what is the 70 current composition of your household?

(Indicate subject child by asterisk)

$1=$ Full information

$2=$ Partial information

- No information

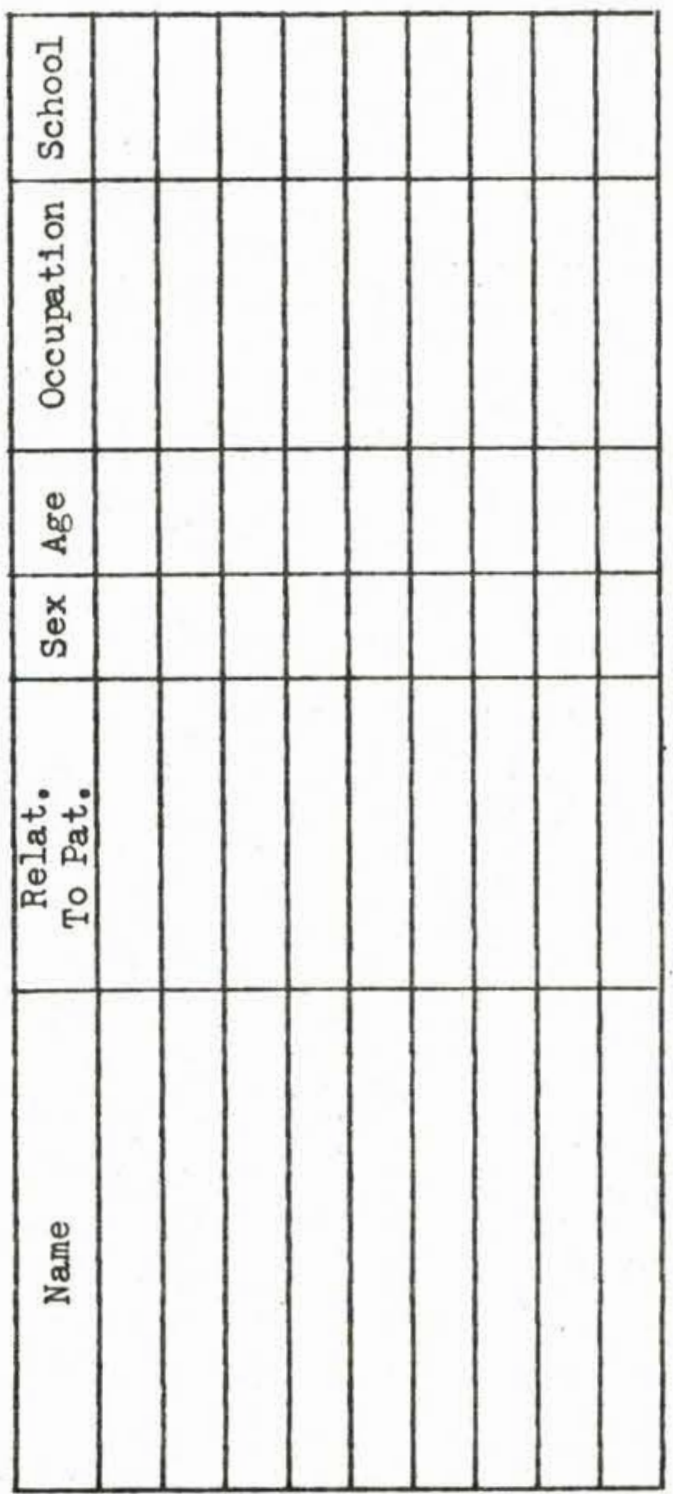


$22 \mathrm{~b}$ What is the are difference between (your child) and the next oldest child in the family?

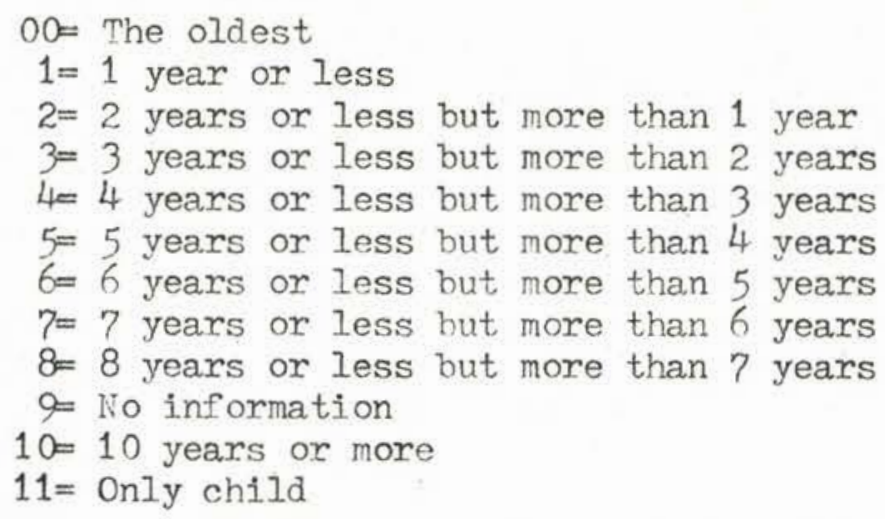

22c What is the are difference between (your child) and the next younrer child in the family?

$00=$ The youngest

$1=1$ year or less

$2=2$ years or less but more than 1 year

$3=3$ years or less but more than 2 years

$4=4$ years or less but more than 3 years

$5=5$ years or less but more than 4 years

$6=6$ years or less but more than 5 years

$7=7$ years or less but more than 6 years

$8=8$ years or less but more than ? years

$9=$ No information

$10=10$ years or more

$11=$ The only child

22d With regard to (your child's) brothers and sisters, do they currently have or have they had any similar problems?

1= 1 or more with similar behavior problems

$2=1$ or more with a history of school failure

$3=1$ or more with similar history of health problems

$4=1$ or more on juvenile probation

$5=1$ or more institutionalized for emotional/ mental retardation problems

$6=1$ or more separated from family by court action

$7=$ Siblings normal, no problems, no separations

$99=$ No information

$10=$ Combination 1,2 and 3 (con't.)

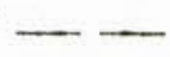


$11=$ Combination 2 and 3

$12=$ Combination 1 and 3

$13=$ Combination 1 and 3,5 or 6

$14=$ Combination 1 and 3,4 or 5

15= Combination 1 and 2,5 or 6

22e What members of (your child's) extended family (aunts, uncles, grandparents, etc.) or special people in (your child's) life (neighbors, etc.) associate with (your child) on a regular basis?

\begin{tabular}{|l|l|}
\hline Relationship To Child & Frequency of Visits \\
\hline & \\
\hline & \\
\hline & \\
\hline
\end{tabular}

$22 f$ What brothers or sisters to (your child) have illnesses requiring a physician's care?

$1=$ Physical problems

\begin{tabular}{|c|c|c|}
\hline Sibling & For what & Who Seen \\
\hline & & \\
\hline & & \\
\hline
\end{tabular}

$2=$ Neurological problems

\begin{tabular}{|c|c|c|}
\hline Sibling & For what & Who Seen \\
\hline & & \\
\hline & & \\
\hline
\end{tabular}

$3=$ Psychological problems

\begin{tabular}{|l|l|l|}
\hline Sibling & For What & Who Seen \\
\hline & & \\
\hline & & \\
\hline
\end{tabular}

$4=$ Combination 1,2 and 3

$5=$ Combination 1 and 3

$6=$ Combination 1 and 2 (con't.) 
$\eta=$ Combination 2 and 3

$8=$ None

$9=$ No information

(Nuclear Family - Parental Background)

Child's Mother

23a What is the mother's relationship to the child?

78

(CHILD'S LEGAL GUARDIAN)

$1=$ Biological mother

$2=$ Adoptive mother

$3=$ Step mother

$4=$ Foster mother

$5=$ Other (specify)

ge No information

23b Mother's place of birth:

City State

23c Mother's date of birthı

23d Mother's current age:

$79-80$

$$
\begin{array}{rlrl}
00 & =\text { Less than } 20 & & \\
1=21-25 & 4=36-40 & 7=51-55 \\
2=26-30 & 5=41-45 & 8=56-60 \\
3=31-35 & 6=46-50 & 9=61 \text { or over }
\end{array}
$$

23e Mother's educational attainment:

81

$0=$ Less than 8 years

$1=$ Less than 10 years

$2=$ Iess than 12 years

$3=$ High school diploma or equivalent (GED, etc.)

$4=$ Some college (no derree)

$5=$ Collepe degree

$6=$ Advanced or professional

$9=$ No information

Case Number

$82-84$ 
$23 f \quad$ How did mother get along in school?

$1=$ Good student (no problems)

$2=$ Fair student (few problems)

$3=$ Poor student (many problems)

$g=$ No information

23g How many children were there in the mother's

family? (Include step, foster, adopted, etc.)

$00-98$

$99=$ No information

23h What was the mother's position in her family?

$88-89$

$1=$ oldest

$2=2$ nd oldest

$3=3 r d$ oldest etc.

$99=$ No information

$23 i$ One a scale of one to nine, how does the child's mother rate her childhood?

\begin{tabular}{lrrrrrrrr}
1 & 2 & 3 & 4 & 5 & 6 & 7 & 8 & 9 \\
\hline Bad & & So-so & & Average & & Good & Excel
\end{tabular}

23.j Mother's employment:

$1=$ Presently not employed (but normally employed)

$2=$ Employed part time

$3=$ Employed full time

$4=$ Not normally employed

$9=$ No information

$23 \mathrm{k} \quad$ What type of work does she do?

\section{Employer}

Duties

231 Who takes care of the children while mother is working?

$1=$ Babysitter (not related incluaing neighbor)

$2=$ Babysitter (child care center)

$3=$ Brother or sister (sibling)

$4=$ Babysitter (related to child)

$8=$ Not applicable

Relation

ge No information 
$23 \mathrm{~m}$ What history of illness does the mother have requiring a physician's care?

$1=$ Physical problems

\begin{tabular}{|c|c|}
\hline Problem & Physician \\
\hline & \\
\hline & \\
\hline
\end{tabular}

$2=$ Neurological problems

\begin{tabular}{|c|c|}
\hline Problem & Physician \\
\hline & \\
\hline & \\
\hline
\end{tabular}

$3=$ Psychological problems

\begin{tabular}{|c|c|}
\hline Problem & Physician \\
\hline & \\
\hline & \\
\hline
\end{tabular}

$4=$ Combination 1,2 and 3

$5=$ Combination 1 and 2

$6=$ Combination 2 and 3

$7=$ Combination 1 and 3

$8=$ None

qo information

\section{Child's Father}

24a What is the father's relationship to the child? (CHILD'S LEGAL GUARDIAN)

$1=$ Biological father

$2=$ Adoptive father

$3=$ Step father

$4=$ Foster father

$5=$ other (specify)

$q=$ No information

$24 \mathrm{~b} \quad$ Father's place of birth:

\section{Gity}

$24 \mathrm{c} \quad$ Father's date of birth: 
24d Father's current age:

$00=$ Juess than 20
$1=21-25$
$4=36-40$
$7=51-55$
$2=2 \hbar-30$
$5=41-45$
$8=56-60$
$3=31-35$
$6=46-50$
$g=61$ or older

$24 \mathrm{e}$ Father's educational attainment:

96

$0=$ Less than 8 years

$1=$ Iess than 10 years

$2=$ Iess than 12 years

$3=$ Hi.gh school diploma or equivalent (GED, etc.)

$4=$ Some collece

$5=$ Collece degree

$6=$ Advanced or professional

$\varphi=$ No information

$24 f$ How did the father et alon in school?

$1=$ Cood student (no problems)

$2=$ Fair student (few prohlems)

$3=$ Poor student (many problems)

c No information

$24 \mathrm{~g}$ How many children were there in the father's family? (Tnclude ster, foster, adopted, etc.)

$98-99$

$00-98$

$99=$ No information

$24 \mathrm{~h}$ What was the fathers' position in his family? 100-101

$$
\begin{aligned}
1= & \text { Oldest } \\
2= & \text { nd oldest } \\
3 & =3 \mathrm{rd} \text { oldest } \\
& \text { etc }
\end{aligned}
$$

$24 i$ On a scale of one to nine, how does the child's father rate his childhood?

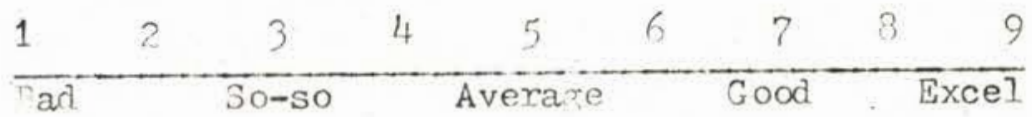


Field Pinld ame And Description

$24 j$ Father's employment:

$1=$ Presently not employed (history of unemployment)

$2=$ Presently employed (history of unemployment)

$3=$ Presently employed (no history of unemployment)

o No information

$24 \mathrm{k}$ What type of work does he do?

\section{Employer}

Duties

241 What history of illness does the father have requiring a physician's care?

$1=$ Physical problems

\begin{tabular}{|c|c|}
\hline Problem & Physician \\
\hline & \\
\hline & \\
\hline
\end{tabular}

$2=$ Neurological problems

\begin{tabular}{|c|c|}
\hline Problem & Physician \\
\hline & \\
\hline & \\
\hline
\end{tabular}

$3=$ Psychological problems

\begin{tabular}{|c|c|}
\hline Problem & Physician \\
\hline & \\
\hline & \\
\hline
\end{tabular}

$4=$ Combination 1,2 and 3

$5=$ Combination 1 and 2

$6=$ Combination 2 and 3

$7=$ Conbination 1 and 3

$8=$ Hone

$q=$ No information

(Current Family Status)

Einancial 
25a What is the source of the family's income?

$1=$ Father's income

$2=$ Mother's income

$3=$ Combination 1 and 2

$4=A F D C$

$5=$ Other welfare rrants

$6=$ Social Security grant

$7=$ Unemployment compensation

$8=$ Other (specify)

$q=$ No information

$25 \mathrm{~b}$ What is the amount of the family's annual income?

106

$1=$ Under $\$ 3,000$

$2=\$ 3-\$ 4,999$

$3=\$ 5-\$ 6,999$

$4=\$ 7-\$ 8,999$

$5=\$ 9-\$ 14,999$

$6=\$ 15-\$ 19,909$

$7=\$ 20,000$ and over

$q=1$ io information

\section{Housine}

26a Does your family:

$1=$ Live in your own home (buyinr)

$2=$ Rent $a$ house

$3=$ Rent an apartment

$4=$ Other (specify)

co Ho information

26b How many years has your farily resided in your: present community?

$(00-99)$

108-10?

Are you satisfied with yom current housing

110 situation?

$1=$ Ves

$2=10$

$3=$ Don't know

$Q=$ lio information

$26 d \quad H o w$ many moves have you made in the last ten years? 111

$0=$ No moves

$1=1$ move

$2=2$ moves etc.

$g=$ No information 
26 Do you have any plans to move in the noxt

year or so?

$1=Y e s$

$2=1: 0$

$3=$ Don't know

$9=$ No information

\section{Status of Marriase}

27a Marriare situation at present:

$1=$ lamiare divided. Father not at home (divorced, senarated, dead). Mother has custody of natural chiliren.

$2=$ larria $\%$ divided, lother not at home (divorced, senarated, dead). Father has custody of natural children.

$3=$ larriare divided. Father not at home. Clinic child adopted.

$4=$ harriare divided. Nother not raisine children. Responsibility for care of children assumed by relatives.

$5=$ child in foster home.

$6=$ Panily intact. Child adonted.

$7=$ Family intact. Child born to marriage partners. One or more siblings adopted or foster child reared as foster sibling.

$8=$ Panily intact. One or more previous marriares by either parent. Child born in previous mamiages.

lo No information.

$10=$ Family intact. Always intact. All children born to marriare nartners.

$11=$ Family presently intact, One or more vrevious marriages by either nartner. Child horm in present marriage.

$12=$ Family presently intact. One or more nrevious marriames by either nartner. Child adopted in nrevious marriage.

13= Pamily intact. One or inore previous marriages by either partner. Child adonted in present marriage.

$14=0$ ther (specify)

(Explanation) 
$27 \mathrm{~b}$ What was the date of your current marriage?

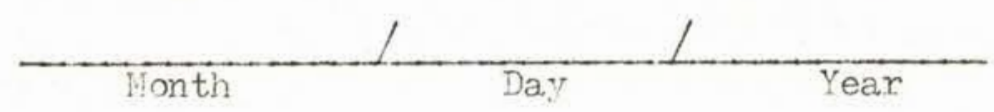

2?c How Iono: have you been married? (In years) 115-116

27d On a scale of one to nine, how would you rate the current state of your marriage?

\begin{tabular}{lllllllll}
1 & 2 & 3 & 4 & 5 & 6 & 7 & 9 \\
\hline Bad & & So-so & Avera e & Good & Excel
\end{tabular}

(Ixolanation) 
I. Description of problem:

II. Peculiarities of circunstances and personalities involved:

III. Grumeration of causal factors in order of importance:

TV. Appraisal of assets for reconstruction:

A) Within identified patient

B) Within nuclear and extended family 
APPENDIX J

Interviews 


\section{INTERVIEWS}

Ms. Patsy Carter, A.C.S.W., Selzure Clinic, University of Washington, Seattle, Washington. Dater May 16, 1972.

Staff, Epilepsy Center of Michigan, 10 Peterboro, Detroit, Michigan. Dater July 25, 1972. 